MARCELO BETTI MASCARO

\title{
CONEXÕES E CARACTERIZAÇÃO NEUROQUÍMICA DE VIAS NEURAIS ENVOLVIDAS COM O CONTROLE DOS MOVIMENTOS MANDIBULARES
}

Tese apresentada ao Programa de Pós-Graduação em Ciências Morfofuncionais do Instituto de Ciências Biomédicas da Universidade de São Paulo, para obtenção do Título de Doutor em Ciências (Anatomia). 


\section{CONEXÕES E CARACTERIZAÇÃO NEUROQUÍMICA DE VIAS NEURAIS ENVOLVIDAS COM O CONTROLE DOS MOVIMENTOS MANDIBULARES}

Tese apresentada ao Programa de Pós-Graduação em Ciências Morfofuncionais do Instituto de Ciências Biomédicas da Universidade de São Paulo, para obtenção do Título de Doutor em Ciências.

Área de concentração: Anatomia

Orientador: Prof ${ }^{\mathrm{a}}$. Dr ${ }^{\mathrm{a}}$. Carol Fuzeti Elias 
DADOS DE CATALOGAÇÃO NA PUBLICAÇÃO (CIP)

Serviço de Biblioteca e Informação Biomédica do

Instituto de Ciências Biomédicas da Universidade de São Paulo

(c) reprodução total

Mascaro, Marcelo Betti.

Conexões e caracterização neuroquímica de vias neurais envolvidas com o controle dos movimentos mandibulares / Marcelo Betti Mascaro. -- São Paulo, 2007.

Orientador: Carol Fuzeti Elias.

Dissertação (Doutorado) - Universidade de São Paulo. Instituto de Ciências Biomédicas. Departamento de Anatomia. Área de concentração: Ciências Morfofuncionais. Linha de pesquisa: Complexo trigeminal.

Versão do título para o inglês: Connections and neurochemical characterization of neural pathways involved in the control of jaw movements.

Descritores: 1. Núcleo motor do trigêmeo 2. Núcleo mesencefálico do trigêmeo 3. Orexina 4. Fator liberador de corticotrofina 5.

Tirosina hidroxilase 6. Bruxismo I. Elias, Carol Fuzeti II.

Universidade de São Paulo. Instituto de Ciências Biomédicas.

Programa de Pós-Graduação em Ciências Morfofuncionais. III. Título. 


\section{UNIVERSIDADE DE SÃO PAULO \\ INSTITUTO DE CIÊNCIAS BIOMÉDICAS}

Candidato(a): $\quad$ Marcelo Betti Mascaro.

Título da Tese: $\quad$ Conexões e caracterização neuroquímica de vias neurais envolvidas com o controle dos movimentos mandibulares .

Orientador(a): $\quad$ Carol Fuzeti Elias.

A Comissão Julgadora dos trabalhos de Defesa da Tese de Doutorado, em sessão pública realizada a .................................., considerou

\section{( ) Aprovado(a) ( ) Reprovado(a)}

Examinador(a): Assinatura:

Nome:

Instituição:

Examinador(a): Assinatura:

Nome:

Instituição:

Examinador(a): Assinatura:

Nome:

Instituição:

Examinador(a): Assinatura:

Nome:

Instituição:

Presidente: Assinatura:

Nome:

Instituição: 


\section{Certificado}

Certificamos que o protocolo registrado sob $\mathrm{n}^{\circ} 107$ nas fls. 9 do livro 2 para uso de animais em experimentação, sob a responsabilidade da Profa. Dra. Carol Fuzeti Elias, Coordenadora da Linha de Pesquisa "Caracterização neuroquímicadas aferências do núcleo motor do trigêmeo" do qual participou(aram) o(s) aluno(s): Marcelo Betti Mascaro, Aline S.Teirceira, está de acordo com os Principios Éticos de Experimentação Animal adotado pelo Colégio Brasileiro de Experimentação Animal (COBEA) e foi aprovado pela COMISSÃO DE ETICA EM EXPERIMENTAÇÃO ANIMAL (CEEA) em 16.12.2004.

São Paulo, 01 de fevereiro de 2005.

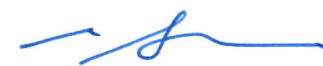

Profa. Dra. Marilia C. Leite. Seelaender Coordenadora da CEEA

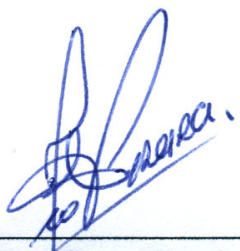

Prof. Dr. Francisco Carlas Pereira Secretärio da CEEA 


\section{DEDICATÓRIA}

\section{0 garoto aprende as regras.}

Com o tempo se ilude.

\section{Quando privado de todos os seus pensamentos, luta cada vez mais. \\ A té que decide fazer um juramento a si mesmo, jura, que a partir daquele dia, $\begin{array}{cl}\text { nunca, ninguém, levará } & \text { J. Hetfield } \\ \text { sua força de vontade... } & \text { L. Ulrich } \\ \text { K. Hammett }\end{array}$}

Aos meus pais Cláudia e gosé.

$\dot{E}$ difícil entender o que é ser bom filho. Agente só começa a aprender quando vira pai. Obrigado por tudo.

À minfra esposa Monique que me surpreende sempre com seu carintho e dedicação. Só nós sabemos como foi chegar aqui e sem você eu não chegaria.
À Maria, Domingas e Márcio que participaram de todos os momentos da minha vida, vocês sempre foram e serão muito importantes. Ao meu filho Marco, minha
vitória contra o tempo. Muitas
vezes acho que você me faz
crescer, outras acho que volto a
ser criança. Em todas fico feliz. 


\section{AGRADECIMENTOS}

Ao Departamento de Anatomia do Instituto de Ciências Biomédicas da Universidade de São Paulo, pela oportunidade oferecida para a realização do Curso de Pós-Graduação.

Ao Prof. Dr. Newton Sabino Canteras, Coordenador da Comissão de Pós-Graduação do Departamento de Anatomia do Instituto de Ciências Biomédicas da Universidade de São Paulo, pelo valoroso trabalho na melhoria do Programa.

A minha orientadora Prof ${ }^{a}$. Dr ${ }^{a}$. Carol Fuzeti Elias que mais uma vez apostou no meu trabalho, sempre disposta a trocar idéias e buscar novos rumos, incentivando e tornando a pesquisa mais empolgante e recompensadora. Obrigado!

Ao Prof. Dr. Jackson Cioni Bittencourt que mesmo com tantas preocupações e tarefas sempre cede um pouco do seu tempo para saber como anda o projeto, sua disposição e maneira simples der ser servem como exemplo.

À Profa. Dra . Andréa da Silva Torrão e ao Prof. Dr. Luis Roberto G. Britto por cederem alíquotas de anticorpos para o enriquecimento do trabalho.

Ao Prof. Dr. Bruno König Jr. que foi a primeira pessoa a permitir que eu tomasse contato com a pesquisa ainda no tempo da graduação. Sem o seu auxílio e incentivo inicial provavelmente eu não estaria terminando o Doutorado.

A todos os outros professores do Departamento de Anatomia que de maneira direta ou indireta sempre nos influenciam e nos engrandecem.

A todos os meus amigos da Pós-Graduação e do Laboratório de Neuroanatomia Química, mais uma vez, à LucianeValéria Sita e Tatiane Araújo Rondini que por diversas vezes pararam as suas pesquisas para me ajudar. Vocês sempre terão minha admiração e meu carinho por todo esses anos de convivência. À Suzana Souto pela ajuda com o material na impressão. Sem você as figuras perderiam muito em qualidade. 
A todos os auxiliares e técnicos do Departamento de Anatomia e do ICB, em especial a $\mathrm{Sr}^{\mathrm{a}}$. Joelcimar Martins da Silva pela dedicação e ajuda nas reações deste trabalho e ao Sr. Adilson Alves pela disposição e atenção cedida no uso de determinados protocolos e do microscópio confocal.

Aos funcionários da Secretaria e da Administração do Departamento de Anatomia que sempre, com muito zelo, cuidaram da parte burocrática na qual também estamos envolvidos.

A todos os funcionários do Departamento de Anatomia pela agradável convivência durante o curso.

Aos funcionários da Biblioteca do Instituto de Ciências Biomédicas da Universidade de São Paulo que atuam de maneira impecável em suas funções, facilitando de sobremaneira o nosso trabalho.

À FAPESP que forneceu os recursos materiais necessários à pesquisa.

Por fim, ao nosso grande mestre, Deus, que sutilmente ajuda quando fazemos a nossa parte com dedicação, vontade e boas intenções. 


\section{RESUMO}

Mascaro MB. Conexões e caracterização neuroquímica de vias neurais envolvidas com o controle dos movimentos mandibulares [Tese]. São Paulo: Instituto de Ciências Biomédicas da Universidade de São Paulo; 2007.

Os movimentos orofaciais são atividades complexas realizadas pelos músculos mastigatórios e da expressão facial. Em particular, os movimentos mandibulares envolvem a atividade de motoneurônios localizados principalmente no núcleo motor do trigêmeo (MO5). O Mo5 está localizado na formação reticular pontina, cercado por um anel de neurônios pré-motores denominada região h. Estudos utilizando traçadores retrógrados têm demonstrado que estes neurônios pré-motores estão distribuídos no tronco encefálico e em regiões prosencefálicas envolvidas com o controle autonômico e com o estresse, o que é sugerido, também, por estudos eletrofisiológicos. O controle do ritmo, tipo de movimento e força mastigatória podem estar alterados em certas patologias como nas desordens motoras orofaciais, dentre elas o bruxismo noturno, as discinesias e as distonias orais, além das disfunções têmporomandibulares, patologias estas, ainda pouco compreendidas. No presente trabalho foram utilizados 11 ratos (Wistar), os quais foram submetidos a cirurgia de implante de traçador retrógrado subunidade b da toxina colérica $(\mathrm{CTb})$ no Mo5. Após perfusão e processamento do material verificamos a presença de células retrogradamente marcadas no tronco encefálico e no prosencéfalo. Neste último, foram observadas células no núcleo central da amígdala (CeA), na área hipotalâmica lateral (LH) e no núcleo parasubtalâmico (PSTh). Para confirmação destas marcações prosencefálicas 21 ratos foram submetidos à cirurgia de implante de traçador anterógrado dextrana biotinilada (BDA). Fibras imunorreativas ao BDA foram notadas na periferia e em menor quantidade no interior do Mo5 em todos os casos considerados bons. Além do controle anterógrado, foi realizado um estudo neuroquímico através de duplas marcações utilizando técnicas de histoquímica, imunohistoquímica e hibridização in situ, envolvendo neuromediadores como a orexina (ORX), o fator liberador de corticotrofina (CRF), o ácido gama amino butírico (GABA) e a dopamina, além do receptor para canabinóide, tipo 1 e da enzima NADPH diaphorase. Cocluímos que neurônios do CeA, LH e PSTh, influenciam direta ou indiretamente o Mo5 através dos pré-motoneurônios da região h e do núcleo mesencefálico do trigêmeo; que alguns neurônios do CeA que se projetam para o Mo5 são influenciados pelo CRF e/ou, pela dopamina; que alguns neurônios da LH que se projetam para o Mo5 são imunorreativos a ORX e que alguns neurônios do 
PSTh que se projetam para o Mo5 são influenciados pela dopamina. Além disso, o Me5 recebe grande inervação do CeA e moderada da LH e do PSTh. Possuindo ainda, grande aferência de fibras imunorreativas ao CRF, ORX e dopamina.

Palavras-chave: Núcleo motor do trigêmeo. Núcleo mesencefálico do trigêmeo. Tirosinahidroxilase. Orexina. CRF. Bruxismo. 


\begin{abstract}
Mascaro MB. Connections and neurochemical characterization of neural pathways involved in the control of jaw movements [PhD Thesis]. São Paulo: Instituto de Ciências Biomédicas da Universidade de São Paulo; 2007.

Jaw movement is achieved by triggering of motoneurons located mainly in the trigeminal motor nucleus (Mo5). Masticatory movements, rhythm and muscle force can be altered in temporomandibular disfunctions, bruxism and oral diskinesias/dystonias. Studies have shown that premotor neurons innervating the Mo5 are located in the brainstem, and electrophysiology suggested the existence of a subcortical relay in the corticofugal-Mo5 pathway. Through the injection of the retrograde tracer cholera toxin b subunit/CTb in the Mo5, we found retrograde labeled neurons in the brainstem including the $\mathrm{h}$ region and the mesencephalic trigeminal nucleus (Me5), the central nucleus of amygdala (CeA), the lateral hypothalamic area (LH) and the parasubthalamic nucleus (PSTh). As control, we injected the anterograde tracer biotin dextran amine and found that these areas project direct or indirectly via the h region or the Me5 to the Mo5. Some LH neurons that project to Mo5 express orexin; some CeA neurons that project to the Mo5 receive corticotrophin releasing factor (CRF) and tyrosine hydroxylase (TH) fibers, and PSTh neurons that project to the Mo5 receive TH innervation. The Me5 is also innervated by CeA, LH and PSTh neurons and by CRF, orexin and $\mathrm{TH}$ immunoreactive fibers.
\end{abstract}

Key-words: Motor trigeminal nucleus. Mesencephalic trigeminal nucleus. Tyrosine hydroxylase. Orexin. CRF. Bruxism. 


\section{LISTA DE FIGURAS}

Figura 1: Núcleos do complexo trigeminal.

Figura 2: Citoarquitetura do núcleo motor do trigêmeo. 25

Figura 3: Esquema dos locais de injeções consideradas boas no núcleo motor do trigêmeo. 38

Figura 4: Local de injeção do traçador retrógrado subunidade b da toxina colérica. 39

Figura 5: Quantificação subjetiva das células marcadas retrogradamente com a subunidade b da toxina colérica e aferências do núcleo motor do trigêmeo de núcleos do tronco encefálico. 43

Figura 6: Neurônios do núcleo central da amígdala se projetam para o núcleo motor do trigêmeo. 44

Figura 7: Neurônios da área hipotalâmica lateral se projetam para o núcleo motor do trigêmeo. 45

Figura 8: Neurônios do núcleo parasubtalâmico se projetam para o núcleo motor do trigêmeo. 46 
Figura 9: Desenho esquemático do local de injeção dos casos considerados bons com o traçador anterógrado dextrana amina biotinilada no núcleo central da amígdala. 48

Figura 10: Controle anterógrado através de implante do traçador dextrana amina biotinilada no núcleo central da amígdala. 49

Figura 11: Desenho esquemático do local de injeção dos casosconsiderados bons com o traçador anterógrado dextrana amina biotinilada na área hipotalâmica lateral. 50

Figura 12: Controle anterógrado através de implante do traçador dextrana amina biotinilada na área hipotalâmica lateral.

Figura 13: Desenho esquemático do local de injeção dos casos considerados bons com o traçador anterógrado dextrana amina biotinilada no núcleo parasubtalâmico. 52

Figura 14: Controle anterógrado através de implante do traçador dextrana amina biotinilada no núcleo parasubtalâmico 53

Figura 15: Caracterização neuroquímica das células retrogradamente marcadas. 56

Figura 16: Esquema mostrando células retrogradamente marcadas na área hipotalâmica lateral com a subunidade b da toxina colérica, células imunorreativas à orexina e células duplamente marcadas. 57 
Figura 17: Neurônios do núcleo central da amígadala expressam o RNAm da enzima descarboxilase do ácido glutâmico e a enzima nicotinamida adenina dinucleotídeo fosfato diaforase.

Figura 18: Neurônios retrogradamente marcados que recebem inervação de fibras imunorreativas à tirosina hidroxilase. 59

Figura 19: Aferências prosencefálicas para o núcleo mesencefálico do trigêmeo. 60

Figura 20: Neuroquímica das aferências do núcleo mesencefálico do trigêmeo. 61 


\section{LISTA DE TABELAS}

Tabela 1. Resumo e quantificação de aferências do núcleo motor do trigêmeo. 


\section{LISTA DE ABREVIAÇÕES}

ATM - articulação temporomandibular

BDA - dextrana amina biotinilada

BST - núcleo da estria terminal

CeA - núcleo central da amígdala

CRF - fator liberador de corticotrofina

$\mathrm{CTb}$ - subunidade b da toxina colérica

DAB - tetracloreto de diaminobenzidina

DBH - dopamina beta hidroxilase

DEPC - dietil pirocarbonato

DpMe - núcleo mesencefálico profundo

DTM - disfunção temporomandibular

DTT - ditiotreitol

EDTA - ácido etilenodiaminotetracético

EW - núcleo de Edinger-Westphal

$\mathrm{FG}^{\circledR}$ - fluorogold

$\mathrm{F}$ - fórnice

GABA - ácido gama amino butírico

GAD - ácido glutâmico descarboxilase

$\mathrm{Gi}$ - núcleo gigantocelular

GiA - núcleo gigantocelular parte alfa

I - córtex da ínsula

IPAC - núcleo intersticial do ramo posterior da comissura anterior

IRt - núcleo reticular intermediário

KPBS - tampão potássio-fosfato

LC - locus coeruleus

LH - área hipotalâmica lateral

M1 - córtex motor primário

M2 - córtex motor secundário

Me5 - núcleo mesencefálico do trigêmeo

Mo5 - núcleo motor do trigêmeo

NB - neurobiotina

NADPHd - nicotinamida adenina dinucleotídeo fosfato diaforase

NAS - sulfato de amônia e níquel

NDS - soro normal de burro

NB - neurobiotina

NO - óxido nítrico

NOS - óxido nítrico sintase

NTS - núcleo do trato solitário

Opt - trato óptico

ORX - orexina

P5 - zona peritrigeminal

PAG - substância cinzenta periaquedutal

PBS - tampão fosfato de sódio

PCRtA - formação reticular parvicelular parte alfa

PHA-L - Phaseolus vulgaris

PO - núcleo posterior do tálamo

Pr5 - núcleo principal do trigêmeo 
PSTh - núcleo parasubtalâmico

PVH - núcleo paraventricular do hipotálamo

RPC - núcleo rubro porção parvicelular

Scp - pedúnculo cerebelar superior

SNC - sistema nervoso central

Sp5 - núcleo espinal do trigêmeo

Sp5C - subnúcleo caudal espinal do trigêmeo

Sp5I - subn. interpolar espinal do trigêmeo

Sp50 - subnúcleo oral espinal do trigêmeo

STh - núcleo subtalâmico

Su5 - núcleo supratrigeminal

TEA-HCL - trietanolamina hidrocloreto

TH - tirosina hidroxilase

VPM - núcleo ventro-póstero-medial do tálamo 


\section{SUMÁRIO}

1 INTRODUÇÃO__ 20

2 MATERIAL E MÉTODO _ 28

2.1 Animais e ambiente _ 28

2.2 Cirurgia para Implante de traçadore retrógrado subunidade b da toxina colérica (CTb) 28

2.3 Cirurgia para Implante de traçador anterógrado dextrana amina biotinilada (BDA)__ 29

2.4 Perfusão e microtomia __ 30

2.5 Imunoperoxidase para visualização do traçador retrógrado $\mathrm{CTb} \_30$

2.6 Dupla marcação de imunofluorescência para identificar as células retrógradamente marcadas com CTb e o neuromediador ou receptor de interesse (CRF, ORX, catecolaminas, GABA e receptor CB1 ) 31

2.7 Dupla marcação NADPH diaforase e imunoperoxidase 32

2.8 Histoquímica para o traçador anterógrado BDA e reação de impregnação pela prata 33

2.9 Coloração pelo Método de Nissl_ 34

2.10 Hibridização in situ para estudo de dupla marcação 34

2.10.1 Pré-tratamento 34

2.10.2 Hibridização in situ com Radioisótopo ${ }^{35} \mathrm{~S}$ 35

2.11 Análise dos resultados e produção das ilustrações 36

3 RESULTADOS 37

3.1 Estudo das aferências do núcleo motor do trigêmeo (Mo5) ___ 37

3.1.1 Estudo das injeções consideradas boas___ 37

3.1.2 Aferências do Mo5__ 40

3.1.2.1 Tronco encefálico__ 40

3.1.2.2 Prosencéfalo _ـ 41

3.2 Controle anterógrado __ 47

3.3 Duplas marcações___ 54

4 DISCUSSÃO _ 62

4.1 Considerações metodológicas __ 62

4.2 Considerações sobre a citoarquitetura e hodologia do Mo5 __ 64

4.3 Considerações clínicas _ 78 
5 CONCLUSÃO

85

REFERÊNCIAS BIBLIOGRÁFICAS

86

ANEXOS 


\section{INTRODUÇÃO}

O nervo trigêmeo é o quinto par de nervos cranianos e é dividido em três ramos: o oftálmico, o maxilar e o mandibular. Os dois primeiros são exclusivamente sensitivos e o terceiro é misto, ou seja, possui uma porção sensitiva e uma motora. O nervo trigêmeo é responsável pela sensibilidade da cabeça, tanto em relação a tato, pressão, temperatura, como dor. Sua parte motora, representada pelo nervo mandibular, inerva os músculos da mastigação. Distúrbios no controle dos músculos mastigatórios podem gerar dor e alterações nos padrões de mastigação o que é observado nas mialgias relacionadas às disfunções temporomandibulares (DTMs) e nas desordens motoras orofaciais, esse termo foi utilizado por Clark (2006) para agrupar uma série de patologias de hipo ou hiperatividade dos músculos orofaciais, dentre elas o bruxismo noturno, as discinesias e distonias orais induzidas ou não por drogas.

As DTMs são também chamadas de síndrome de Costner, disfunção mandibular, síndrome da dor e disfunção miofascial, desordens craniomandibulares ou disfunção craniomandibular. Todos estes termos são sinônimos para caracterizar algumas condições dolorosas orofaciais que possuem etiologia multifatorial, envolvendo aspectos biológicos individuais, alterações oclusais e distúrbios psico-emocionais (Siqueira e Ching, 1999).

Embora a maioria das classificações, segundo os mesmos autores, separe as dores têmporo-mandibulares em dois subgrupos tradicionais, musculares e articulares, não se deve esquecer que existem graus variados de comprometimento e lesão tecidual. Desta forma, pode ocorrer uma mistura entre os dois subgrupos (Rauhala et al., 1999), sendo importante à determinação da causa primária, o que em certos casos influenciará o tratamento e prognóstico.

Vários estudos epidemiológicos têm sido feitos a respeito das DTMs, mas ainda não existe uma sistematização destes estudos. Assim, os métodos usados, fatores pesquisados e resultados obtidos são muito variáveis. Porém, em todos, nota-se uma grande preocupação com as dores dos músculos da mastigação, independentemente destas serem primárias ou relacionadas a distúrbios intra-articulares.

O bruxismo noturno é uma patologia multifatorial, sendo uma das causas das DTMs. Atualmente acredita-se que aparentemente não há relação direta entre o bruxismo e interferências oclusais, sendo a patologia uma desordem do sono, mediada pelo sistema nervoso central (Attanasio, 1991; Lobbezo e Naeije, 2001). 
O termo “ranger os dentes”, ou frender (Ferreira, 1999), denotando agressividade, tem sido descrito historicamente desde os tempos bíblicos como no Antigo Testamento no livro profético das Lamentações onde podemos ler: "Recolheu o seu furor contra mim, e ameaçando-me, rangeu os dentes contra mim: com os olhos terríveis me olhou o meu inimigo”. Na literatura odontológica o termo bruxomania foi utilizado, em um artigo científico, em 1907, pelos médicos franceses Marie e Pietkiewicz para explicar um fenômeno que se caracterizava pelo rangimento e apertamento dos dentes. A palavra bruxomania é composta pela palavra “bruxo” e pela palavra “mania”. Bruxo é uma palavra derivada do grego "brychein” que significa ranger os dentes, ou "brosis" que quer dizer "ato de comer” e, em sentido mais intenso, corrosão (Orlando, 2000). Mania também é um termo derivado de uma raiz grega cujo significado é loucura, o que denota, desde o início, a relação existente com o sistema nervoso central. O termo bruxismo foi primeiramente utilizado por Frohmannn em 1931 para denotar disfunção dos movimentos mandibulares (Attanasio, 1991).

O bruxismo noturno é um fator causal das DTMs (Attanasio, 1991; Molina et al.,1999) que afeta diretamente os músculos da mastigação aumentando seu tônus e podendo levar a distúrbios intra-articulares, como deslocamentos do disco da articulação temporomandibular (ATM) e dor. Segundo Sessle (1999), que estuda as bases neuronais das dores da ATM e dores associadas aos músculos da mastigação, há uma comunicação entre o sistema sensitivo trigeminal e o núcleo motor do trigêmeo. Desta forma, haveria um reflexo muscular à dor intra-articular, representado por um aumento da atividade tanto dos músculos de elevação quanto dos de abaixamento da mandíbula na tentativa de funcionar como bloqueio, limitando a função. Esta contínua excitação levaria a um quadro doloroso. Porém, como e em quais regiões do sistema nervoso central isso se processa, ainda não se sabe. Desta forma, o bruxismo pode causar distúrbios primários musculares que poderão provocar outros intraarticulares que aumentarão ainda mais os musculares na tentativa de imobilizar a ATM. Além disso, segundo Camparis e Siqueira (2006), cerca de 65\% dos pacientes que possuem bruxismo relatam dores de cabeça freqüentes e um aumento do fluxo sanguíneo na artéria cerebral média foi verificado durante uma contração intensa do músculo masseter (Hasegawa et al., 2007).

A quantidade de bruxômanos envolvidos nas pesquisas epidemiológicas relacionadas às DTMs é um dado fortemente ressaltado (Szentpétery et al., 1986; Agerberg e Inkapool, 1990; Duckro et al., 1990; De Kanter et al., 1993). Molina et al. (1999), em um estudo com 276 pacientes encaminhados à Faculdade de Odontologia da Universidade do Texas, puderam relacionar o bruxismo com sinais e sintomas das DTMs. Os autores concluíram que pacientes 
com grau severo de bruxismo apresentaram a menor abertura da boca, além de maiores taxas de dor retrodiscal e capsulite; isto sugere que os que apresentavam o grau severo deveriam ter um aumento dos impulsos nociceptivos das ATMs aumentando o tônus dos músculos da mastigação para que houvesse um efeito imobilizante protetor. Desta forma, os autores concluíram que o bruxismo é um fator significante para a etiologia e progressão das desordens mio-articulares. Mais recentemente, em outro estudo, Guler et al. (2003), analisando através de ressonância magnética, a ATM de pacientes com bruxismo e comparando com um grupo controle, concluíram que alterações na superfície articular do côndilo são mais prevalentes em pacientes com bruxismo que apresentam deslocamento anterior de disco com redução.

Uma alteração nos padrões de contração dos músculos orofaciais é o que ocorre nas discinesias orais. Estas alterações são classificadas de acordo com o padrão dos movimentos anormais ou de acordo com a causa. Nas discinesias orais ocorrem movimentos involuntários repetitivos, às vezes com alteração de tonicidade envolvendo os músculos da língua, da mímica facial e da mastigação. Apesar de repetitivos, os movimentos não são rítmicos como um tremor. Muitas das discinesias orais estão relacionadas com o uso de drogas que interferem com o mecanismo de ação da dopamina ou da serotonina (Blanchet et al., 2005, Clark, 2006). Além disso, devido ao número de repetições e a alterações no tônus muscular, as discinesias orais podem muitas vezes causar desgastes dentais e dores de cabeça, musculares e articulares (Basset et al., 1986; Osborne et al., 1989; Blanchet et al., 2005, Clark, 2006). As distonias orais são semelhantes as discinesias porém, tendem a ser mais intermitentes, com contrações mais momentâneas e potentes (Clark et al. 1993; Clark e Takeuchi, 1995; Clark, 2006).

Portanto, observamos que o conhecimento do nervo trigêmeo e dos núcleos do complexo trigeminal e suas conexões no sistema nervoso central são essenciais para a melhor compreensão das causas das alterações musculares associadas às dores intra-articulares nas DTMs e das desordens motoras orofaciais, dentre elas o bruxismo noturno, as discinesias e distonias orais.

O complexo trigeminal é constituído pelo núcleo mesencefálico (Me5), núcleo principal (Pr5), núcleo supratrigeminal (Su5), núcleo espinal (Sp5), o qual é por sua vez dividido em três subnúcleos: oral (Sp5O), interpolar (Sp5I) e caudal (Sp5C); e, finalmente, pelo núcleo motor (Mo5) (figura 1). O Sp5C, por ser considerado uma extensão do corno dorsal da medula espinal, é dividido em lâminas que em sentido látero-medial recebem numeração de I a V (Paxinos, 1995) (figura 1). 
A partir da porção sensitiva do complexo trigeminal, as sensações de tato, pressão, dor e temperatura da cabeça são transmitidas até os núcleos ventro-póstero-medial (VPM) e posterior (Po) do tálamo e posteriormente ao córtex sensitivo, onde se tornarão conscientes (Waite e Tracey, 1995).

O Mo5 localiza-se medialmente ao Pr5. Em relação a musculotopia, é dividido em duas partes principais, uma dorso-lateral, maior, que ocupa toda a extensão do núcleo e uma ventro-medial, menor, que ocupa os dois terços caudais. Na porção dorso-lateral estão os corpos celulares dos motoneurônios dos músculos de fechamento da boca, que são o masséter, o temporal e o pterigóideo medial. Na porção ventro-medial estão, principalmente, os motoneurônios dos músculos de abertura que são o ventre anterior do digástrico e o milohióideo. O pterigóideo lateral possui dois ventres que agem em diferentes movimentos. Assim, o ventre inferior participa do movimento de abertura bucal, protrusão e lateralidade, enquanto o superior está ativo principalmente na elevação da mandíbula e no apertamento dos alimentos durante a mastigação (Ruangsri et al., 2005). O músculo pterigóideo lateral possui seus motoneurônios na porção dorso-lateral do Mo5, juntamente com os motoneurônios dos músculos de fechamento da boca, porém, localizados na parte mais ventral e medial. Este tipo de organização foi descrita por meio de injeção de traçadores retrógrados na musculatura do rato e gato (Mizuno et al., 1975), macaco (Mizuno et al., 1981) e cobaia (Uemura-Sumi et al., 1982).

O Mo5 está cercado por uma região que contém diversos neurônios pré-motores, denominada região h (Kolta et al., 2000) ou concha do Mo5 (Yamamoto et al., 2007). Esta região é composta pela área supratrigeminal, dorsalmente; área intertrigeminal, lateralmente, entre o Mo5 e o Pr5; área justatrigeminal, medialmente; e a formação reticular ventral ao Mo5 (Kolta et al., 2000) (figura 2). Em um estudo eletrofisiológico em ratos, Kolta (1997) demonstrou que há conexões entre os neurônios pré-motores da região h, além disso, os autores concluíram que estímulos na região justa e intertrigeminal geram inibição dos motoneurônios massetéricos, enquanto estímulos da região supratrigeminal, formação reticular ventral e caudal geram potenciais excitatórios nestes motoneurônios. Desta forma, estes neurônios pré-motores, têm papel chave na produção dos movimentos e reflexos mandibulares. 

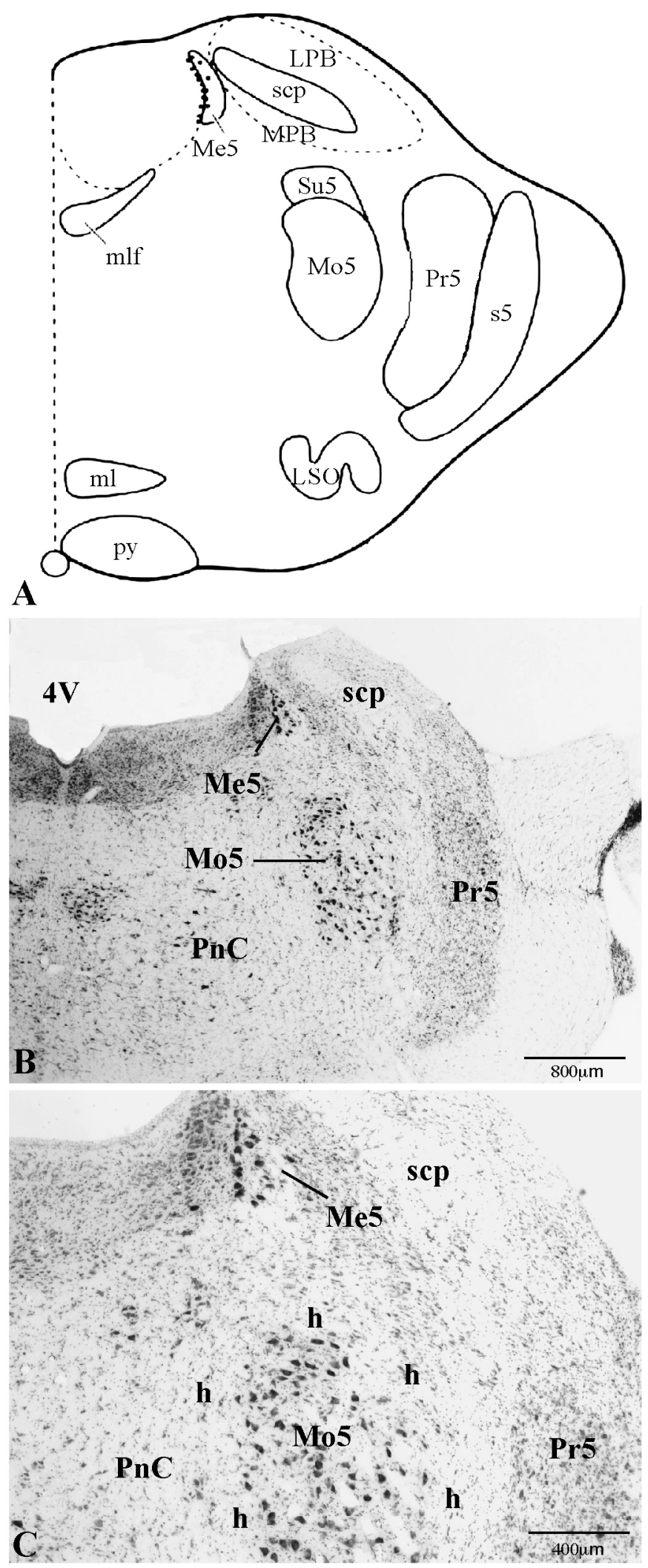

Figura 2. Citoarquitetura do núcleo motor do trigêmeo (Mo5). Em A, esquema de corte coronal mostrando o Mo5 e núcleos adjacentes (figura modificada de Paxinos, 1995). Em B, corte coronal do encéfalo de rato ao nível do Mo5 mostrando a citoarquitetura da região. Em $\mathbf{C}$, aumento de B.

Abreviações: $4 \mathrm{~V}$, quarto ventrículo; $\mathrm{h}$, região $\mathrm{h}$; Me5, núcleo mesencefálico do trigêmeo; PnC; núcleo pontino caudal; Pr5, núcleo principal do trigêmeo; scp, pedúnculo cerebelar superior. 
Em relação as aferências, o Mo5 recebe projeções dos neurônios pré-motores da região h, além de diversos núcleos, tanto do complexo trigeminal, quanto de outros, localizados, principalmente, no tronco encefálico. Diversos estudos utilizando injeções de traçadores retrógrados no Mo5, em várias espécies animais foram realizados demonstrando estas aferências (Travers e Norgren, 1983; Grzanna et al., 1987; Fort et al., 1990; Turman e Chandler, 1994; Li et al., 1995; Li et al., 1996; Yasui et al., 1997; Kolta et al., 2000; Luo et al., 2001; Mascaro et al., 2005; Yamamoto et al., 2007). Porém, até o presente momento, não há consenso sobre conexões diretas entre núcleos do prosencéfalo e o Mo5, o que sugeriria que entre os mamíferos, apenas os primatas possuiriam este tipo de conexão (Travers e Norgren, 1983).

Porém, estudos eletrofisiológicos, sugerem conexões diretas entre a amígdala (Bobo e Bonvallet, 1975), área hipotalâmica lateral (LH) (Landgren e Olsson, 1980; Weiner et al., 1993) e subtálamo (Kawamura e Tsukamoto,1960a) com o Mo5.

A conexão entre amígdala e Mo5 estaria relacionada às respostas emocionais conforme demonstram os estudos de Valles et al. (2006) que detectaram a expressão da proteína Fos, um marcador da atividade neuronal, em neurônios da amígdala de ratos, após estes serem submetidos a um estímulo estressante de imobilização. Demonstrando ainda, a expressão deste marcador em núcleos diencefálicos como o paraventricular do hipotálamo (PVH) e do tronco encefálico como o locus coeruleus (LC) que estão relacionados ao controle autonômico (Prewitt e Herman, 1998; Reyes et al., 2005; Martin et al., 2006). Além disso, o estudo de Knapska et al. (2006), detectou a mesma expressão de Fos do estudo de Valles et al. (2006), porém com os ratos sendo submetidos a um outro tipo de estímulo estressante, o de choques nas patas. Ratos que apenas observaram este estímulo estressante também tiveram o mesmo padrão de expressão de Fos. Este aumento de expressão de Fos na amígdala ocorre tanto nos casos de estímulos estressantes, como, por exemplo, nas síndromes de abstinência a drogas como os canabinóides (Rodrigues de Fonseca et al.,1997). O aumento de Fos na amígdala é acompanhado por um aumento extracelular do fator liberador de corticotrofina (CRF) (Rodrigues de Fonseca et al.,1997), que atua nas respostas ao estresse participando do controle autonômico. Além disso, a amígadala parece intermediar vários sinais da abstinência aos canabinóides, dentre eles os movimentos mastigatórios (Castañé et al., 2004).

A amígdala tem conexões com o Su5 (Takeuchi et al., 1988) e com o Me5, acredita-se que estas últimas, utilizam o CRF como neuromediador (Sakanaka et al., 1986).

Mais recentemente, autores (de Lecea et al., 1998; Sakurai et al., 1998) descreveram a existência de um neuropeptídeo denominado hipocretina ou orexina que só é produzido por 
neurônios localizados na LH. Axônios imunorreativos à orexina foram descritos fazendo conexões com motoneurônios trigeminais (Fung et al., 2001). Segundo Peever et al. (2003) a orexina influenciaria a liberação pré-sináptica de glutamato em neurônios no Mo5, além disso, de acordo com Suzuki et al. (2005), a orexina pode produzir um comportamento ansiogênico em ratos após ser administrada intracerebroventricularmente.

Estímulos elétricos em outras áreas como no córtex da ínsula, na cápsula interna, e no subtálamo gerariam movimentos mastigatórios, segundo Kawamura e Tsukamoto, (1960a).

Recentemente, utilizando injeções do traçador retrógrado fluorogold (FG) no Mo5 (Mascaro et al., 2005), observamos neurônios retrogradamente marcados no núcleo central da amígdala (CeA); região perifornicial da LH e no núcleo parasubtalâmico (PSTh), localizado medialmente a cápsula interna e recentemente descrito por Goto e Swanson (2004). Estas áreas influenciariam o Mo5 diretamente ou indiretamente através da região h e do Me5 podendo atuar no ritmo, movimento ou força mastigatória.

O objetivo do presente trabalho é estudar as vias motoras trigeminais, refinando resultados obtidos anteriormente que demonstraram projeções do CeA, LH e PSTh para o Mo5, utilizando traçadores retrógrados e anterógrados. Além disto, também é nosso objetivo estudar a neuroquímica destas projeções, visando colaborar na compreensão das vias envolvidas nas mialgias relacionadas às DTMs e nas desordens motoras orofaciais. 


\section{MATERIAL E MÉTODOS}

\subsection{Animais e ambiente}

Foram utilizados 32 ratos adultos, jovens e machos (Sprague-Dawley), com peso entre 280 e 310 g, criados no Biotério do Departamento de Anatomia, localizado no Instituto de Ciências Biomédicas III. Os animais foram acondicionados aos pares em gaiolas forradas com maravalha que foi trocada duas vezes por semana, tendo acesso livre à água e ração e sendo mantidos em ambiente com temperatura controlada $\left(21\right.$ a $\left.22^{\circ} \mathrm{C}\right)$ e ciclo claro-escuro 12/12, com as luzes sendo acesas as 6:00 horas.

\subsection{Cirurgia para implante de traçador retrógrado subunidade b da toxina colérica (CTb)}

A cirurgia para implante de traçador retrógrado subunidade b da toxina colérica (CTb), List Biological Laboratories; California, USA) no núcleo motor do trigêmeo (Mo5) foi realizada em 11 ratos, com o auxílio de um aparelho estereotáxico no qual a cabeça do animal é fixada em quatro pontos: maxilas e meatos acústicos externos.

Os animais foram previamente anestesiados através de injeção subcutânea no volume de $0,2 \mathrm{ml} / 100 \mathrm{~g}$ de peso de uma solução anestésica composta por: acepromazina $(0,2 \mathrm{mg})$ (Univet; São Paulo, Brasil), xilazina (5mg) (Bayer; São Paulo, Brasil), cetamina (1mg) (Virbac; Roseira, Brasil). Após a anestesia foi realizada tricotomia na região craniana e cérvico-dorsal, fixação no aparelho estereotáxico e antissepsia com álcool etílico a 70\%. Posteriormente foi realizada uma incisão sagital mediana de cerca de $2 \mathrm{~cm}$ na região craniana, divulsão, hemostasia, afastamento dos tecidos e com o auxílio de um microscópio cirúrgico foram localizados dois pontos craniométricos de referência: o bregma, no cruzamento da sutura sagital com a coronal e o lambda, no cruzamento da sutura sagital com a lambdóidea. O implante do CTb foi feito através de iontoforese, que consiste no deslocamento do traçador para o tecido através de corrente elétrica, por meio de uma micropipeta de vidro confeccionada com 10 a 15 $\mu$ m de diâmetro interno, preenchida com uma solução de CTb a 1\% em água destilada e introduzida no encéfalo através de craniotomia. No caso, foram utilizados $5 \mu \mathrm{A}$ de corrente positiva contínua intermitente (ligado/desligado) com ciclos de 7 
segundos por cerca de 10 minutos que atingiram a solução de CTb através de fio de prata introduzido dentro da pipeta (Li et al., 1995; Yasui et al., 1997).

A injeção no núcleo motor do trigêmeo seguiu as coordenadas descritas no Atlas de coordenadas estereotáxicas do cérebro do rato de Paxinos e Watson (1998) tendo como ponto de referência o bregma. Desta forma, as coordenadas usadas foram: ântero-posterior (AP) 9,2mm; médio-lateral (ML) 2,1mm e dorso-ventral (DV) 7,6mm, sendo que a medida DV teve como ponto de referência a dura-máter .

Após a injeção, a pipeta foi deixada em posição por 5 minutos, o fio de prata foi retirado e só então a pipeta foi removida, para que contaminações de outras áreas com o traçador fossem evitadas durante a remoção.

Por fim, foi realizada uma limpeza dos tecidos com peróxido de hidrogênio a 10\% e a incisão foi reposicionada e mantida com clipes metálicos. Após a cirurgia o animal permaneceu cerca de 15 dias no biotério do Departamento de Anatomia, tempo necessário para o transporte axonal do traçador.

\subsection{Cirurgia para implante de traçador anterógrado dextrana amina biotinilada (BDA)}

Realizamos o implante de traçador neuronal anterógrado dextrana amina biotinilada (BDA-10000, Invitrogen; São Paulo, Brasil) em 21 animais, nas regiões prosencefálicas que apresentaram maior quantidade de células retrogradamente marcadas, a saber: núcleo central da amígdala (CeA), área hipotalâmica lateral (LH) e núcleo parasubtalâmico (PSTh). O BDA foi utilizado em uma concentração de 10\% em tampão fosfato de sódio (PBS), 10mM, pH 7,4 (Reiner et al., 2000; Novikov, 2001).

As pipetas utilizadas tinham cerca de $15 \mu \mathrm{m}$ de diâmetro interno e a técnica cirúrgica seguiu os mesmos passos que as utilizadas para implante de CTb. As coordenadas usadas para o CeA foram: AP 2,1; ML 3,4 e DV 7,7, para a LH foram AP: 2,6; ML 1,4 e DV 8,0 e para o PSTh foram AP: 2,8; ML 1,5 e DV 7,6. Foram utilizados $5 \mu \mathrm{A}$ de corrente contínua intermitente (ligado/desligado) com ciclos de 7 segundos por cerca de 7 minutos. Após a cirurgia, o animal permaneceu entre 20 e 24 dias no biotério do Departamento de Anatomia, tempo necessário para o transporte anterógrado do traçador, quando então, foi submetido à perfusão. 


\subsection{Perfusão e microtomia}

Em todos os experimentos os animais foram submetidos à perfusão e microtomia. Após injeção intraperitonial de uma mistura de drogas (acepromazina, xilasina e cetamina), os animais, após anestesia profunda, sofreram toracotomia e foi realizada uma incisão no ventrículo esquerdo, sendo a aorta canulada. Após isso, uma nova incisão foi realizada no átrio direito e a perfusão foi iniciada com solução salina 0,9\% (100 ml) e a seguir fixador a $4^{\circ} \mathrm{C}$ (700 a $900 \mathrm{ml}$ em 25 minutos); o fixador foi composto por 4\% de paraformaldeído (Sigma-Aldrich; São Paulo, Brasil) e 3,8\% de Bórax (Sigma-Aldrich, São Paulo, Brasil) em um $\mathrm{pH}$ de 9,5. A partir desse momento todos os cuidados foram tomados no preparo e manuseio para não ocorrer contaminação com RNAses, devido à possibilidade dos encéfalos serem utilizados no procedimento de hibridização in situ, portanto as soluções utilizadas foram feitas de forma a ficar livre de RNAses e os encéfalos acondicionados em recipientes estéreis.

Os encéfalos foram, então, removidos e permaneceram por cerca de 1 hora e 30 minutos em uma solução de fixador, sendo depois trocados para uma solução de pós-fixação composta por tampão fosfato de sódio, dietil pirocarbonato e água (1xPBS - DEPC $\mathrm{H}_{2} \mathrm{O}$ ) com 20\% de sacarose (LabSynth; Diadema, Brasil) para crioproteção. Os encéfalos permaneceram nesta solução por 24 horas, quando foram removidos para que a microtomia fosse iniciada. Esta foi realizada em um micrótomo de congelação, secções em plano frontal, com espessura de cortes de $30 \mu \mathrm{m}$, coletados de maneira seqüencial e distribuídos em séries de 1 a 5 . Os cortes foram depositados em placas de cultura utilizadas com coletores de tecidos (Costar ${ }^{\circledR}$ ) de 6 subdivisões, estéreis, preenchidos previamente com solução anti-congelante (20\% glicerol, 30\% etilenoglicol, 50\% DEPC-PBS).

\subsection{Imunoperoxidase para visualização do traçador retrógrado CTb}

Uma série de cortes de todo o encéfalo foi lavada 2 vezes em KPBS por 10 minutos. Posteriormente, os cortes foram colocados em uma solução contendo KPBS + Triton X-100 0,3\% e solução de peróxido de hidrogênio a $0,3 \%$, por 30 minutos; então os cortes foram lavados em KPBS até serem eliminadas as bolhas e colocados em outra solução contendo KPBS + Triton X-100 0,3\% e soro normal de burro (NDS; Jackson Laboratories; Maine, USA) a 3\% por 1 hora. Finalmente, foi acrescentado à solução o anticorpo primário anti-CTb feito em cabra, a uma concentração de 1:50000 (List Biological Laboratories; Califórnia, 
USA) e a incubação foi feita sob agitação e temperatura ambiente por aproximadamente 18 horas.

No dia seguinte os cortes foram lavados em KPBS 3 vezes por 10 minutos cada e colocados em solução contendo KPBS + Triton X-100 0,3\% e o anticorpo secundário biotinilado feito em burro contra cabra a uma concentração de 1:1000 (Jackson Laboratories; Maine, USA), por 1 hora. Então, os tecidos foram novamente submetidos a 3 lavagens em KPBS cada uma de 10 minutos e colocados no complexo ABC (Vectastain Kit Elite, Vector Laboratories; Califórnia, USA) a 1:500 por mais 1 hora. Após lavagem em KPBS, 3 vezes de 10 minutos, o tecido foi transferido para uma outra solução contendo KPBS, sulfato de amônia e níquel (NAS) (Biolab; Auckland, New Zealand) a 0,05\%, o cromógeno tetracloreto de diaminobenzidina (DAB) (Sigma-Aldrich; São Paulo, Brasil) a 0,05\% e peróxido de hidrogênio a 0,001\%. Após 3 a 5 minutos a reação foi parada com banhos de KPBS e, finalmente, os cortes foram montados em lâminas previamente gelatinizadas, desidratados em seqüência crescente de álcool etílico, deslipidificados em xilol (Merck \& Co. Inc.; New Jersey, USA) onde permaneceram por, pelo menos, 24 horas quando foram montadas as lamínulas com o meio de montagem permanente, DPX (Sigma-Aldrich; São Paulo, Brasil). As lâminas foram posteriormente analisadas em microscopia de luz (Leica DMR).

\subsection{Dupla marcação de imunofluorescência para identificar as células retrógradamente marcadas com CTb e o neuromediador ou receptor de interesse (CRF, ORX, catecolaminas, GABA e receptor $\mathrm{CB} 1$ )}

Nos casos com injeções do traçador retrógrado CTb considerados bons , uma série de cortes de todo o encéfalo foi lavada 2 vezes em KPBS por 10 minutos, então, foi acrescentado o anticorpo primário anti-CTb feito em cabra, a uma concentração de 1:2000 (List Biological Laboratories; Califórnia, USA) + 0,3\% Triton X-100. O tecido foi deixado em mesa agitadora e temperatura ambiente por aproximadamente 18 horas. No dia seguinte o tecido foi incubado por 1 hora no anticorpo secundário feito em mula contra cabra conjugado a Cy3 (Jackson Laboratories; Maine, USA) ou Alexa Fluor 596 (Invitrogen; São Paulo, Brasil) na concentração de 1:200. Após mais 2 lavagens com KPBS, o tecido foi novamente incubado em um dos cinco anticorpos primários descritos a seguir: o anticorpo anti-fator liberador de corticotrofina (CRF, gentilmente cedido pelo Dr. Paul Sawchenko e Dr. Wylie Vale - The Salk Institute, Califórnia, USA) feito em coelho, na concentração de 1:1000; o anticorpo antiorexina (ORX, Península Laboratories, Inc.; California, USA) feito em coelho na 
concentração de 1:1.000; o anticorpo anti-tirosina hidroxilase (TH, Chemicon International, Inc.; Califórnia, USA), feito em ovelha, a uma concentração de 1:5000; o anticorpo antidopamina beta-hidroxilase (DBH) (Chemicon International, Inc.; Califórnia, USA) feito em ovelha em uma concentração de 1:000; o anticorpo anti-ácido gama amino butírico (GABA) (Protos Immunoresearch; California, USA) feito em cobaia, em uma concentração de 1:100 ou o anticorpo anti-receptor de canabinóides (Santa Cruz Biotechnology, Inc; California, USA) CB1-H feito em coelho, CB1-N, ou CB1-K feitos em cabra, todos a uma concentração de 1:75. A incubação foi feita em KPBS + 0,3\% Triton X-100 por 18 horas. No dia seguinte os cortes foram incubados por 1 hora no anticorpo secundário conjugados à fluoresceína isotiocianato (FITC) (Jackson Laboratories; Maine, USA) ou Alexa Fluor 488 (Invitrogen; São Paulo, Brasil) na concentração de 1:200.

\subsection{Dupla marcação NADPH diaforase e imunoperoxidase}

A enzima óxido nítrico sintase (NOS) é a responsável pela síntese de óxido nítrico (NO), através de átomos de nitrogênio e da L-arginina na presença de oxigênio e da enzima nicotinamida adenina dinucleotídeo fosfato (NADPH) diaforase (Hope et al., 1991; Dawson et al., 1991). Para observação de neurônios retrogradamente marcados com CTb na região mais medial do CeA que produzam NO, realizamos uma dupla marcação com as técnicas de imunoperoxidase para marcar o CTb e de histoquímica NADPH diaforase para marcar esta enzima que se colocaliza com a NOS.

O tecido foi previamente lavado em PBS por aproximadamente 18 horas com algumas trocas de solução durante esse período. Em seguida os cortes foram transferidos para uma solução a $37{ }^{\circ} \mathrm{C}$ de Tris-HCl, 0,1\% de Triton X-100, NADPH (0,02\%; Sigma-Aldrich; São Paulo, Brasil) e Nitroblue Tetrazóleo (0,02\%; Sigma-Aldrich; São Paulo, Brasil) diluídos no escuro, onde o tecido permaneceu durante a reação. O tempo de reação é variável e freqüentes observações foram feitas sob microscópio, até que a coloração desejada fosse atingida (células com tonalidade azul clara). Para parar a reação foram feitas novas lavagens com PBS (15 minutos cada).

O procedimento utilizado nas técnicas combinadas foi o mesmo utilizado nas técnicas simples, iniciando-se pela NADPHd. A técnica de NADPHd produz uma material azul e a imunoperoxidase um material castanho, desta forma, verificamos neurônios em azul (NADPHd simples) e em marrom (CTb simples) se existissem células duplamente marcadas, provavelmente, elas seriam visualizadas na coloração preta. 


\subsection{Histoquímica para o traçador anterógrado dextrana amina biotinilada (BDA) e reação de impregnação pela prata}

Uma série de cortes de todo o encéfalo de cada animal que recebeu o implante do traçador anterógrado BDA foi submetida à reação de histoquímica para a sua visualização (Reiner et al., 2000; Novikov, 2001). Os cortes foram lavados com KPBS 2 vezes de 10 minutos cada e colocados em uma solução contendo KPBS + Triton X-100 0,3\% e peróxido de hidrogênio a 0,3\%, por 30 minutos. Então, foram lavados em KPBS até serem eliminadas as bolhas. O tecido foi, posteriormente, colocado em uma solução contendo o complexo ABC (Vector Laboratories, Califórnia, USA) na concentração de 1:500. Após lavagem em KPBS, 3 vezes de 10 minutos, o tecido foi transferido para uma outra solução contendo KPBS e o cromógeno (DAB) (Sigma-Aldrich; São Paulo, Brasil) a 0,05\% e peróxido de hidrogênio a 0,001\%. Após 3 a 5 minutos, a reação foi parada com banhos de KPBS e, finalmente, os cortes foram montados em lâminas previamente gelatinizadas, desidratados em seqüência crescente de álcool etílico, deslipidificados em xilol (Merck \& Co. Inc.; New Jersey, USA) onde permaneceram por cerca de 4 dias quando foram rehidratados em seqüência decrescente de álcool etílico para serem submetidos à reação de impregnação pela prata, com o intuito de evidenciar a marcação de fibras pelo traçador anterógrado BDA, possibilitando, desta forma, uma análise mais eficiente tanto quantitativa como qualitativa das fibras (Breder et al., 1992; de Lacalle et al., 1993).

Todos os recipientes utilizados na reação foram colocados previamente em solução de ácido nítrico por cerca de 12 horas para que não houvesse interferências de resíduos na reação. Foi preparada solução de nitrato de prata a 1\% equilibrada com hidróxido de amônia. Então, a solução foi filtrada e as lâminas imersas. Todo o conjunto permaneceu em banho termostático a $56{ }^{\circ} \mathrm{C}$ por 45 minutos. Após isso, as lâminas foram colocadas em uma nova solução contendo água destilada e solução de cloreto de ouro a 0,01\% e deixadas em mesa agitadora por 10 minutos. Finalmente as lâminas foram colocadas em uma nova solução de tiossulfato de sódio a 5\% e deixadas em mesa agitadora por 5 minutos. Entre cada uma destas etapas o material foi submetido a um banho em água corrente por 10 minutos. As lâminas foram então, desidratadas em concentrações crescentes de álcool etílico, diafanizadas em xilol e cobertas com DPX (Sigma-Aldrich; São Paulo, Brasil). Após 2 dias, elas foram limpas removendo-se os excessos de DPX e observadas em microscopia de luz e campo escuro. 


\subsection{Coloração pelo Método de Nissl}

Uma série de cortes das injeções de traçadores retrógrado ou anterógrado consideradas boas foram submetidos à coloração com tionina (método de Nissl), como referência para interpretação dos dados obtidos. Esta reação é utilizada das mais diversas formas O protocolo utilizado consiste na desidratação dos cortes em seqüência crescente de álcool etílico (50\% $70 \%$ - 2 vezes 95\% - 3 vezes absoluto), 3 minutos em cada, sendo posteriormente deslipidificados em xilol (2 vezes de 3 minutos cada) e então, reidratados em concentrações crescentes de álcool etílico, colocados por 20 segundos na solução de tionina a 0,25\%, mergulhados 10 vezes em água destilada e novamente desidratados e deslipidificados, sendo finalmente cobertos com lamínulas e DPX como meio de montagem (Sigma-Aldrich; São Paulo, Brasil).

\subsection{Hibridização in situ para estudo de dupla marcação}

Para realização da hibridização in situ, os casos com implante de traçador retrógrado considerados bons foram processados pelo método de imunoistoquímica para detecção do traçador, com o cuidado de não haver contaminação com RNAse, e foram montados em lâminas estéreis com aderência eletrostática (Microscopic Plus, Fisher) e deixados secar a temperatura ambiente para, em seguida, passarem pelo procedimento de hibridização.

\subsubsection{Pré-tratamento}

O pré-tratamento foi inteiramente feito com soluções livres de RNAses. Os cortes foram colocados em uma solução de formaldeído 4\% em 1×PBS-DEPC durante 5 minutos e, em seguida, foram lavados 2 vezes em $1 \times$ PBS e incubados em solução de Proteinase K (0,5 $\mu \mathrm{g} / \mathrm{mL}$ ) em solução contendo 0,5M EDTA (ácido etilenodiaminotetracético, 2mM pH 8,0) $1 \mathrm{M}$ Tris- $\mathrm{HCl} \mathrm{pH}$ 8,0, DEPC $\mathrm{H}_{2} \mathrm{O}$, por 30 minutos a temperatura ambiente, para quebrar ligações peptídicas e aumentar a penetração da sonda. Os cortes foram, em seguida, lavados em DEPC $\mathrm{H}_{2} \mathrm{O}$, em solução de trietanolamina hidrocloreto $\mathrm{pH}$ 8,0, 0,1M (TEA-HCl) e acetilados em TEA-HCl/anidrido acético $0,1 \mathrm{M}$ durante o período de 10 minutos à temperatura ambiente, para neutralizar a possível ocorrência de íons livres e melhorar a penetração da sonda. Os cortes foram, em seguida, lavados em $2 \times$ tampão citrato de sódio $0,3 \mathrm{M}$ - Cloreto de 
Sódio 3M (SSC), sendo, posteriormente, iniciada a desidratação e deslipidificação dos mesmos em álcoois etílicos de concentração crescente e xilol (por 15 minutos). Por fim, as lâminas secaram a temperatura ambiente por aproximadamente 30 minutos e foram acondicionadas em caixas juntamente com cápsulas de sílica para absorver a umidade. A armazenagem foi feita em freezer a $-30{ }^{\circ} \mathrm{C}$ até o início da hibridização.

\subsubsection{Hibridização in situ com Radioisótopo ${ }^{35} \mathrm{~S}$}

Para a técnica de hibridização in situ simples com ${ }^{35} \mathrm{~S}$ utilizamos a sonda do ácido glutâmico descarboxilase (GAD-67) para identificar os neurônios gabaérgicos no CeA. Os plasmídeos foram linearizados através da enzima de restrição (direção anti-senso) conforme orientação do laboratório de origem, e isolados com fenol-clorofórmio-isoamilálcool. As sondas foram marcadas com ${ }^{35} \mathrm{~S}$ através de transcrição in vitro usando a enzima polimerase T3, a $37{ }^{\circ} \mathrm{C}$ por 1 hora. Depois disto, o cDNA foi digerido pela adição de $1 \mu \mathrm{L}$ de RQ1 DNAse a $37{ }^{\circ} \mathrm{C}$ por dez minutos, na presença de $1 \mu \mathrm{L}$ de RNAsin. Em seguida, os NTPs não incorporados foram removidos utilizando microcolunas de resina (Probe Quant G-50). Realizado esse procedimento, foi feita a contagem de incorporação do ${ }^{35} \mathrm{~S}$ em aparelho de cintilação para a verificação da quantidade de incorporação de radioativo na sonda. As sondas foram utilizadas à concentração de $10^{6} \mathrm{cpm} / \mathrm{mL}$. Cada sonda foi, então, acrescentada a um tampão de hibridização previamente preparado, contendo 50\% de formamida, $20 \mathrm{mM}$ TrisHCl pH 7,5, EDTA 2 mM, ditiotreitol (DTT) 10mM, 0,02\% RNAt de levedura, 0,1\% de RNA total de levedura, 20\% de sulfato de dextrana e 1x solução de Denhardt que sofreu um choque térmico (5 minutos a $90{ }^{\circ} \mathrm{C}$ e 5 minutos no gelo). Em seguida foram acrescentadas ao tampão $750 \mu \mathrm{L}$ de formamida 50\%, $15 \mu \mathrm{L}$ de Lauril Sulfato 10\% (SDS), $15 \mu \mathrm{L}$ de tiossulfato de sódio $10 \%$ e $30 \mu \mathrm{L}$ de $5 \mathrm{M}$ DTT. A solução de hibridização contendo a sonda foi aplicada à superfície das lâminas contendo os cortes histológicos previamente pré-tratados. As lâminas foram cobertas com lamínulas flexíveis (Sigma-Aldrich; São Paulo, Brasil) e levadas à estufa de hibridização por aproximadamente 18 horas a $56{ }^{\circ} \mathrm{C}$. No dia seguinte, as lamínulas foram retiradas, o tampão de hibridização foi lavado e o excesso de sonda será retirado através de banhos em RNAase a 0,2\% e de estringência (aumento de temperatura e diminuição na concentração de SSC) para retirar as possíveis hibridações inexpecíficas.

Após os banhos, as lâminas foram desidratadas em concentrações crescentes de álcool etílico e deixadas secar a temperatura ambiente. Em seguida foram transferidas para cassetes e, em sala escura, colocadas em contato com filme (Kodak auto-radiográfico - Biomax MR). 
Três dias depois o filme foi revelado com revelador Kodak (2 minutos) passando por água (banhos rápidos), fixador Kodak (2 minutos) e, finalmente, em água corrente. Verificada a incorporação da sonda pelo tecido, as lâminas foram mergulhadas em emulsão autoradiográfica. A emulsão autoradiográfica (Kodak) foi, em sala escura, derretida a $40^{\circ} \mathrm{C}$, e diluída em 50\% com água destilada, com cuidado para não formar bolhas. Então as lâminas foram mergulhadas na emulsão e colocadas na estufa por 3 horas antes de serem bem lacradas em caixas de lâminas juntamente com cápsulas de sílica para absorver a umidade e foram armazenadas em câmara fria a $4{ }^{\circ} \mathrm{C}$. Depois de 15 dias as lâminas foram reveladas com revelador Kodak (2 minutos), água (5 mergulhos), fixador Kodak (2 minutos) e água corrente (15 minutos). As lâminas foram desidratadas em soluções crescentes de álcool etílico e submetidas à coloração de Nissl como descrito anteriormente, deslipidificadas em xilol e cobertas com DPX e lamínula.

\subsection{Análise dos resultados e produção das ilustrações}

As lâminas foram analisadas em um microscópio Leica DMR e as imagens captadas através de uma câmera digital SPOT $\mathrm{RT}^{\circledR}$ associada ao programa Image ProPlus ${ }^{\circledR}$ em um computador Dell ou captadas em um microscópio confocal usando o programa LSM.510. As imagens adquiridas, foram ajustadas em relação a brilho, contraste e nitidez no programa Photoshop 7.0 (Adobe). Os desenhos foram realizados em uma câmera lúcida adaptada em um microscópio Leica. Posteriormente, foram digitalizados através de um scanner e transformados em pranchas através do programa Canvas 6.0 (Deneba). Este mesmo programa foi utilizado para a montagem das pranchas com as imagens. As pranchas com imagens foram impressas em uma impressora térmica (8670PS - Kodak) em papel fotográfico e os desenhos em uma impressora Epson em papel glossy. 


\section{RESULTADOS}

\subsection{Estudo das aferências do núcleo motor do trigêmeo (Mo5)}

De um total de 11 injeções com o traçador retrógrado subunidade b da toxina colérica (CTb), quatro foram consideradas boas. A partir destas, as aferências do núcleo motor do trigêmeo (Mo5) foram estudadas. Foram considerados bons os casos nos quais o centro da injeção estava no interior do Mo5 e o halo da injeção observado, principalmente após a imunoistoquímica para o CTb, não ultrapassava os limites do Mo5 ou o fazia em pequena extensão (Figura 3). Nestes casos, o núcleo mesencefálico do trigêmeo (Me5) apresentava-se bastante marcado em toda a sua extensão e, além disso, em todos os casos bons, houve reação motora do animal (contração do masseter ipsilateral) durante a passagem da corrente elétrica no ato cirúrgico. Os casos utilizados foram os Mo5D-1, Mo5D-7, Mo5D-9 e Mo5D-10 (Figura 3). Consideramos o caso Mo5D-9 como o melhor caso para ser descrito, pois obtivemos uma injeção no centro do Mo5, cujo halo apresentava uma pequena contaminação da região da formação reticular dorso-medial, e cujo transporte foi considerado bom (Figura 4). Em todos os casos bons foram verificadas marcações nas mesmas regiões, variando apenas, em pequeno grau, a quantidade de células marcadas retrogradamente.

\subsubsection{Estudo das injeções consideradas boas}

No caso Mo5D-1 (Figura 3A), a injeção foi centralizada no interior do Mo5, porém houve pequena contaminação do núcleo parabraquial lateral, da formação reticular ventromedial e também da região posterior ao Mo5. Além disso, observou-se um pequeno rastro do traçador no cerebelo.

No caso Mo5D-7 (Figura 3B) o centro da injeção também ocorreu no Mo5, porém houve um halo maior que contaminou parcialmente o Su5 e o núcleo parabraquial medial, além da formação reticular anterior ao Mo5.

O caso Mo5D-9 (Figura 3C), conforme já relatado, foi considerado referência. 

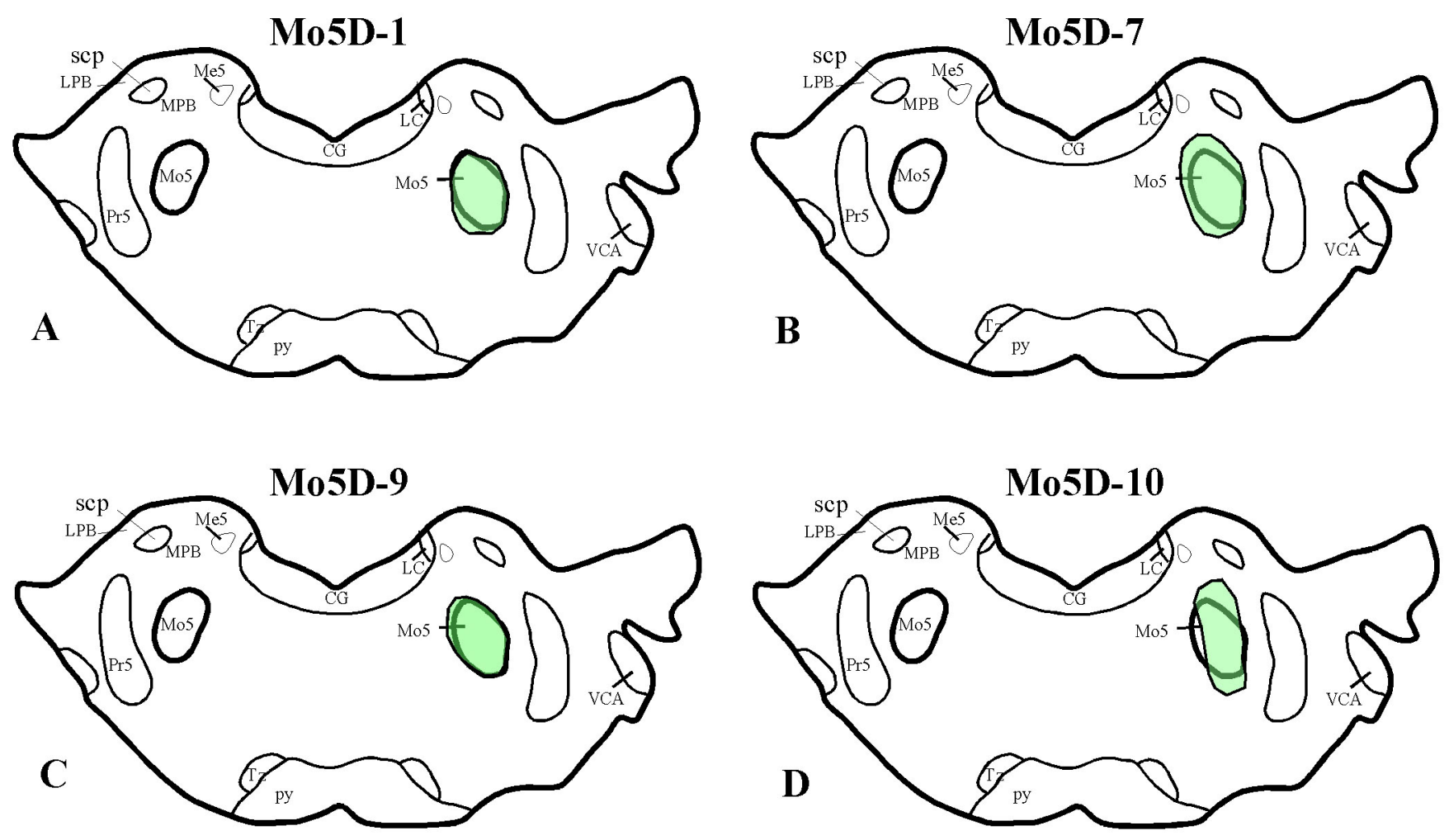

Figura 3. Esquema dos locais de injeções consideradas boas no núcleo motor do trigêmeo (Mo5). Em A, Mo5D-1; em B, Mo5D-7; em C, Mo5D-9; em D, Mo5D-10.

Abreviações: $\mathrm{CG}$, substância cinzenta central; LC, locus coeruleus; LPB, núcleo parabraquial lateral; Me5, núcleo mesencefálico do trigêmeo; MPB, núcleo parabraquial medial; Pr5, núcleo principal do trigêmeo; py, trato piramidal; scp, pedúnculo cerebelar superior; Tz, núcleo do corpo trapezóide; VCA, núcleo coclear ventral anterior. 

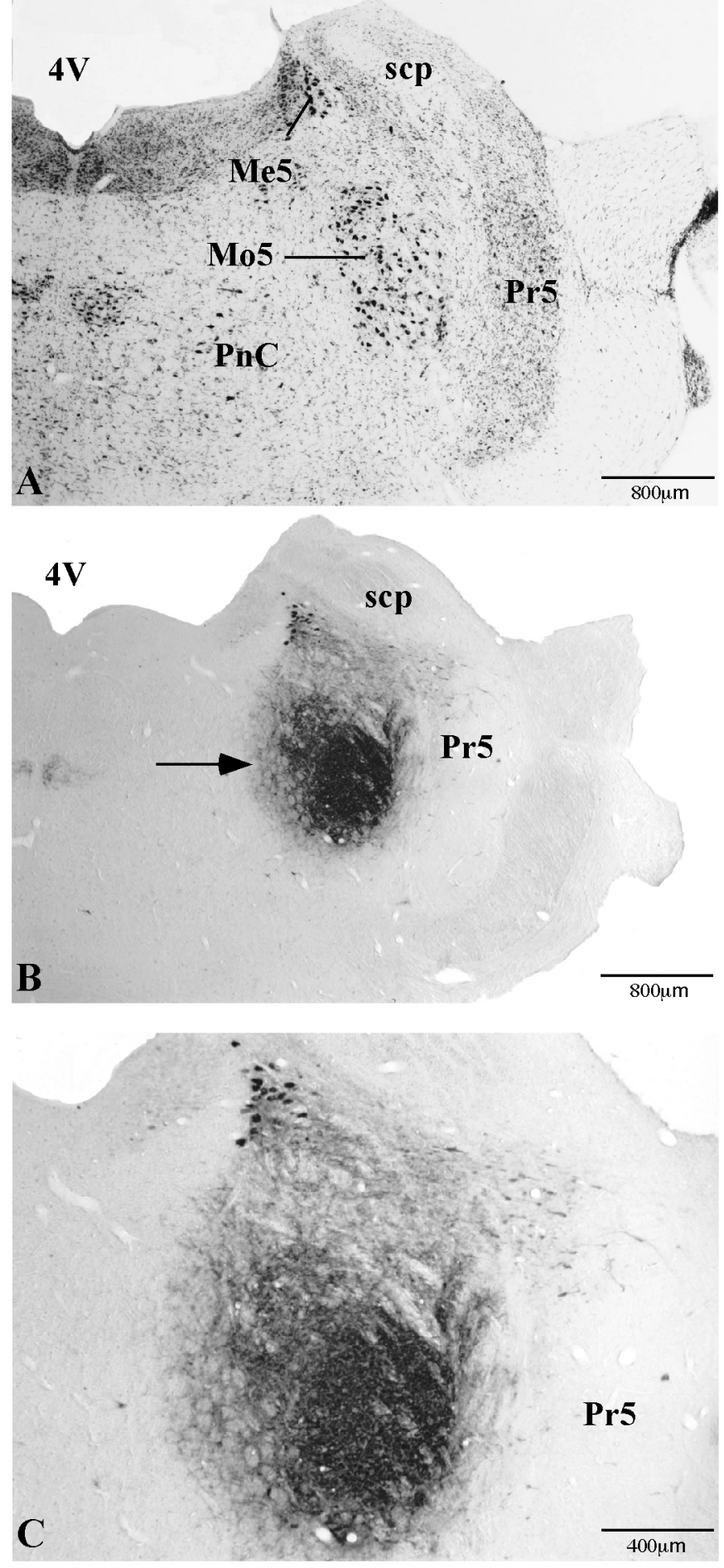

Figura 4. Local de injeção do traçador retrógrado subunidade $b$ da toxina colérica (CTb). Em A, secção coronal do encéfalo de rato mostrando a citoarquitetura da região do núcleo motor do trigêmeo (Mo5). Em B, injeção de CTb no Mo5 (seta), caso Mo5D-9 considerado referência. Em C, aumento de B.

Abreviações: $4 \mathrm{~V}$, quarto ventrículo; $\mathrm{h}$, região $\mathrm{h} ; \mathrm{Me} 5$, núcleo mesencefálico do trigêmeo; PnC; núcleo pontino caudal; Pr5, núcleo principal do trigêmeo; scp, pedúnculo cerebelar superior. 
Em relação ao Mo5D-10 (Figura 3D), a injeção também foi centralizada no Mo5, ocorrendo um halo de contaminação semelhante ao caso Mo5D-7, porém sem contaminação da formação reticular anterior ao Mo5.

\subsubsection{Aferências do Mo5}

Todos os casos considerados bons apresentaram o mesmo padrão de corpos celulares retrogradamente marcados.

As marcações obtidas no tronco encefálico são semelhantes as já descritas por vários autores (Travers e Norgren, 1983; Grzanna et al., 1987; Fort et al., 1990; Turman e Chandler, 1994; Li et al., 1995; Li et al., 1996; Yasui et al., 1997; Kolta et al., 2000; Luo et al., 2001; Mascaro, 2002). Na região prosencefálica foram observadas marcações já relatadas por nós (Mascaro 2002; Mascaro et al., 2005) quando utilizamos o traçador fluorogold (FG). Desta forma, iniciaremos a descrição dos resultados pela região de tronco encefálico, cujas marcações são mais descritas e aceitas pela literatura e posteriormente, nos reportaremos ao prosencéfalo (Tabela 1).

\subsubsection{Tronco encefálico}

Foi observada pequena quantidade de células, com predominância ipsilateral, na substância cinzenta periaquedutal (PAG), as quais se localizavam na porção mais rostral da PAG, antes da formação do aqueduto mesencefálico, na região da comissura posterior. Quantidade semelhante de células foi notada por toda a extensão do núcleo de EdingerWestphal (EW) e complexo do oculomotor da sua porção inicial até o nível final do EW. Quantidade moderada foi verificada no núcleo mesencefálico profundo (DpMe) e no núcleo rubro porção parvicelular (RPC) contralaterais. O mesmo padrão foi verificado no Mo5 contralateral, porções mais caudais, bilaterais do subnúcleo oral espinal e interpolar do trigêmeo (Sp5O) e (Sp5I), além dos núcleos gigantocelular (Gi) e gigantolcelular parte alfa (GiA). Também, uma quantidade moderada de células foi verificada ipsilateralmente no núcleo do trato solitário (NTS).

Células marcadas em grande quantidade foram observadas no complexo trigeminal; isto ocorreu ipsi e contralateralmente no núcleo supratrigeminal (Su5) e no Sp5O. No Sp5O, as marcações foram predominantes nas porções mais dorsais e rostrais do núcleo, 
bilateralmente, e estas marcações foram se tornando escassas à medida que se avançava para posterior.

Quantidade máxima de células, fortemente marcadas, foi notada, ipsilateralmente e por toda extensão do Me5. Grande quantidade de marcação também foi verificada, bilateralmente, na zona peritrigemial (P5), localizada caudalmente ao Mo5, como também na formação reticular parvicelular parte alfa (PCRtA), onde a marcação foi pronunciada principalmente nas suas porções mais dorsais e rostrais diminuindo na região do Sp5I e tornando-se contínua até o final da PCRtA. Distribuição semelhante foi verificada no núcleo reticular intermediário (IRt), até o seu final, no nível do subnúcleo caudal espinal do trigêmeo (Sp5C).

\subsubsection{Prosencéfalo}

Em relação ao prosencéfalo, obtivemos pequena quantidade de células retrogradamente marcadas, de forma difusa, bilateral e nas porções mais rostrais do córtex motor secundário (M2) e córtex motor primário (M1), além do córtex da ínsula (I), sendo que no último houve uma predominância das marcações ipsilaterais e estas ocorreram por toda a sua extensão rostro-caudal. Observando os cortes em direção caudal, foi verificada também uma marcação pequena de corpos celulares e fibras no núcleo intersticial do ramo posterior da comissura anterior (IPAC); esta marcação foi apenas ipsilateral e ocorreu das porções mais rostrais do núcleo, no nível do início da formação hipocampal, até as porções mais caudais onde se inicia o núcleo central da amígdala (CeA).

Uma quantidade maior de células marcadas foi verificada ipsilateralmente, por toda a extensão rostro-caudal do CeA, principalmente em sua região mais medial (Figura 6) e em alguns casos também nas porções mais caudais do núcleo paraventricular do hipotálamo (PVH), em cortes no nível do CeA. Uma quantidade moderada de células marcadas, também foi verificada no núcleo parasubtalâmico (PSTh) (Figura 8), ipsilateralmente por toda a sua extensão rostro-caudal.

Marcação semelhante foi notada no núcleo intersticial da estria terminal (BST), porém, apenas em suas porções mais rostrais. Além disso, uma pequena quantidade de células e fibras marcadas foi observada na área hipotalâmica lateral ( $\mathrm{LH}$ ) ipsilateral, principalmente na região perifornicial dorsal (Figura 7). 
Tabela 1. Resumo e quantificação de aferências do núcleo motor do trigêmeo.

\begin{tabular}{|c|c|c|}
\hline Regiões & Ipsilateral & Contralateral \\
\hline Córtex motor secundário (M2) & + & + \\
\hline Córtex motor primário (M1) & + & + \\
\hline Córtex da ínsula (I) & + & + \\
\hline BST & + & - \\
\hline IPAC & + & - \\
\hline N. central da amígdala (CeA) & ++ & - \\
\hline N. paraventricular do hipotálamo (PVH) & ++ & - \\
\hline Área hipotalâmica lateral (LH) & + & - \\
\hline N. parasubtalâmico (PSTh) & ++ & - \\
\hline Substância cinzenta periaquedutal (PAG) & + & + \\
\hline N. rubro porção parvicelular (RPC) & - & ++ \\
\hline N. Edinger-Westphal (EW) & + & + \\
\hline Complexo do oculomotor & + & + \\
\hline N. mesencefálico profundo (DpMe) & + & ++ \\
\hline N. parabraquial (PB) & ++ & - \\
\hline N. mesencefálico do trigêmeo (Me5) & ++++ & + \\
\hline N. motor do trigêmeo (Mo5) & - & ++ \\
\hline N. principal do trigêmeo (Pr5) & +++ & ++ \\
\hline N. supratrigeminal (Su5) & +++ & +++ \\
\hline Região justatrigeminal & - & + \\
\hline Região intertrigeminal & - & + \\
\hline Região peritrigeminal & +++ & +++ \\
\hline F.reticular parvicelular parte alfa (PCRtA) & ++++ & +++ \\
\hline N. reticular intermediário (IRt) & +++ & +++ \\
\hline N. gigantocelular $(\mathrm{Gi})$ & ++ & ++ \\
\hline N. gigantocelular parte alfa (GiA) & ++ & - \\
\hline Subn.oral espinal do trigêmeo (Sp5O) & +++ & ++ \\
\hline N.pálido da rafe (Rpa) & ++ & ++ \\
\hline N.obscuro da rafe (Rob) & ++ & ++ \\
\hline Subn. interpolar espinal do trigêmeo (Sp5I) & ++ & + \\
\hline N. do trato solitário (NTS) & ++ & - \\
\hline
\end{tabular}



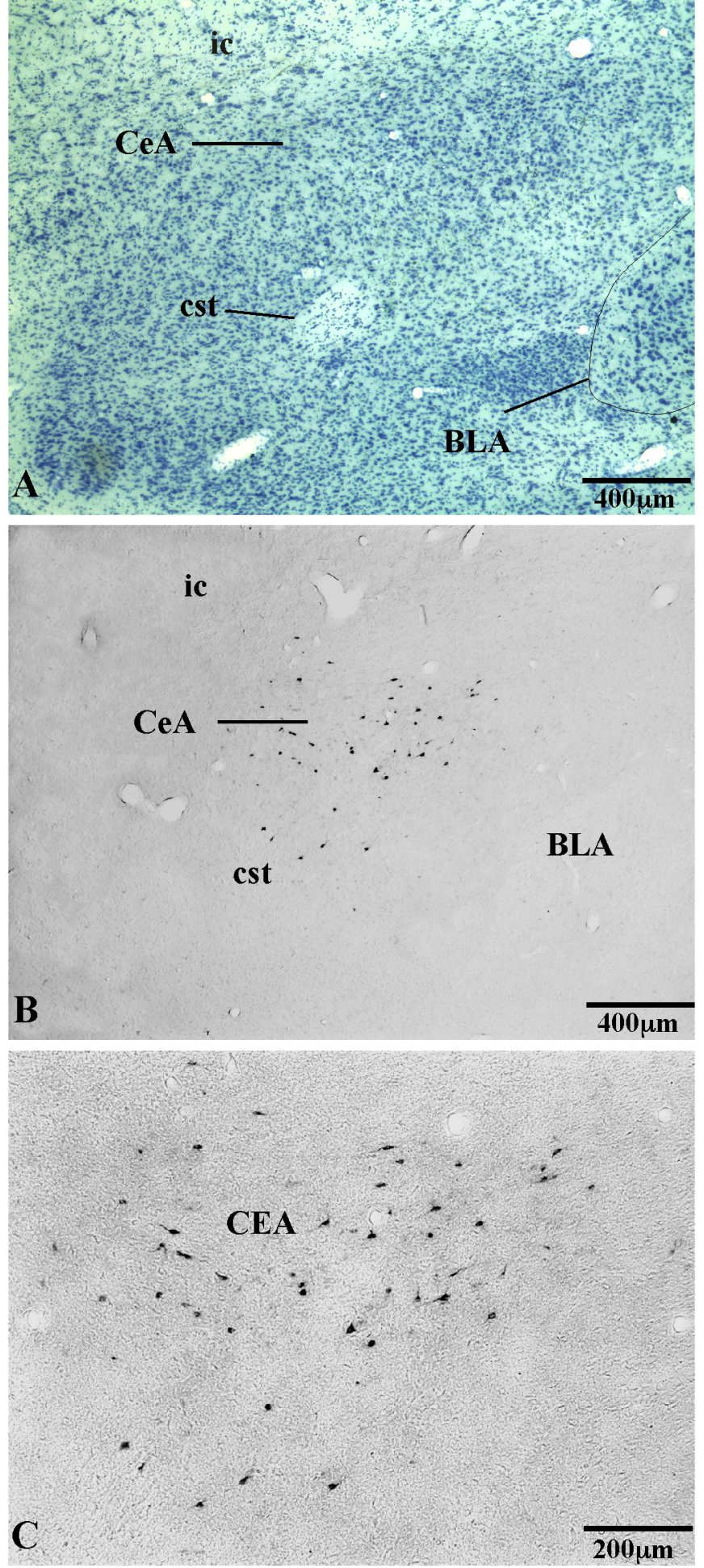

Figura 6. Neurônios do núcleo central da amígdala (CeA) se projetam para o núcleo motor do trigêmeo (Mo5). Em A, coloração de Nissl, mostrando a citoarquitetura da região. Em $\mathbf{B}$, células retrogradamente marcadas no $\mathrm{CeA}$. Em $\mathrm{C}$, maior aumento de $\mathrm{B}$.

Abreviações: BLA, núcleo basolateral da amígdala; ic, cápsula interna; cst, estria terminal comissural. 

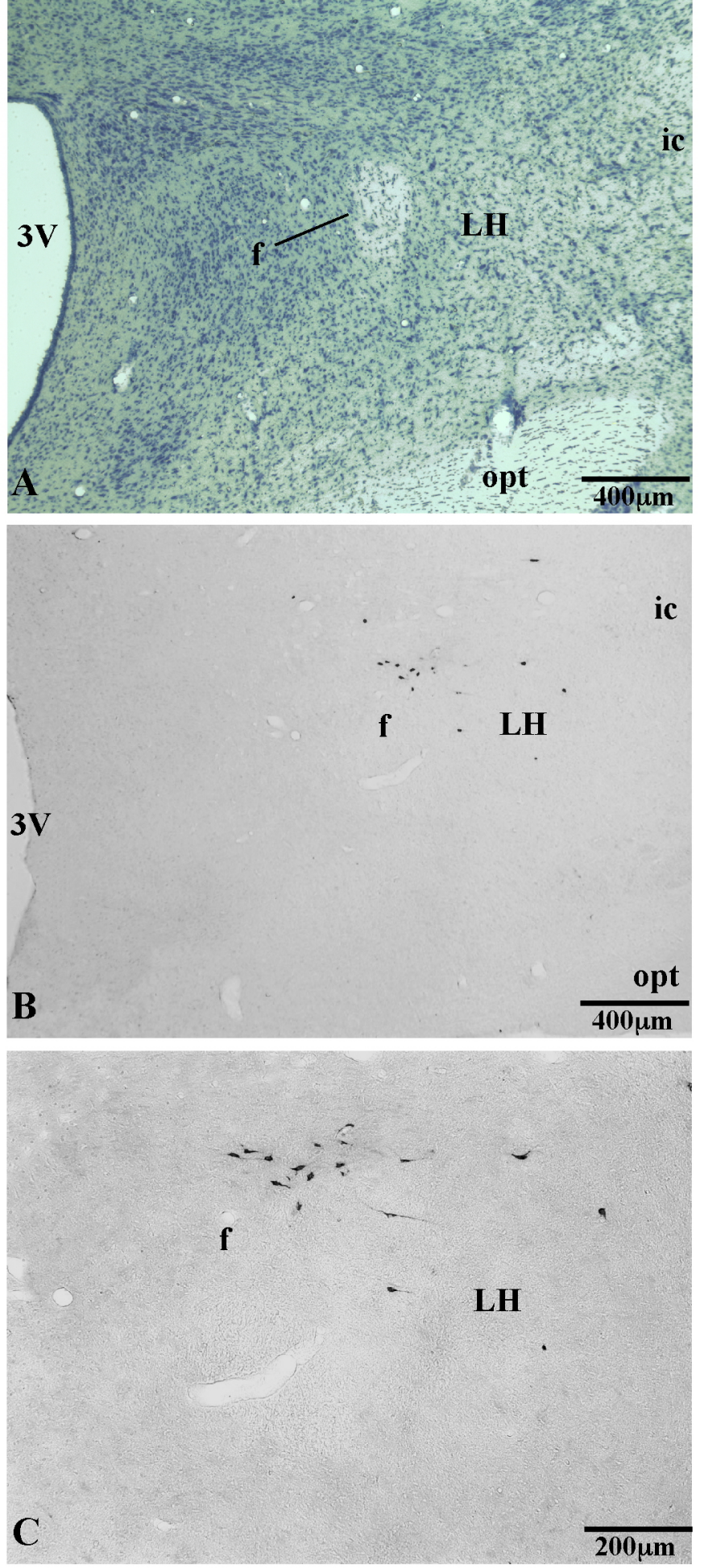

Figura 7. Neurônios da área hipotalâmica lateral (LH) se projetam para o núcleo motor do trigêmeo (Mo5). Em A, coloração de Nissl, mostrando a citoarquitetura da região. Em $\mathbf{B}$, células retrogradamente marcadas na região perifornicial da LH. Em C, maior aumento de B.

Abreviações: $3 \mathrm{~V}$, terceiro ventrículo; f, fórnice; ic, cápsula interna; opt, trato óptico. 


\subsection{Controle anterógrado}

O controle anterógrado foi realizado para se confirmar a marcação retrógrada de alguns núcleos. Foram usados para o controle 21 animais. Em todos foi usada injeção do traçador anterógrado dextrana amina biotinilada (BDA), pelo método da iontoforese, com corrente de $5 \mu \mathrm{A}$ alternada positiva por 7 minutos. Foram obtidas 13 injeções consideradas boas, nas quais o núcleo desejado foi atingido e houve um bom transporte do traçador.

Seguindo estes parâmetros obtivemos três casos bons para o núcleo central da amígdala, o CeA-1, e os CeA-3 e CeA-4, três caso bons para a área hipotalâmica lateral os LH-1, LH-3 e o LH-4 e sete casos bons para o núcleo parasubtalâmico os PSTh-1, PSTh-2, PSTh-3, PSTh-4, PSTh-5, PSTh- 8 e PSTh-9.

No caso CeA-1 (Figura 9A e B), a injeção pode ser observada lateralmente ao trato óptico (opt), contaminando tanto o CeA, quanto o núcleo medial ântero-dorsal da amígdala e a divisão intra-amigdalóide do BST. No caso CeA-3 (Figura 9C e D), a injeção pode ser observada no interior do CeA, lateralmente ao opt, e a cápsula interna e medialmente à cápsula externa, ocorrendo a formação de um halo que contaminou o núcleo intersticial posterior da comissura anterior (IPAC) dorsalmente e a área de transição amígdalo-estriatal súpero-lateralmente. No caso CeA-4 a injeção também se localizou no interior do CeA ocorrendo uma pequena contaminação tanto do IPAC quanto da divisão intramigdalóide do BST.

Nos casos LH-1, LH-3 e LH-4, a injeção atingiu a área hipotalâmica lateral dorsalmente ao fórnice (Figura 11). No caso LH-4 a injeção foi mais próxima ao fórnice (Figura 11E e F). Em todos os casos foram observadas fibras reativas ao BDA ao redor do Mo5 ipsilateral, principalmente na região h medial ao núcleo e em menor quantidade no seu interior (Figura 12C e D).

Nos casos PSTh-1, PSTh-2, PSTh-3, PSTh-4, PSTh-5, PSTh- 8 e PSTh-9 as injeções tiveram seus centros muito próximos à região final da cápsula interna, lateralmente a LH (Figura 13) . Foram observadas fibras reativas ao BDA em todos os casos ao redor do Mo5 ipsilateral na região h e em menor quantidade no seu interior (Figura 14C e D).

Em todos os casos de controle anterógrado do CeA, LH e PSTh, observamos fibras reativas ao BDA no núcleo mesencefálico do trigêmeo (Me5), sendo que esta quantidade foi grande para o CeA e moderada para a LH e para o PSTh (Figura 19) 

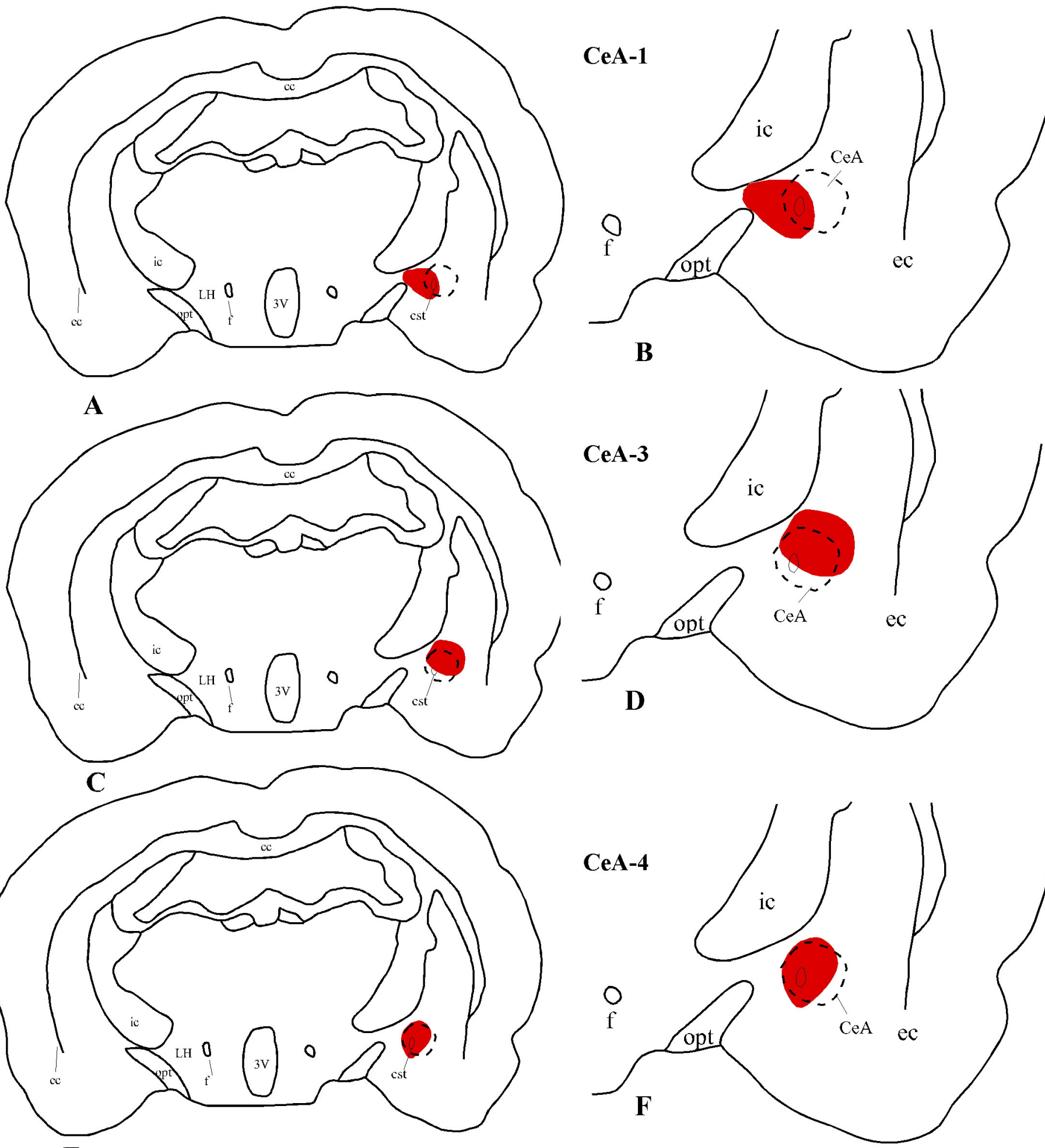

$\mathbf{E}$

Figura 9. Desenho esquemático do local de injeção dos casos considerados bons com o traçador anterógrado dextrana amina biotinilada (BDA) no núcleo central da amígdala (CeA). Em vermelho o local de injeção, em linha tracejada o CeA. Em A, caso CeA-1; em B, aumento do local de injeção de A; em C, caso CeA-3; em D, aumento do local de injeção de C; em $\mathbf{E}$, caso CeA-4; em $\mathbf{F}$, aumento do local de injeção de $\mathrm{E}$.

Abreviações: $3 \mathrm{~V}$, terceiro ventrículo; cc, corpo caloso; ec, cápsula externa; f, fórnice; ic, cápsula interna; opt, trato óptico. 


\section{CeA}

$\mathbf{A}$

cst
BLA

$200 \mu \mathrm{m}$

B
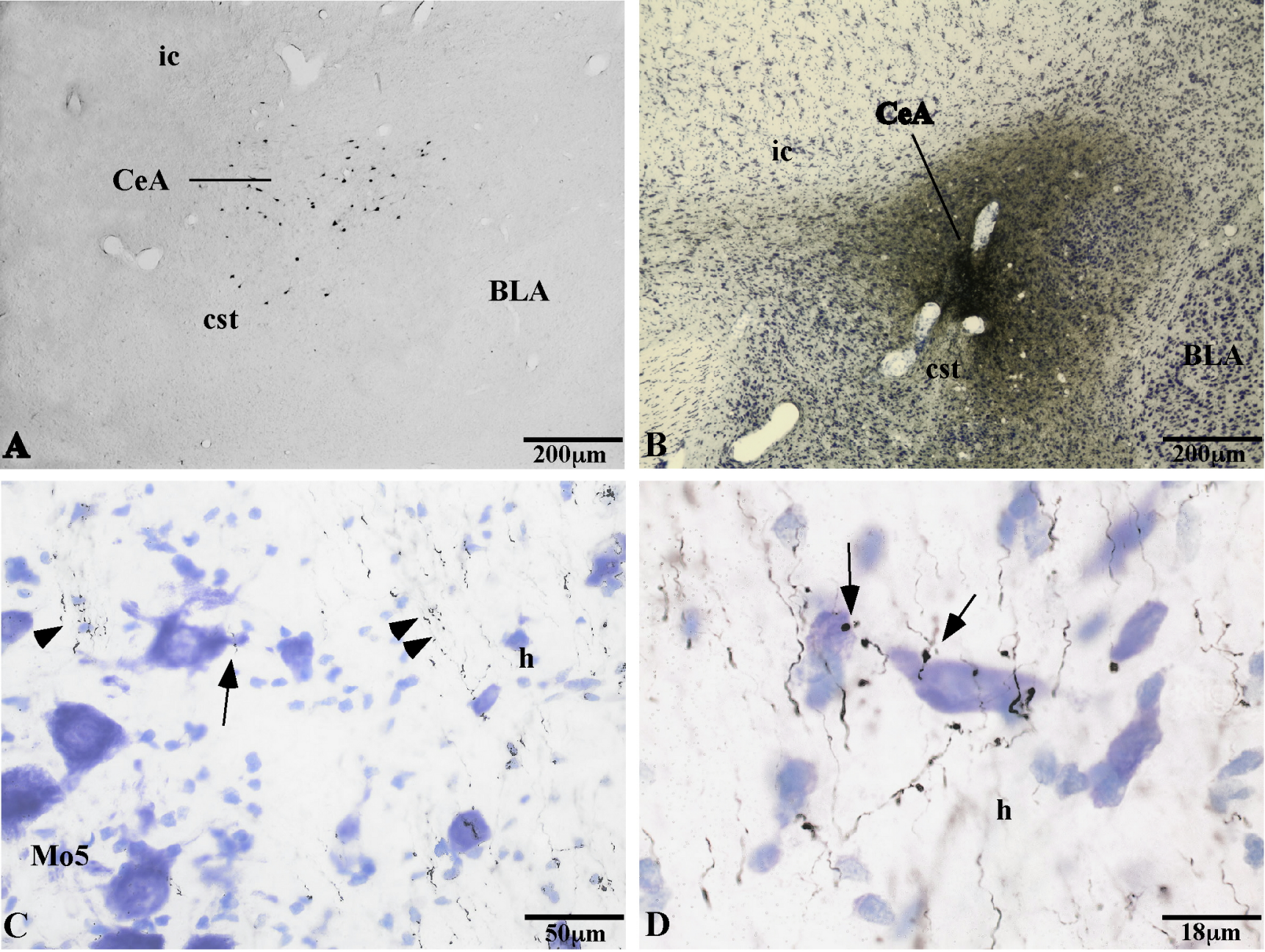
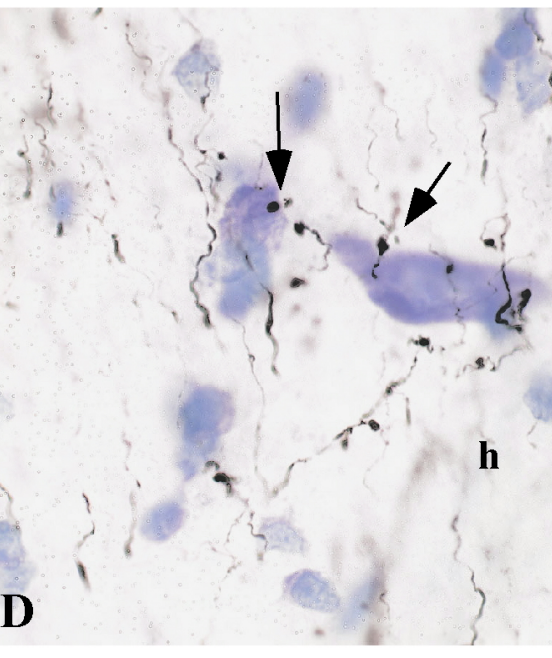

$18 \mu \mathrm{m}$

Figura 10. Controle anterógrado através de implante do traçador dextrana amina biotinilada (BDA) no núcleo central da amígdala $(\mathrm{CeA})$. Em $\mathbf{A}$, células retrogradamente marcadas no $\mathrm{CeA}$ após injeção da subunidade $b$ da toxina colérica ( $\mathrm{CTb}$ ) no núcleo motor do trigêmeo (Mo5) (como referência). Em $\mathbf{B}$, coloração de Nissl e imunoistoquímica para visualização da injeção de BDA com centro no CeA. Em C, fibras passando no interior do núcleo motor do trigêmeo (cabeça de seta), com a presença de aparente botão sinápticos (seta), além de fibras na região $\mathrm{h}$ (h), medial ao núcleo (duas cabeças de seta). Em D, aparentes contatos sinápticos com células da região h, mediais ao Mo5 (setas).

Abreviações: BLA, núcleo basolateral da amígdala; cst, estria terminal comissural; ic, cápsula interna. 


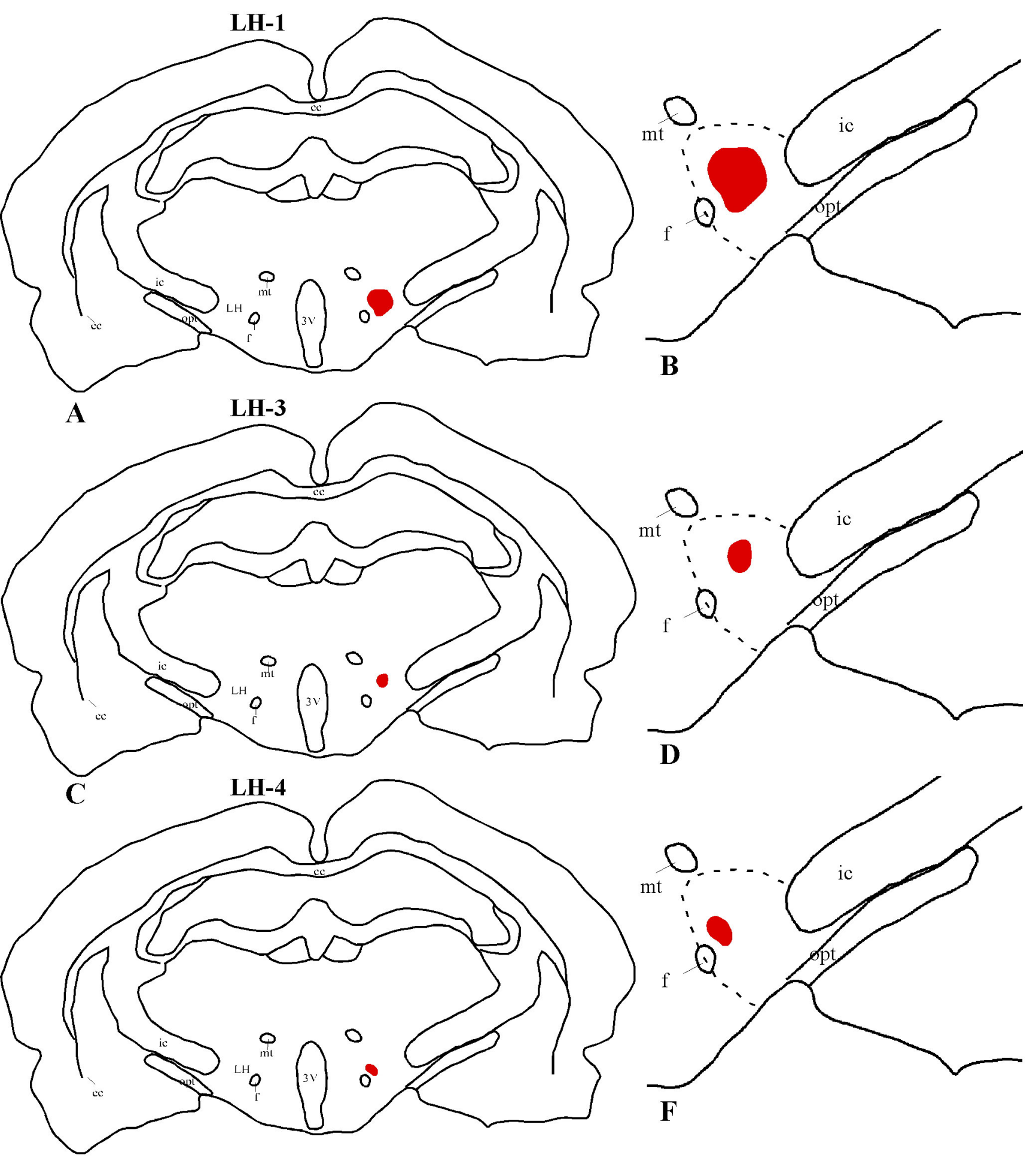

$\mathbf{E}$

Figura 11. Desenho esquemático do local de injeção de casos considerados bons com o traçador anterógrado dextrana amina biotinilada (BDA) na área hipotalâmica lateral (LH). Em vermelho o local de injeção, em linha tracejada a LH. Em A, caso LH-1; em $\mathbf{B}$, aumento da região de injeção de A; em $\mathbf{C}$, caso LH-3; em D, aumento da região de injeção de C. Em $\mathbf{E}$, caso LH-4; em $\mathbf{F}$, aumento da região de injeção de $\mathrm{E}$.

Abreviações: $3 \mathrm{~V}$, terceiro ventrículo; cc, corpo caloso; ec, cápsula externa; f, fórnice; ic, cápsula interna; mt, trato mamilotalâmico; opt, trato óptico. 


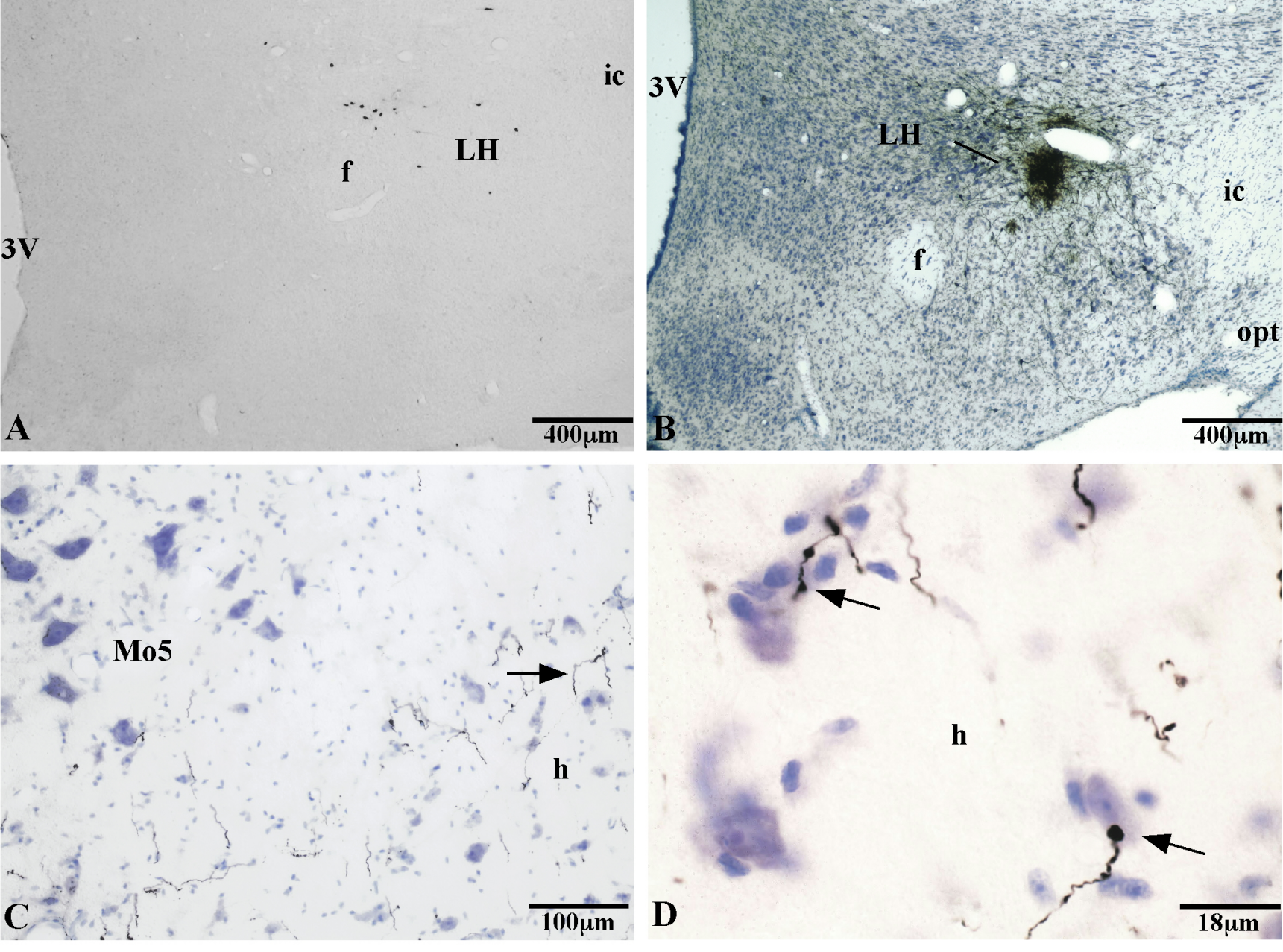

Figura 12. Controle anterógrado através de implante do traçador dextrana amina biotinilada (BDA) na área hipotalâmica lateral $(\mathrm{LH})$. Em A, células retrogradamente marcadas na $\mathrm{LH}$, principalmente perifornicial após injeção da subunidade b da toxina colérica $(\mathrm{CTb})$ no núcleo motor do trigêmeo (Mo5) (como referência). Em B, coloração de Nissl e imunoistoquímica para visualização da injeção de BDA. Em C, fibras passando principalmente na região h (h), medialmente ao Mo5 (seta). Em D, fibras na região $h$ medial ao Mo5 e aparentes contatos sinápticos (setas). Abreviações: $3 \mathrm{~V}$, terceiro ventrículo; f, fórnice; ic, cápsula interna. 


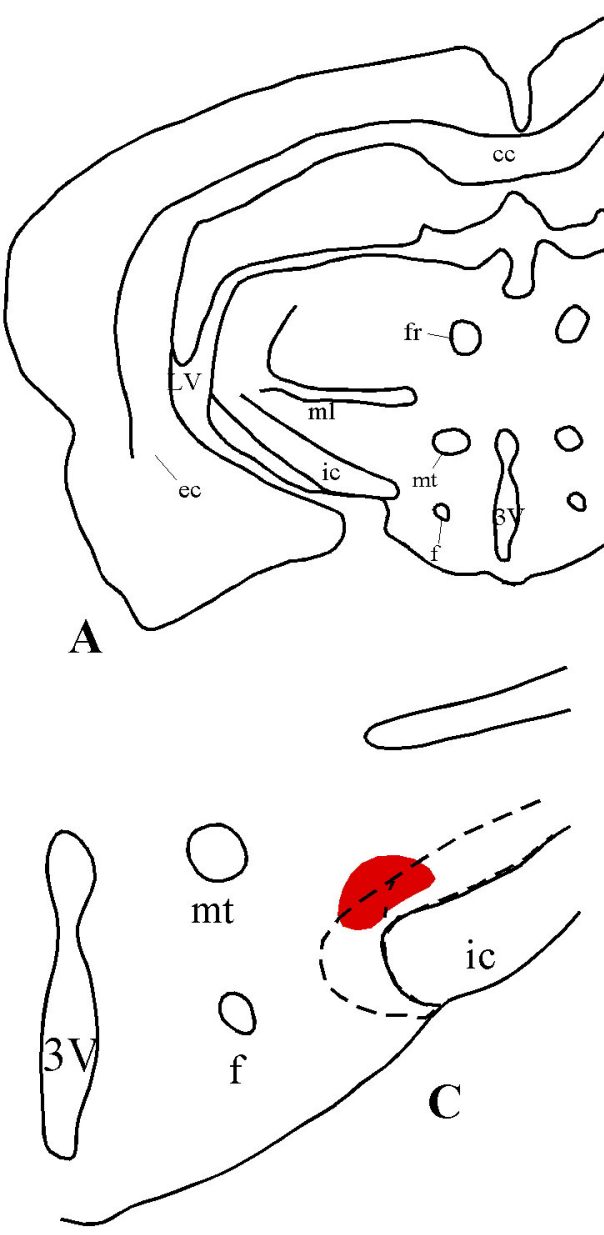

PSTh-2
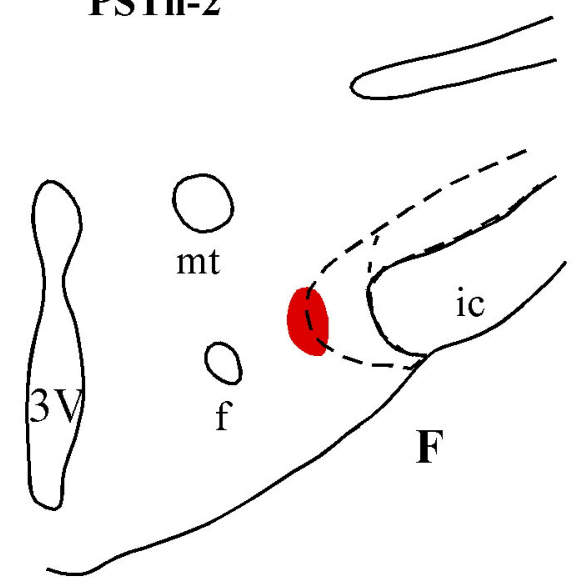

PSTh-5

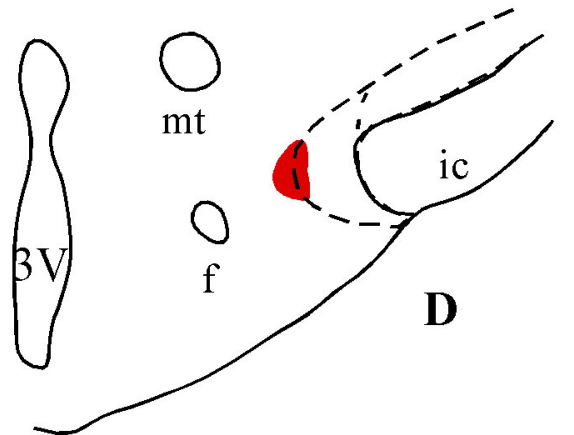

PSTh-3

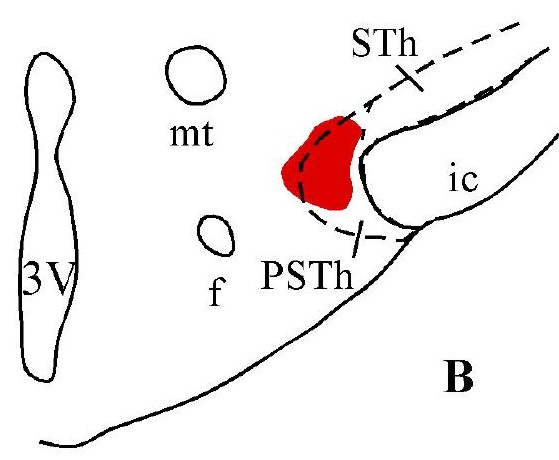

PSTh-1

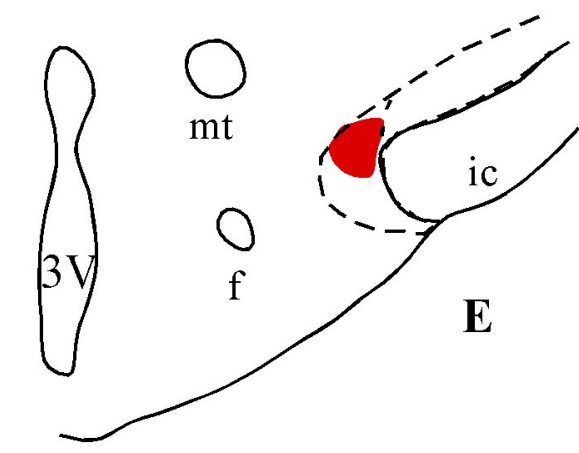

PSTh-4

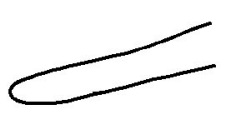

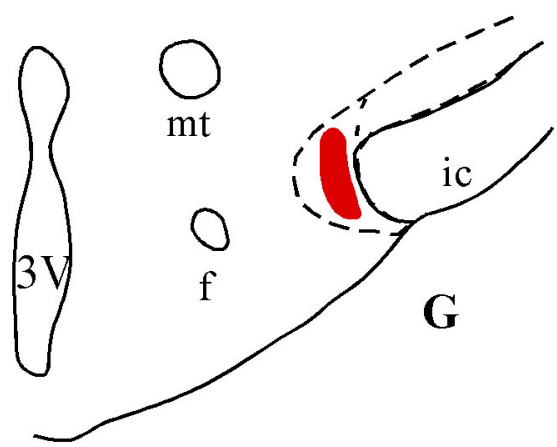

PSTh-8

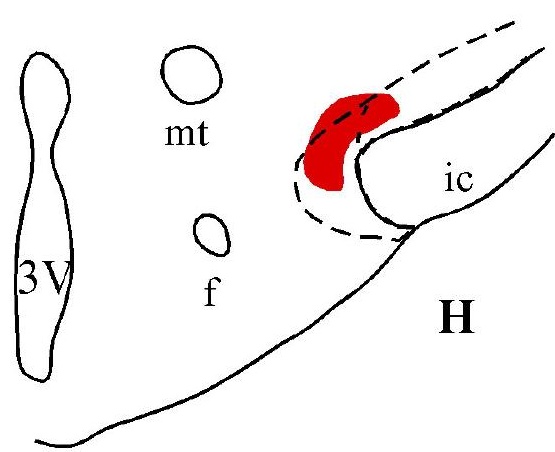

PSTh-9

Figura 13. Desenho esquemático do local de injeção dos casos considerados bons com o traçador anterógrado dextrana amina biotinilada (BDA) no núcleos parasubtalâmico (PSTh). Em vermelho os locais de injeção, em linha tracejada o PSTh e o núcleo subtalâmico (STh). Em A, caso PSTh-1 (como referência); em $\mathbf{B}$, aumento da região de injeção de A; em $\mathbf{C}$, caso PSTh-2; em D, caso PSTh-3; em $\mathbf{E}$, caso PSTh-4; em F, caso PSTh-5; em G, caso PSTh-8 e em H, caso PSTh-9.

Abreviações: $3 \mathrm{~V}$, terceiro ventrículo; cc, corpo caloso; ec, cápsula externa; fr, fascículo retroflexo; f, fórnice; ic, cápsula interna; LV, ventrículo lateral; ml, lemnisco medial; mt, trato mamilotalâmico. 


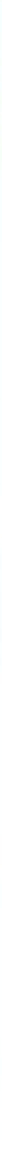

Figura 14. Controle anterógrado através de implante do traçador dextrana amina biotinilada (BDA) no núcleo parasubtalâmico (PSTh). Em A , células retrogradamente marcadas no PSTh após injeção da subunidade b da toxina colérica $(\mathrm{CTb})$ no núcleo motor do trigêmeo (Mo5) (como referência). Em $\mathbf{B}$, coloração de Nissl e imunoistoquímica para visualização da injeção de BDA (seta). Em C, fibras passando na região h (h), medialmente ao Mo5 (seta) e em seu interior (cabeça de seta). Em D, fibras na região $h$ inferior ao Mo5 e aparente contato sináptico (seta).

Abreviações: $\mathrm{f}$, fórnice; ic, cápsula interna. 


\subsection{Duplas Marcações}

Para um estudo neuroquímico das aferência pesquisou-se a presença de células duplamente marcadas principalmente na LH e no CeA.

Em uma série de cada um dos casos Mo5D-7, Mo5D-9 e Mo5D-10 foi verificada a presença de células imunorreativas a orexina (ORX) na LH (Figura 15 C; Figura 16). Foram analisados dois níveis distintos da LH nos 3 casos, a saber: -3,1mm do bregma (Figura 16C e D) e -3,6mm do bregma (Figura 16E e F). Verificamos, no nível mais rostral, 12 células imunorreativas ao CTb no caso Mo5D-7, 8 no caso Mo5D-9 e 31 no caso Mo5D-10. Destas 4 eram duplas (CTb e ORX) no caso Mo5D-7 (33,3\%), 3 no caso Mo5D-9 (37,5\%) e 7 no caso Mo5D-10 (22,5\%). Assim, neste nível, considerando o erro padrão, tivemos 31,1 +/- 4,4\% de células que se projetam para o Mo5 e são imunorreativas a ORX. No nível mais caudal, verificamos 11 células imunorreativas ao CTb no caso Mo5D-7, 10 no caso Mo5D-9 e 28 no caso Mo5D-10. Destas, não haviam duplas (CTb e ORX) no caso Mo5D-7 (0\%), 1 dupla no caso Mo5D-9 (10\% ) e 2 no caso Mo5D-10 (7,1\%). Assim, neste nível tivemos 5,7 +/- 3\% de células que se projetam para o Mo5 e são imunorreativas a ORX. Desta forma, em relação a esses dois níveis, temos 18,4 +/- 3,7\% de células duplamente marcadas para CTb e ORX.

Utilizando-se novas séries dos três casos já citados, verificou-se a presença de células imunorreativas ao fator liberador de corticotrofina (CRF) no CeA, porém células duplamente marcadas foram observadas apenas ocasionalmente (Figura 15A e B). As células imunorreativas ao CRF concentram-se mais na porção lateral do CeA, enquanto as células retrogradamente marcadas concentram-se na região mais medial deste núcleo. Porém fibras e aparentes terminais imuorreativos ao CRF foram observados muito próximos às células retrogradamente marcadas presentes em posições mais laterais (dado não apresentado).

A presença do neurotransmissor inibitório ácido gama amino butírico (GABA) foi verificada através de hibridização in situ no CeA. Células duplamente marcadas foram verificadas esporadicamente (Figura 17A e B), porém em todos os casos realizados notamos a presença de considerável marcação de fundo ("background”); então tentamos a imunoistoquímica com dupla fluorescência. As marcações do GABA foram discretas, não visualizamos células duplamente marcadas. Células gabaérgicas em maior quantidade foram observadas mais lateralmente no núcleo lateral da amígdala.

Uma série dos casos Mo5D- 9 e 10 foram utilizadas para se verificar a presença de células nitrérgicas no CeA. Células contendo o óxido nítico (NO) foram observadas 
principalmente no núcleo medial da amígdala e em menor quantidade na região mais medial do CeA, porém não foram verificadas duplas marcações (Figura 17C e D).

Utilizando casos controles, tentamos obter marcação fluorescente para os receptores de canabinóides (CB1-R), porém não conseguimos reações nítidas para estes receptores. A presença deles pode ser notada no CeA nas reações de imunoperoxidase (lâminas gentilmente cedidas pela Prof ${ }^{a}$. Dr ${ }^{\mathrm{a}}$ Andréa Torrão).

Além disso, foi pesquisada a presença de fibras imunorreativas à tirosina hidroxilase (TH), em núcleos do tronco encefálico e nos núcleos CeA, PSTh além da LH. Foi verificada uma quantidade grande de fibras no Me5 e PCRtA, moderada de TH nos CeA e PSTh e pequena na LH. Algumas destas fibras presentes no CeA, PSTh, PCRtA e Me5 parecem conter botões sinápticos realizando aparentes contatos com neurônios retrogradamente marcados (Figura 19; Figura 20D). Não foram encontradas células duplamente marcadas. Estes resultados já foram publicados no Neuroscience Letters (Mascaro et al., 2005; vide anexo) 


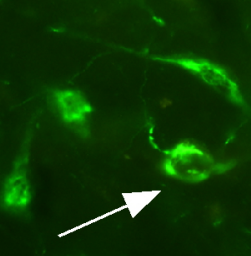

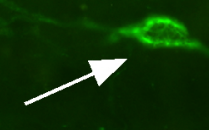

LH

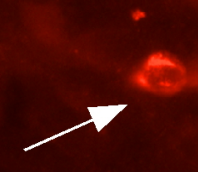

ORX-IR

Figura 15. Caracterização neuroquímica das células retrogradamente marcadas. Fotomicrografias de fluorescência mostrando células marcadas com fluoresceína (FITC, verde) e células marcadas com Cy3 (vermelhas). Em A, célula imunorreativa ao fator liberador de corticotrofina (CRF) no núcleo central da amígdala (CeA). Em B, a mesma célula também imunorreativa ao traçador retrógrado subunidade $b$ da toxina colérica $(\mathrm{CTb})$ (seta) injetado no núcleo motor do trigêmeo. Em $\mathbf{C}$, células imunorreativa à orexina (ORX) na área hipotalâmica lateral $(\mathrm{LH})$ (setas). Em D, as mesmas células também imunorreativas ao $\mathrm{CTb}$. 
Mo5D-9

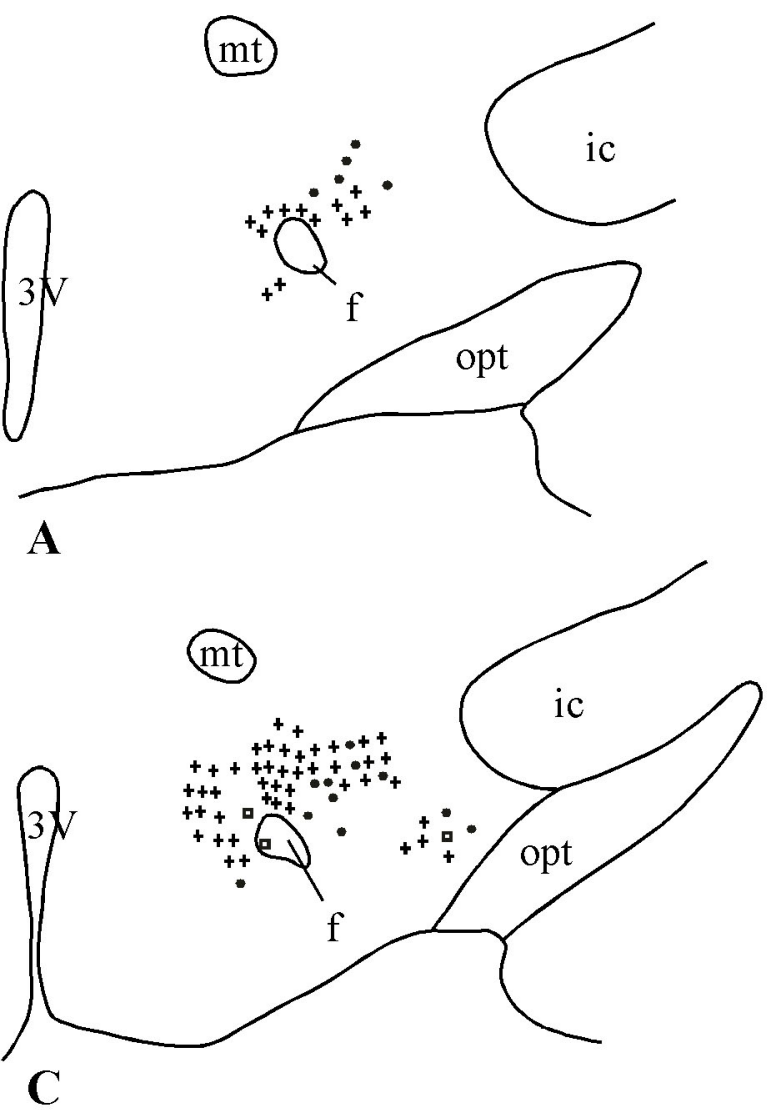

Mo5D-10

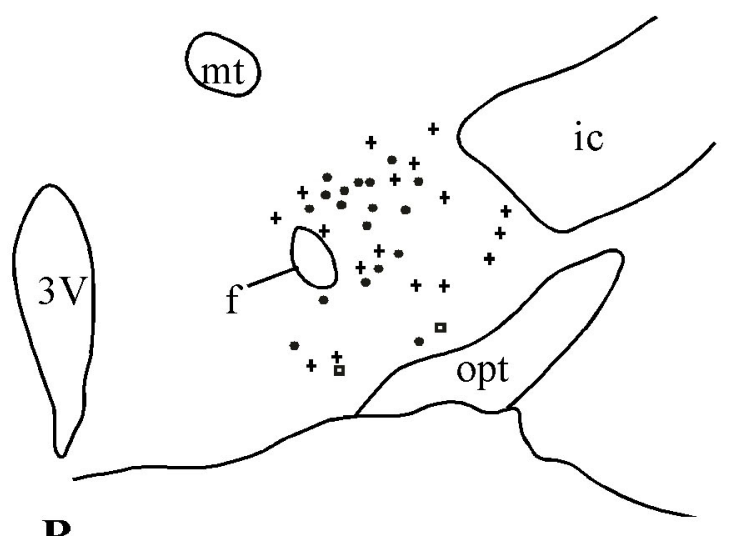

B
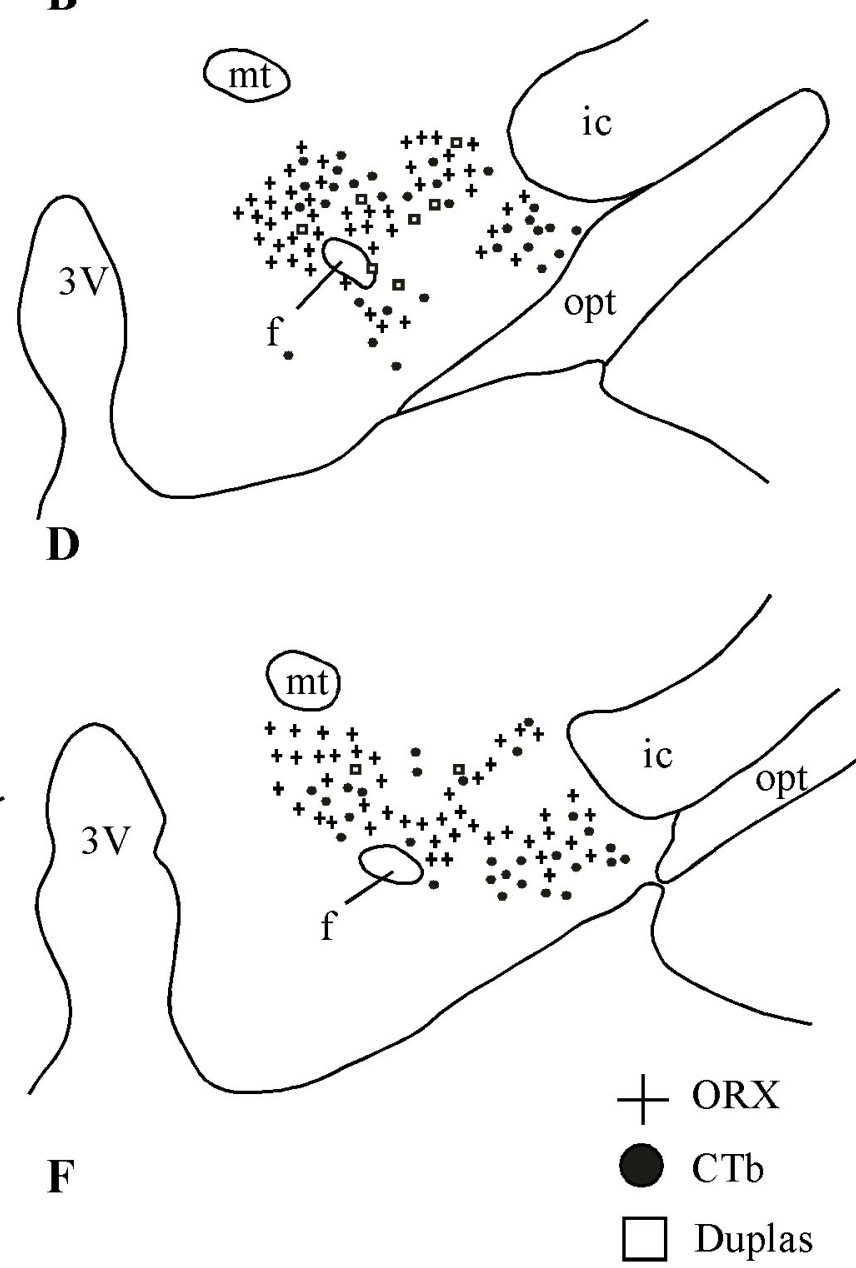

Figura 16. Esquema mostrando células retrogradamente marcadas na área hipotalâmica lateral com a subunidade $\mathrm{b}$ da toxina colérica ( $\mathrm{CTb}$, círculos pretos), células imunorreativas à orexina (ORX, cruzes) e células duplamente marcadas CTb e ORX (quadrados não preenchidos). Em A, C e E, caso Mo5D-9 em três níveis diferentes de corte, rostral, médio e caudal respectivamente. Em B, D e F, caso Mo5D-10 em três níveis diferentes de corte, rostral, médio e caudal respectivamente.

Abreviações: $3 \mathrm{~V}$, terceiro ventrículo; f, fórnice; cápsula interna; $\mathrm{mt}$, trato mamilotalâmico; opt, trato óptico. 



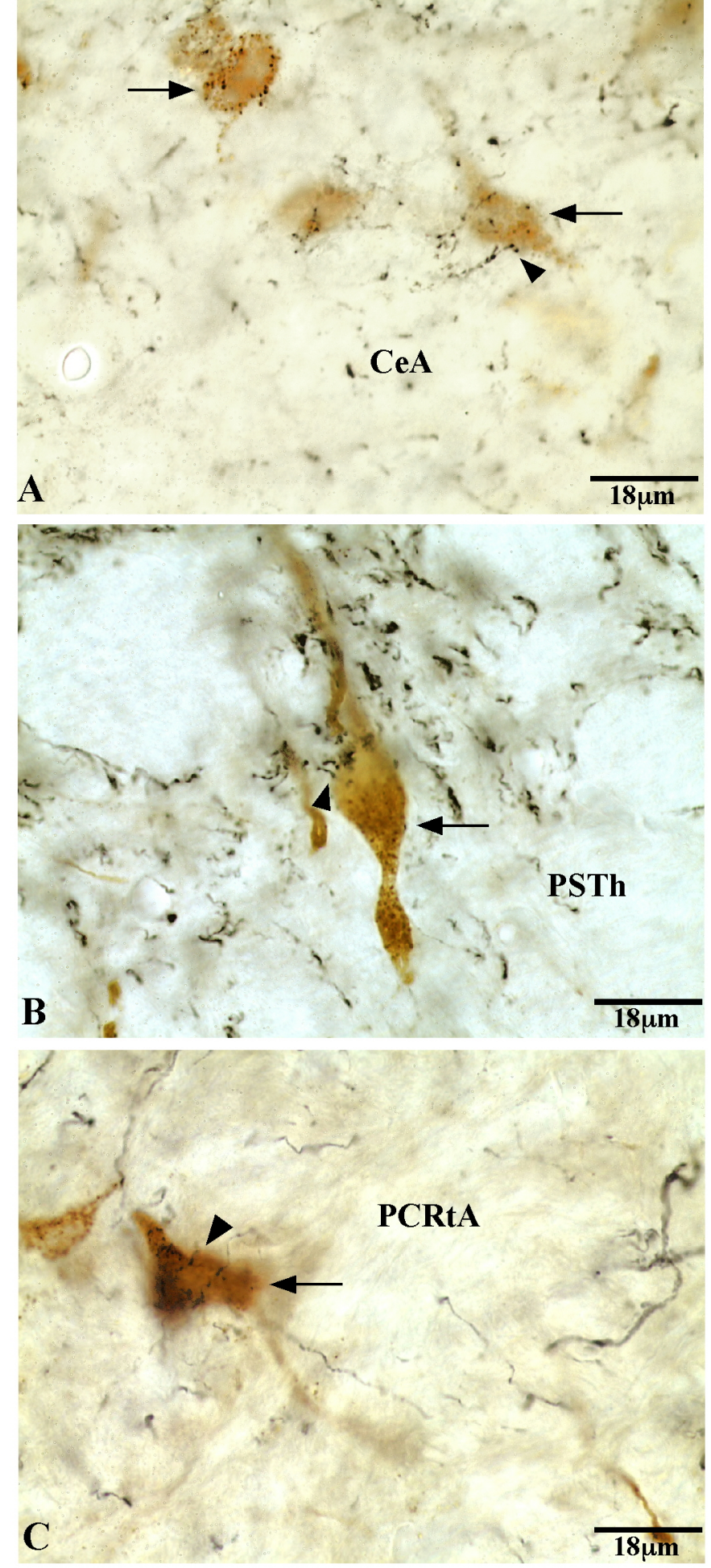

Figura 18. Neurônios retrogradamente marcados que recebem inervação de fibras imunorreativas à tirosina hidroxilase $(\mathrm{TH})$. Em $\mathbf{A}$, fotomicrografia do núcleo central da amígadala (CeA) com neurônios retrogradamente marcados (setas) e aparentes contatos sinápticos com fibras imunorreativas à $\mathrm{TH}$ (cabeça de seta). Em B, fotomicrografia do núcleo parasubtalâmico (PSTh) com neurônios retrogradamente marcado (seta) e aparentes contatos sinápticos com fibras imunorreativas à $\mathrm{TH}$. Em $\mathbf{C}$, fotomicrografia da formação reticular parvicelular parte alfa (PCRtA) com neurônios retrogradamente marcado (seta) e aparentes contatos sinápticos com fibras imunorreativas à $\mathrm{TH}$. 


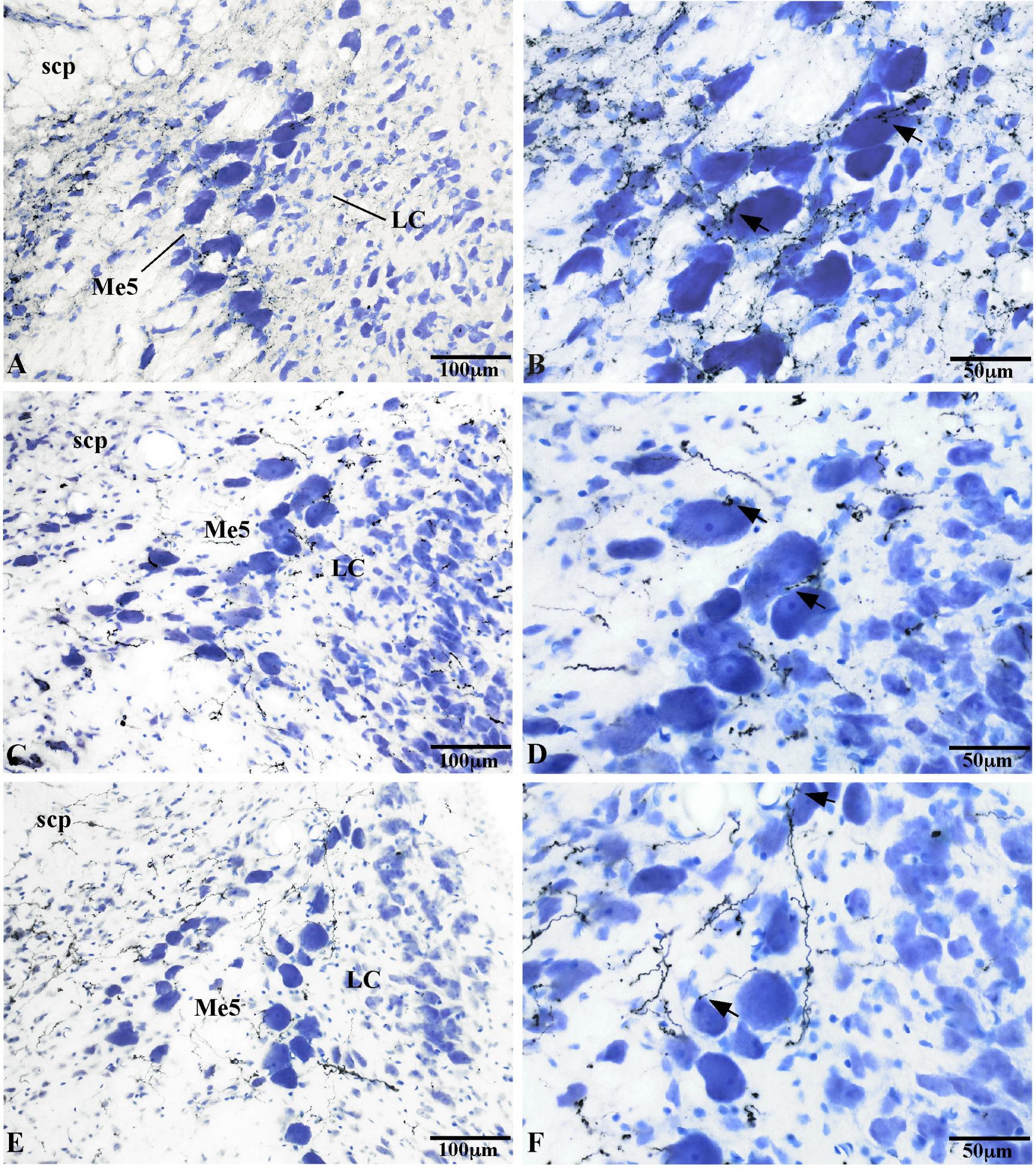

Figura 19. Aferências prosencefálicas para o núcleo mesencefálico do trigêmeo (Me5). Em A, fibras no Me5 após injeção do traçador antrógrado dextrana amina biotinilada (BDA) no núcleo central da amígdala. Em $\mathbf{B}$, maior aumento de A, mostrando aparentes contatos sinápticos (setas). Em $\mathbf{C}$, fibras no Me 5 após injeção de BDA na área hipotalâmica lateral. Em D, maior aumento de C, mostrando aparentes contatos sinápticos (setas). Em D, fibras no Me5 após injeção de BDA no núcleo parasubtalâmico. Em F, maior aumento de E, mostrando aparentes contatos sinápticos (setas) Abreviações: LC, locus coeruleus; scp, pedúnculo cerebelar superior. 

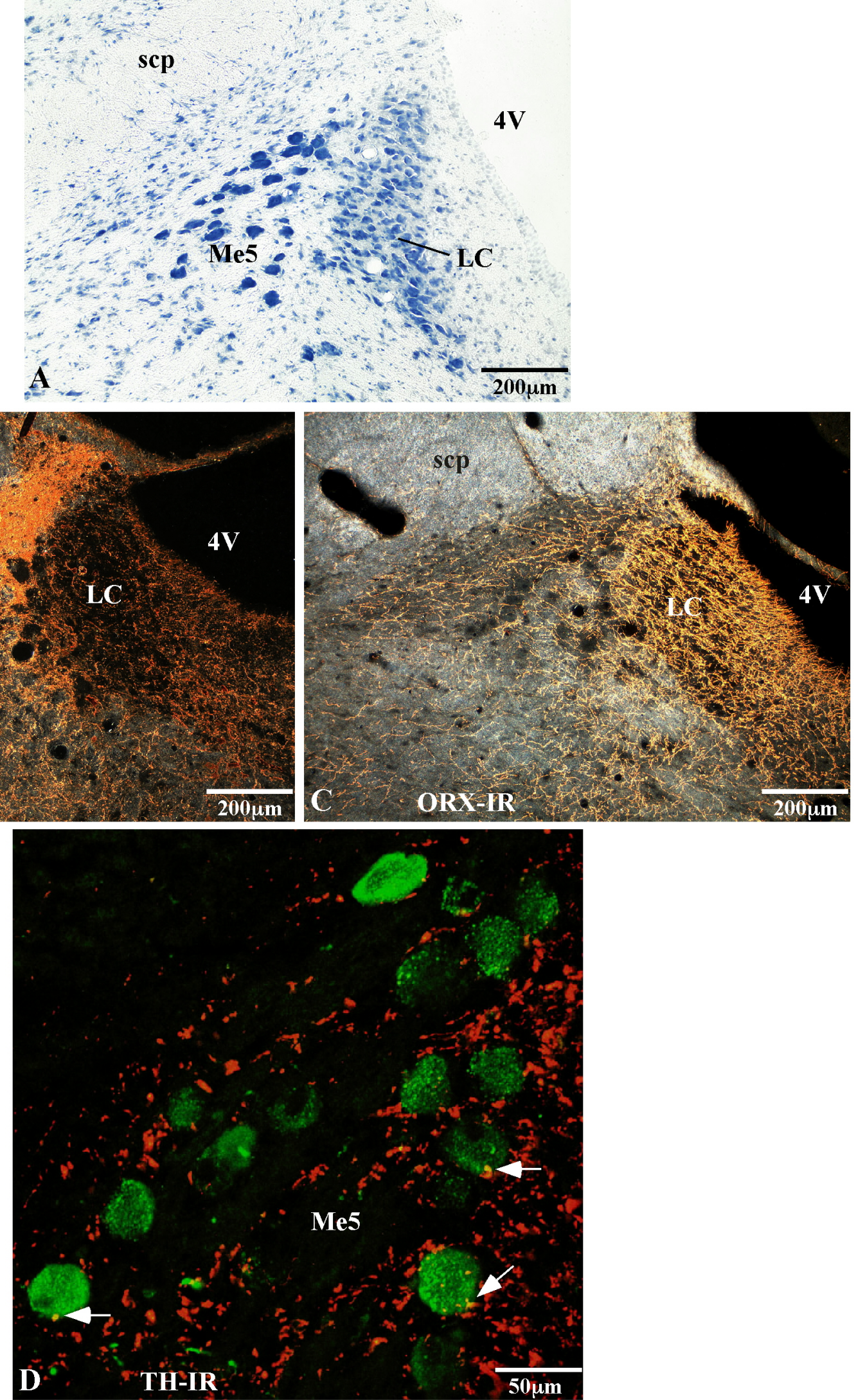

Figura 20. Neuroquímica das aferências do núcleo mesencefálico do trigêmeo (Me5). Em A, citoarquitetura do Me5 e regiões adjacentes. Em $\mathbf{B}$, fotomicrografia em campo escuro mostrando distribuição de fibras imunorreativas (IR) ao fator liberador de corticotrofina (CRF) na região do Me5. Em C, fotomicrografia em campo escuro mostrando distribuição de fibras-IR à orexina (ORX) na região do Me5. Em D, fotomicrografia confocal mostrando células retrogradamente marcadas (fluoresceína, verde) após injeção de traçador retrógrado no núcleo motor do trigêmeo e fibras-IR à tirosina hidroxilase (TH) (CY3, vermelho); possíveis contatos sinápticos (setas). Abreviações: 4V, quarto ventrículo; LC, locus coeruleus; scp, pedúnculo cerebelar superior. 


\section{DISCUSSÃO}

\subsection{Considerações metodológicas}

Para que fossem estudas as aferências do núcleo motor do trigêmeo (Mo5), injeções de traçadores retrógrados foram realizadas. Inicialmente, foi utilizado o traçador retrógrado Fluorogold (FG), através de injeção por iontoforese (Mascaro et al., 2005). Existem diversos trabalhos que comparam vários traçadores retrógrados, fluorescentes ou não, quanto a tipos de injeção, número de células retrogradamente marcadas, tempo de transporte dos traçadores, possibilidade de duplas marcações, etc (Trojanowisk et al., 1982; Wan et al., 1982; Cavada et al., 1984; Kruse et al., 1993; Richmond et al., 1994; Novikova et al., 1997). O Traçador FG pode ser manipulado de forma a produzir iontoforeticamente injeções de tamanho pequeno (Schmued e Fallon, 1986; Pieribone e Aston-jones, 1988), além disso, ele oferece uma série de vantagens, dentre as quais: não ser captado por fibras de passagem íntegras, não difundir das células marcadas e ser compatível com outros métodos de neuro-histoquímica (Schmued e Fallon, 1986; Pieribone e Aston-jones, 1988). Porém, houve um problema quanto às reações de imunoistoquímica para visualização do FG e de neuromediadores como o fator liberador de corticotrofina (CRF) e a orexina (ORX), pois os anticorpos primários para o traçador e para os neuromediadores são produzidos em coelhos, desta forma o anticorpo secundário não produz marcações específicas. Para solucionar este problema e confirmar as marcações encontradas com um outro traçador retrógrado, passamos a utilizar a subunidade b da toxina colérica (CTb) cujo anticorpo primário é produzido em cabra. O CTb apresenta vantagens semelhantes ao FG, podendo ainda ser transportado anterogradamente (Luppi et al., 1990) e sendo mais compatível com as técnicas de imunoistoquímica necessárias ao nosso estudo.

Para o controle anterógrado utilizamos como traçador a dextrana amina biotinilada (BDA). O BDA pode ser usado tanto como traçador anterógrado, quanto retrógrado, dependendo de seu peso molecular e do $\mathrm{pH}$ da solução veículo (Reiner et al., 2000; Cavalcante e Canteras, 2007). Este traçador foi o de escolha, pois ele também, apresenta uma série de vantagens conjuntas como: produz uma marcação anterógrada confiável tanto por injeções através de iontoforese como através de pressão, pode-se facilmente conseguir uma injeção de pequeno tamanho, restrita, com um bom transporte; produz uma marcação refinada de fibras e terminais, tolera fixação com glutaraldeído, sem atenuação significante da marcação, o que o faz compatível tanto para microscopia de luz quanto eletrônica (Reiner et 
al., 2000; Cavalcante e Canteras, 2007). Além disso, o BDA se mostrou superior em relação à qualidade de marcação de axônios e terminais em relação a leucoaglutinina Phaseolus vulgaris (PHA-L) e a neurobiotina (NB), que são outros traçadores anterógrados normalmente utilizados (Novikov, 2001).

Em nosso estudo, utilizamos o BDA de alto peso molecular (10k), em uma concentração de 10\% em tampão fosfato de sódio (PBS), 10 mM, pH 7,4; o que possibilita um transporte predominantemente anterógrado devido ao peso molecular e ao $\mathrm{pH}$ fisiológico do veículo. Além disso, a injeção foi realizada por iontoforese com corrente elétrica do tipo alternada, positiva, de $5 \mu \mathrm{A}$ por 7 minutos, metodologia recomendada na literatura (Reiner et al., 2000; Novikov, 2001).

Durante nossas injeções observamos uma fácil difusão do traçador, sem obstruções da pipeta, além disso, com injeções relativamente pequenas, conseguimos um grande transporte. Porém em 4 casos não conseguimos observar a injeção e nem houve transporte do traçador. $\mathrm{O}$ caso ocorreu com outros pesquisadores do laboratório em época semelhante. Não acreditamos que o problema estivesse no material de histoquímica pois com o mesmo material conseguimos verificar marcações em outros casos, nem que o problema fosse com o lote de BDA, pois usando o mesmo lote conseguimos boas injeções. Não encontramos na literatura outras explicações para o ocorrido; assim, acreditamos que isso se deu, talvez, pela possível degradação da biotina à temperatura ambiente. Desta forma, recomendamos, apenas por observações empíricas, que o traçador seja mantido em baixas temperaturas e a pipeta preenchida apenas no momento da injeção. Porém, testes deveriam ser realizados para confirmar ou não nossas suspeitas. Um outro ponto negativo do traçador, seria o tempo para se conseguir uma injeção adequada. No caso, foi utilizada uma corrente alternada positiva de $5 \mu \mathrm{A}$ por 20 minutos, o que consideramos um tempo relativamente longo. Encontramos na literatura relatos de utilização de tempos de até 50 minutos de passagem de corrente (Yasui et al., 1997). Este problema foi solucionado quando passamos a preparar a solução de BDA em água e não em PBS. Fazendo dessa forma, conseguimos obter injeções de bom tamanho com corrente de $5 \mu \mathrm{A}$ por 5 a 7 minutos. 


\subsection{Considerações sobre a citoarquitetura e hodologia do Mo5}

O controle do ritmo, da força e dos movimentos mastigatórios é, em última instância, determinado pelos motoneurônios presentes no núcleo motor do trigêmeo (Mo5). Diversos núcleos localizados no tronco encefálico e no prosencéfalo contêm neurônios pré-motores que irão influenciar de forma direta ou indireta o Mo5. Assim, alterações neuroquímicas no Mo5 ou em um ou mais destes núcleos pré-motores poderão gerar disfunções no sistema estomatognático, ou seja, nos músculos mastigatórios, na ATM, nos dentes e até mesmo alterações ósseas na mandíbula e maxila. Isso pode ocorrer em patologias como nas desordens motoras orofaciais, dentre elas o bruxismo noturno, discinesias e distonias orais e nas disfunções temporomandibulares (DTMs).

Nosso estudo foi condizente com a literatura no que tange a extensão e limites do Mo5. Em relação a citoarquitetura, observamos a presença de neurônios grandes, os motoneurônios, com tamanhos entre 35 e $45 \mu \mathrm{m}$ de diâmetro e neurônios pequenos com tamanhos que variaram entre 15 e $20 \mu \mathrm{m}$ de diâmetro. Da mesma forma, a literatura quantifica os neurônios do Mo5 do rato em cerca de 2265 a 2979, os quais também estariam divididos em dois tipos, mas com diâmetros mais variáveis que os observados em nossas lâminas. Os motoneurônios variariam em diâmetro entre 24 e $42 \mu \mathrm{m}$ e os neurônios pequenos entre 8 e $20 \mu \mathrm{m}$ (Travers, 1995).

Vários autores descrevem a divisão do Mo5 em duas partes: uma maior, dorso-lateral que contém os motoneurônios dos músculos de elevação da mandíbula; e uma ventro-medial que só ocupa os dois terços posteriores, que contém os motoneurônios dos músculos de abaixamento da mandíbula (Mizuno et al., 1975; Mizuno et al., 1981; Uemura-sumi et al.,1982; Yamamoto et al., 2007). Em nossos cortes pudemos, após a coloração com tionina pelo método de Nissl, vizualizar esta divisão, porém esta individualização de regiões não foi tão clara em todos os casos. Segundo Terashima et al. (1994) a separação das porções é mais clara na porção intermediária do Mo5, tornando-se menos distinta em níveis mais caudais.

Ao redor do Mo5, temos uma região que contém neurônios pré-motores fusiforme (Card et al., 1986). Esta área é chamada, segundo Kolta et al. (2000), de região h, sendo composta pelo núcleo supratrigeminal (Su5), pelas regiões intertrigeminal lateralmente e justatrigeminal medialmente e pela formação reticular ventral. Yamamoto et al. (2007) preferem chamar esta região de concha do Mo5. Em nossas lâminas pudemos observar uma grande distinção entre o Mo5 com seus motoneurônios e a região h que o circunscreve (Figura 
2B e C). Esta região, considerada alvo de projeções descendentes corticais e límbicas, contém dendritos de motoneurônios do Mo5 que ultrapassam suas margens definidas citologicamente (Travers, 1995).

Nossos resultados foram condizentes com a literatura, em relação às marcações em tronco encefálico. Assim como vários autores (Travers e Norgren, 1983; Grzanna et al., 1987; Fort et al., 1990; Turman e Chandler,1994; Li et al., 1995; Li et al., 1996; Yasui et al., 1997; Kolta et al., 2000; Luo et al., 2001), observamos que a maior parte das projeções para o Mo5 provém dessa região, porém, observamos alguns núcleos com células retrogradamente marcadas pouco descritos (Mascaro et al., 2005).

Iniciando pelas porções mais rostrais do tronco encefálico, pequena quantidade de células retrogradamente marcadas foi notada na substância cinzenta periaquedutal (PAG) ipsilateral, em suas partes mais rostrais, nas porções dorso-lateral e ventro-lateral. Isto não foi verificado em todos os casos de injeções consideradas boas e a quantidade de células marcadas aumentou muito nos casos controle, que contaminaram áreas adjacentes. Um pequeno número de marcações nesta área também foi verificado por Li et al. (1995). Acreditamos, porém, que a PAG não tenha projeções diretas para o Mo5 mas sim indiretas pela formação reticular, e que as marcações observadas são frutos de contaminação. Também, pequena quantidade de células foi observada no núcleo de Edinger-Westphal (EW) e quantidade um pouco maior no complexo oculomotor adjacente. Isto foi verificado em todos os nossos casos, o que também foi descrito por Fort et al. (1990), porém em gatos. Quantidade moderada de células foi observada no núcleo rubro porção parvicelular (RPC) contralateral, esta marcação é discutida na literatura. Travers e Norgren (1983) obtiveram esta marcação em um caso, após injeção de HRP no Mo5. Porém, os autores afirmaram que neste procedimento utilizaram um acesso ventral e que esta marcação talvez fosse devida à contaminação dos tratos rubro-bulbar e rubro-espinal que têm um curso ventral e ventrolateral, respectivamente, em relação ao Mo5. Além disso, os autores relataram que após uma grande injeção no Mo5, por acesso dorsal, não obtiveram esta marcação, então eles concluem que o núcleo rubro não termina significativamente no Mo5.

O núcleo rubro faz parte, segundo Holstege (1995) do sistema somático motor lateral. Ele se projeta de forma contralateral e na maioria das vezes fibras não se projetam diretamente para neurônios motores, mas sim para neurônios pré-motores da formação reticular. Porém, há projeções diretas do núcleo rubro para, por exemplo, o núcleo facial. Em todas as nossas injeções consideradas boas e nos controles retrógrados, observamos células retrogradamente marcadas no núcleo rubro principalmente em sua porção parvicelular, houve 
no entanto, variação na quantidade de células marcadas: maior nos casos controle e menor nas injeções restritas. Assim, acreditamos que este núcleo tenha projeções diretas para o Mo5, assim como tem para o facial, bem como indiretas, através de neurônios pré-motores na formação reticular.

Em relação aos núcleos da rafe, observamos uma pequena quantidade de células marcadas em todos os casos no núcleo pálido (Rpa) e no núcleo obscuro (Rob). Estas verificações concordam com Fort et al. (1990), Li et al. (1995), Li et al. (1996), Nagase et al. (1997) e Yamamoto et al. (2007). Porém, células marcadas no núcleo magno da rafe e no dorsal da rafe nem sempre foram verificadas, o que também está de acordo com a literatura que afirma que as projeções destes núcleos para o Mo5, se fazem em menor quantidade (FORT et al., 1990; Ribeiro-do-Valle et al., 1991). Segundo Yamamoto et al. (2007) neurônios dos Rpa e Rob produzem potenciais pós-sinápticos excitatórios tanto em motoneurônios dos músculos de abaixamento quanto em motoneurônios dos músculos de elevação da mandíbula, sem uma predominância. Porém, Kolta et al. (2000), sugerem que o maior alvo dos neurônios dos núcleos da rafe seriam os motoneurônios dos músculos de abaixamento da mandíbula, e que estes neurônios teriam como principal eferência, não o Mo5, mas a região h. Ao contrário, Nagase et al. (1997) afirmam que há maior número de contatos sinápticos entre neurônios com terminais imunorreativos a serotonina e motoneurônios dos músculos de elevação da mandíbula. Em nosso trabalho verificamos marcação mais acentuada nos Rpa e Rob nos casos controle, onde houve contaminação da região h, o que condiz com Kolta et al. (2000). Em relação aos contatos sinápticos, Nagase et al. (1997) afirmam que possivelmente, nos núcleos da rafe, há neurônios não produtores de serotonia ou, os neurônios que produzem serotonina também produzem algum outro neurotransmissor. Sendo assim, a afirmação de Kolta et al. (2001) pode estar correta, porém quando se analisam apenas os terminais com serotonina, a maior parte dos contatos sinápticos aconteceria com os motoneurônios dos músculos de elevação da mandíbula (Nagase et al., 1997). Isto estaria de acordo com Katakura e Chandler (1990), que afirmam que a serotonina agiria de forma modulatória nos motoneurônios, principalmente facilitando a ação excitatória do glutamato nos motoneurônios de elevação da mandíbula.

No complexo trigeminal observamos uma grande quantidade de células retrogradamente marcadas. De todas as regiões marcadas, destacam-se o núcleo mesencefálico do trigêmeo (Me5) ipsilateralmente. No Me5 contralateral a marcação apresentou-se pequena. O Me5, de acordo com nossas observações, parece exercer um papel fundamental no controle mastigatório. Esse núcleo possui neurônios pseudounipolares que 
têm proprioceptores nos músculos de elevação da mandíbula e mecanorreceptores no ligamento periodontal. Estes terminais captam informações e as transferem principalmente para a formação reticular pontina parvicelular (PCRt) rostral, núcleo supratrigeminal (Su5) e para o Mo5 (Copray et al., 1990). Os neurônios mesencefálicos recebem densa inervação de fibras imunorreativas a uma série de neurotransmissores e neuromediadores como a dopamina e a noradrenalina (Copray et al, 1990; Mascaro et al., 2005) além da serotonina (Copray et al, 1990), do fator liberador de corticotrofina (CRF) cujos corpos celulares parecem estar no núcleo central da amígdala (CeA) (Sakanaka et al., 1986), e da orexina (ORX) e óxido nítrico (NO) Stoyanova e Lazarov (2005a,b). Além disso, no presente trabalho observamos que núcleos prosencefálicos que atuam diretamente no Mo5 ou indiretamente pela região h como o CeA, a área hipotalâmica lateral (LH) e o núcleo parasubtalâmico (PSTh) (Mascaro et al., 2005), têm eferências muito mais densas diretamente para o Me5 que para o Mo5. Desta forma, o Me5 parece funcionar como um centro integrador entre as informações sensoriais periféricas e o controle do ritmo mastigatório atuando sobre a PCRt e da força mastigatória recebendo eferências prosencefálicas e atuando sobre o Mo5.

Células retrogradamente marcadas também foram verificadas na região h ipsilateral, no Su5, no núcleo principal do trigêmeo (Pr5) e no núcleo espinal (Sp5) bilateralmente, com predominância ipsilateral, resultados condizentes com a literatura (Travers e Norgren, 1983; Grzanna et al., 1987; Fort et al., 1990; Turman e Chandler ,1994; Li et al., 1995; Li et al., 1996; Yasui et al., 1997; Kolta et al., 2000; Luo et al., 2001; Yamamoto et al., 2007). Pequenos neurônios apresentaram-se marcados no Mo5 contralateral, o que também foi verificado por KOLTA et al. (2000) e LUO et al. (2001).

No Pr5 e subnúcleo trigeminal espinal oral (Sp5O) observamos que as marcações ocorreram principalmente em suas porções dorsais e médias, o que também aconteceu no subnúcleo trigeminal espinal interpolar (Sp5I). Autores como Travers e Norgren (1983), não encontraram células marcadas neste subnúcleo. Segundo Li et al. (1995) que realizaram o estudo em ratos, a porção dorso-lateral do Mo5, onde se localizam os motoneurônios dos músculos de elevação da mandíbula (Mizuno et al., 1975), receberia projeções principalmente do Me5, região supratrigeminal e parte mais dorsal dos Pr5, Sp5O e Sp5I. Yamamoto et al. (2007), que realizaram o estudo em gatos, concordam com esses dados, afirmando ainda, que as células retrogradamente marcadas no Pr5 e Sp50 estariam na porção mais dorsal e lateral destes núcleos. Porém os autores não encontraram células marcadas no Sp5I. Em relação à porção ventro-medial do Mo5, onde se localizam os motoneurônios dos músculos de abaixamento da mandíbula (Mizuno et al., 1975), foi observado por Li et al. (1995) projeções 
principalmente da parte alfa do núcleo gigantocelular (GiA) e porção média, no sentido dorsoventral, dos Pr5, Sp5O e Sp5I. Yamamoto et al. (2007) também observaram estas células marcadas em porções médias do Pr5 e Sp5O. Em nosso trabalho não pudemos fazer este tipo de diferenciação, pois não conseguimos obter injeções tão restritas e com bom transporte do traçador. Segundo Shigenaga et al. (2000), os neurônios pré-motores do Sp5O seriam inibitórios tanto para os motoneurônios de fechamento como para os de abertura da boca e utilizariam o GABA ou a glicina como neurotransmissor.

Em nosso estudo não observamos conexões diretas do subnúcleo trigeminal caudal (Sp5C) com o Mo5, fato verificado por diversos autores (Travers e Norgren, 1983; Grzanna et al., 1987; Fort et al., 1990; Turman e Chandler, 1994; Li et al., 1995; Li et al., 1996; Yasui et al., 1997; Kolta et al., 2000; Luo et al., 2001; Mascaro et al., 2005; Yamamoto et al., 2007). No entanto, conexões indiretas devem existir devido às verificações realizadas por pesquisadores que utilizaram marcadores de ativação neuronal e eletromiografia, nos quais irritantes colocados na articulação temporomandibular (ATM) de roedores, geraram o aumento da expressão da proteína Fos no Sp5C (Zhou et al., 1999) e aumento dos disparos registrados na eletromiografia para músculos de abaixamento e elevação da mandíbula (Tsai et al., 1999; Tambeli et al., 2001), disparos estes que diminuíram com lesão provocada no Sp5C (Tsai, 1999). Além disso, parece que a ativação dos neurônios do Sp5C se faz através dos receptores N-metil-D-aspartame (NMDA) e neuroquinina-1 (NK1) (Koganemaru et al., 2000), porém segundo Bakke et al. (1998) o receptor envolvido na ativação neuronal seria o NK-2 e não o NK-1. Uma ação inibitória dos neurônios do Sp5C foi exercida pelos receptores do ácido gama amino butírico $\mathrm{GABA}_{\mathrm{A}}$ e GABA $\mathrm{B}$ (Seo et al. 2001; Takemura et al. 2001) e pelos receptores opióides (Tambeli et al., 2001).

Observamos quantidade moderada de células, principalmente ipsilateralmente nos núcleos parabraquial lateral (LPB) e parabraquial medial (MPB), o que condiz com os resultados de Fort et al. (1990), Li et al. (1995), Li et al. (1996) e Yamamoto et al. (2007). Segundo Li et al. (1995), os neurônios da LPB receberiam informações dolorosas e induziriam ao abaixamento da mandíbula, pois se projetam preferencialmente para os motoneurônios responsáveis por esta função, porém, Yamamoto et al. (2007) não verificaram esta preferência de projeção.

Células retrogradamente marcadas também foram verificadas, com pequena predominância ipsilateral, em núcleos da formação reticular pontina e bulbar, como no núcleo gigantocelular (Gi), núcleo gigantocelular parte alfa (GiA), além da formação reticular pontina parvicelular parte alfa (PCRtA), núcleo reticular intermediário (IRt) e mais 
caudalmente no núcleo do trato solitário (NTS), o que está de acordo com trabalhos realizados em ratos, gatos e coelhos (Fort et al., 1990; Mogoseanu et al., 1993; Li et al., 1995; Li et al., 1996; Yasui et al., 1997; Kolta et al., 2000; Luo et al., 2001).

Segundo Lund et al. (1998) os impulsos de neurônios localizados na formação reticular pontina medial e lateral, chegam ao Mo5 diretamente ou através de neurônios prémotores da região h. Os autores acreditam que os grupos mediais, funcionariam como um gerador de ritmo, durante a mastigação, enquanto os grupos laterais agiriam como integradores entre informações sensoriais e comandos descendentes que poderão alterar este ritmo gerado medialmente.

Várias projeções prosencefálicas para o Mo5 ou região h, foram observadas em nosso estudo, diferentemente da maior parte da literatura estudada, que não as descreve (Travers e Norgren, 1983; Mogoseanu et al., 1993; Turman e Chandler, 1994; Li et al., 1995; Li et al., 1996; Yasui et al., 1997; Kolta et al., 2000).

No início dos anos 80, Travers e Norgren (1983) afirmaram que, até aquele momento não havia descrições neuroanatômicas de conexões diretas entre núcleos do prosencéfalo e o Mo5 e que injeções de traçador retrógrado restritas ao Mo5 falharam na marcação de corpos celulares no prosencéfalo. Outros trabalhos mais recentes, nos quais injeções de traçador retrógrado foram realizadas no Mo5, também não descreveram marcações prosencefálicas. Porém, o que pudemos notar foi que a maioria dos autores estava mais preocupada em estudar as marcações retrógradas no tronco encefálico do que possíveis marcações prosencefálicas. Desta forma, muitos deles nem analisaram cortes prosencefálicos (Mogoseanu et al., 1993; Turman e Chandler, 1994; Li et al., 1995; Li et al., 1996; Yasui et al., 1997; Kolta et al., 2000; Yamamoto et al., 2007). Além disso, nestes trabalhos e em outros, nos quais foram estudados cortes prosencéfálicos, o tempo de transporte do traçador foi muito reduzido; o que pode ter impedido a sua chegada em regiões do prosencéfalo. Podemos citar como exemplo Travers e Norgren (1983), que utilizaram injeções de HRP no Mo5 e sacrificaram os animais 24 horas após as injeções.

Resultados diferentes foram obtidos por Fort et al., (1990) que utilizaram injeções da subunidade b da toxina colérica (CTb) no Mo5 e apesar de bloquearem o transporte do traçador 24 horas depois devido à injeção de colchicina no ventrículo lateral e quarto ventrículo, obtiveram discretas marcações no CeA e também em região perifornicial na LH. Porém, os autores afirmaram que estes resultados deveriam ser melhor investigados.

Não encontramos nenhum trabalho utilizando injeções no Mo5 de traçadores retrógrados mais modernos como, por exemplo, o FG ou CTb, no qual os autores observaram 
cortes prosencefálicos. Porém, fibras de um novo peptídeo descrito recentemente denominado orexina ou hipocretina (de Lecea et al., 1998; Sakurai et al., 1998), cujos corpos celulares se localizam exclusivamente na LH, foram encontradas no interior do Mo5, sugerindo múltiplas conexões com os motoneurônios trigeminais (Fung et al., 2001).

Em nosso trabalho verificamos células retrogradamente marcadas em todos os casos de injeções consideradas boas e nos controles no córtex motor secundário (M2), córtex motor primário (M1), córtex da insula (I), núcleo intersticial do ramo posterior da comissura anterior (IPAC); núcleo da estria terminal (BST), CeA, LH, preferencialmente na região perifornicial, núcleo paraventricular do hipotálamo (PVH) e no núcleo parasubtalâmico (PSTh).

As marcações em M2 e M1 e I foram bilaterais e apresentaram-se mais evidentes, em aspectos quantitativos e qualitativos, nos casos controle. Não há descrição deste tipo de conexão direta na literatura em ratos, gatos, cobaias ou coelhos. Travers e Norgren (1983) afirmaram que grandes injeções no Mo5, com contaminação da formação reticular adjacente podem ocasionalmente levar a marcação de células no córtex frontal. Kawamura e Tsukamoto (1960a), obtiveram movimentos mastigatórios rítmicos com estímulos elétricos em córtex cerebral, mais especificamente na área insular e lateralmente a área pós-central. Os movimentos obtidos foram preferencialmente de abaixamento da mandíbula. Segundo Li et al. (1996), neurônios da formação reticular que contêm GABA ou glicina representariam neurônios pré-motores inibitórios que mediariam impulsos do córtex cerebral para os motoneurônios trigeminais de elevação da mandíbula. Desta forma, nos parece certo que o córtex cerebral tem uma ação sobre os neurônios do Mo5 e que provavelmente esta ação é inibir os motoneurônios de elevação da mandíbula o que poderia levar ao seu abaixamento e consequente abertura da boca. Porém, como obtivemos uma marcação muito pequena e esparsa nos casos considerados bons, concordamos com Holstege (1995) que afirmou que "se as conexões entre córtex e motoneurônios existem, elas devem ser extremamente escassas”.

Alguns autores consideram o BST e o CeA em conjunto como a amígdala expandida, além disso, o IPAC medial parece estar intimamente relacionado com este conjunto (Shammah-Lagnado et al., 2001). Segundo Hess (1947) apud Kawamura e Tsukamoto (1960a), foram observados movimentos mandibulares com estímulo elétrico no BST, mas estes dados não foram investigados por outros pesquisadores.

Takeuchi et al. (1988) demonstraram conexões diretas entre neurônios localizados no CeA e neurônios do Su5 ipsilateral, estes últimos, se projetariam para o Mo5 contralateral. Kawamura e Tsukamoto (1960a), não obtiveram movimentos mandibulares com estímulo elétrico no CeA, porém movimentos foram demonstrados com estímulo no núcleo lateral da 
amígdala. Os movimentos gerados foram rítmicos tanto de abaixamento quanto de elevação da mandíbula, predominando este último. No entanto, segundo Kowada et al. (1992), o CeA e o núcleo lateral da amígdala estariam intimamente conectados e o CeA agiria não provocando movimentos de elevação, mas sim, inibindo os motoneurônios de abaixamento. Estes autores sugerem que IPAC, BST e amígdala têm uma ação no Mo5, levando principalmente à elevação da mandíbula devido à inibição dos motoneurônios de abaixamento, ação contrária a do córtex cerebral.

Segundo Holstege (1995), BST e amígdala fazem parte do sistema motor emocional lateral, ou seja estas áreas se projetam para o tronco encefálico percorrendo a formação reticular lateral, onde, no nível da ponte encontra-se o Mo5. Além disso, de acordo com Fort et al. (1990) uma pequena quantidade de células foi observada no CeA, após injeção de CTb no Mo5.

Em nosso trabalho, observamos uma pequena marcação ipsilateral e predominantemente de fibras no IPAC e BST e uma marcação moderada de células e fibras no CeA, principalmente em sua porção medial, porém não no núcleo lateral da amígdala. Nos casos controle a marcação foi apenas um pouco maior. De acordo com o que observamos, nos parece coerente que haja conexões diretas da amígdala expandida e do IPAC com o Mo5 e também, conexões indiretas através de neurônios pré-motores da formação reticular e do Me5. Nossa injeção de controle anterógrado no CeA demonstra a presença de fibras ao redor e no interior do Mo5, algumas com características de terminais e uma grande quantidade de fibras e terminais no Me5.

Em relação a neuroquímica destas projeções, observamos esporadicamente células duplamente marcadas para a CTb e para o fator liberador de corticotrofina (CRF), além de CTb e GABA. Porém não observamos células que se projetam para o Mo5 ou região h reativas ao óxido nítrico (NO) ou que contenham receptores de canabinóides (CB1-R). Todavia, notamos uma grande quantidade de fibras e aparentes terminais imunorreativos ao CRF muito próximos as células retrogradamente marcadas, principalmente aquelas localizadas mais laterais no CeA. O mesmo foi notado em relação às fibras imunorreativas à tirosina hidroxilase (TH) demonstrando a ação da dopamina nas células que se projetam para o Mo5 ou região h.

Segundo Kowada et al. (1992), o CeA inibiria os motoneurônios de abaixamento da mandíbula, por isso pesquisamos células retrógradas imunorreativas ao GABA. Além disso, Nitecka e Ben-Ari (1987) descreveram uma quantidade moderada de células imunorreativas ao GABA no CeA. Realizando hibridização in situ para a enzima ácido glutâmico 
descarboxilase (GAD) produtora do GABA, após imunoistoquímica para o CTb, visualizamos células duplas esporádicas e tivemos um background muito pronunciado. Posteriormente tentamos uma dupla fluorescência, não visualizando células duplamente marcadas. As células imunorreativas ao GABA parecem se localizar mais lateralmente, no núcleo lateral da amígdala. Porém, a marcação para o GABA foi muito discreta, desta forma, seria necessário utilizar outros anticorpos e reavaliar a metodologia para a utilização do GABA.

O CRF é um neuromediador relacionado ao eixo hipotálamo-hipófise-supra renal, que participa da liberação de hormônios relacionados ao estresse (Valles et al., 2003). Os neurônios responsáveis por esta ação estão localizados no núcleo paraventricular do hipotálamo mas, no entanto, o CRF é amplamente distribuído no sistema nervoso central sendo encontrado, por exemplo, na amígdala (Potter et al. 1994). Concordando com nossas observações, células imunorreativas ao CRF foram encontradas por Sakanaka et al. (1986) no CeA, além disso, ainda de acordo com nossos resultados, Cassell et al. (1986) dividiram o CeA em sub-regiões e demonstraram que células que expressam o CRF estão localizadas na região mais lateral do CeA o que também acontece com a expressão de seus receptores (Potter et al. 1994). Portanto, nos parece que o CRF é capaz de influenciar o Mo5 principalmente de forma indireta atuando nas células retrogradamente marcadas na porção mais lateral do CeA e no Me5. Células produtoras de CRF no CeA recebem aferências dopaminérgicas (Eliava et al. 2003). Em nosso estudo demonstramos a ocorrência de possíveis contatos sinápticos entre fibras imunorreativas a TH e neurônios no CeA que se projetam para o Mo5 ou região h, porém provavelmente estes não são neurônios produtores de CRF, pois as duplas marcações foram escassas. Desta maneira, de acordo com a literatura e nosso estudo, a dopamina atuaria sobre neurônios no CeA que não expressam o CRF que poderiam influenciar o Mo5 diretamente ou indiretamente pela região h. Outra possibilidade é a ação da dopamina sobre neurônios do CeA que expressam o CRF, os quais poderiam influenciar o Mo5 indiretamente através do próprio CeA medial, onde estão as células retrogradamente marcadas, e/ou via projeções para o Me5.

De acordo com a literatura, o receptor para os canabinóides do tipo 1 (CB1), também parece ter atuação sobre a motricidade oral. Estes receptores têm agonistas naturais endógenos, os denominados endocanabinóides (Castañé et al. 2004). Segundo Fride (2004a), os endocanabinóides foram detectados no leite materno de ratos e a ativação inicial dos receptores CB1 dos ratos recém nascidos parece ser fundamental para que os movimentos de sucção do leite sejam realizados. Os receptores CB1, são expressos no CeA (Herkenham et al. 1991), além disso, o bloqueio desses receptores após a injeção de um antagonista na amígdala 
de ratos viciados em um potente agonista sintético do CB1, provocou, como sinal de abstinência, movimentos mastigatórios (Castañé et al. 2004). Segundo Rodrigues de Fonseca et al. (1997), a abstinência de canabinóide leva a um aumento da expressão do CRF extracelular e do Fos no CeA. Portanto, o aumento do CRF poderia desencadear os movimentos mastigatórios. Em nosso estudo verificamos a presença dos receptores CB1 no CeA através da técnica da imunoperoxidase (observação pessoal de lâminas gentilmente cedidas pela Profa. Dr ${ }^{\mathrm{a}}$. Andréa da Silva Torrão), porém não conseguimos observar células marcadas através de imunofluorescência mesmo utilizando altas concentrações do anticorpo primário. Sendo assim, duplas marcações não foram obtidas, porém esta hipótese deve ser melhor investigada.

Um outro neuromediador que foi pesquisado no CeA em nosso trabalho foi o óxido nítrico (NO). Segundo McDonald et al. (1993) e Usunoff et al. (2006), células nitrérgicas forma observadas em todos os núcleos da amígdala, com uma concentração moderada no CeA, principalmente em sua porção mais medial (Usunoff et al., 2006).

Na amígdala, a produção de NO parece aumentar em resposta ao estresse de exposição a um predador, ou em resposta ao estresse auditivo condicionado ou à privação de água (Guimarães et al., 2005; Sato et al., 2006; Yao et al., 2007). Porém estes aumentos foram verificados principalmente em outros núcleos da amígdala e não especificamente no CeA. Nosso estudo foi condizente coma literatura, pois verificamos células produtoras de NO em todos os núcleos da amígdala, porém com uma concentração bem menor no CeA. As células nitrérgicas se localizaram principalmente nas porções mediais do CeA, todavia, células duplamente marcadas não foram verificadas.

A LH há tempos vem sendo relacionada com movimentos mandibulares. Segundo Landgren e Olsson (1980), estímulos elétricos na LH de gatos anestesiados, provocam um aumento da freqüência cardíaca, além de uma grande facilitação do reflexo de elevação da mandíbula seguido de uma inibição do reflexo de abaixamento. Este mesmo estímulo em gatos não anestesiados levou a um comportamento de ataque ou defesa, com aumento da atenção, ereção dos pelos, dilatação das pupilas e o já citado aumento da freqüência cardíaca. Em concordância, Weiner et al. (1993) registraram, através de eletromiografia, a atividade muscular do masseter de gatos submetidos a estímulo elétrico de sítios na LH que produziam comportamento de ataque ou defesa e comparou estes dados com os obtidos com uma atividade que simulava a mastigação. $\mathrm{O}$ autor observou que a atividade muscular registrada com os estímulos na LH excedeu e muito a atividade registrada com a mastigação. 
Assim, sendo a LH uma região relacionada com comportamento de ataque ou defesa, é de se esperar que ela influencie ou provoque movimentos de abaixamento ou elevação mandibular. Parece, de acordo com a literatura, que os neurônios dessa região tendem a aumentar a atividade, principalmente dos motoneurônios de elevação.

A LH, também segundo Holstege (1995), faz juntamente com o BST e a amígdala parte do sistema motor emocional lateral, cujos axônios percorrem descendentemente a formação reticular próxima ao Mo5. Também, de acordo com Fort et al. (1990), conforme já citado, um pequeno número de células marcadas na $\mathrm{LH}$, principalmente na região perifornicial, foi verificada após injeção de CTb no Mo5.

Os nossos resultados mostram pequena quantidade de células na LH que foram observadas em todos os casos considerados bons, principalmente na região perifornicial, quantidade esta que aumentou pouco nos casos controle. Além disso, nos controles anterógrados foram observadas fibras ao redor e no interior do Mo5, algumas contendo aparentes terminais. Assim, semelhantemente ao IPAC, BST e CeA, acreditamos que a LH, tem conexões diretas com o Mo5, bem como com neurônios pré-motores da formação reticular e do Me5.

Como já colocado, a LH é a única região do encéfalo que contem neurônios produtores de orexina (de Lecea et al., 1998; Sakurai et al., 1998). Fibras desses neurônios foram encontradas no interior do Mo5, aparentemente fazendo múltiplas sinapses com os motoneurônios (Fung et al., 2001).

A orexina atua essencialmente em uma desordem do sono denominada narcolepsia, caracterizada por uma fragmentação do sono e por uma perda involuntária do tônus muscular denominada cataplexia que ocorre com o indivíduo acordado (Peever et al., 2003). Ainda segundo esses autores a orexina influenciaria a liberação pré-sináptica de neurônios glutamatérgicos no Mo5. Uma atuação indireta no Mo5 é descrita por Stoyanova e Lazarov (2005a) que detectaram abundante quantidade de fibras e aparentes terminais imunorreativos a ORX no Me5. Concordando com a literatura, verificamos em nosso estudo, após análise de dois níveis da LH, em 3 casos, que a maior parte das células duplamente marcadas (CTb/ORX) 31,1 +/- 4,4\% do total das células retrógradas localizam-se no nível 1, -3,1mm do bregma. No nível 2, -3,6mm do bregma, apenas 5,7 +/- 3\% das células retrógradas eram duplas. Desta forma parece haver um grupo específico de células orexinérgicas na LH que se projetam para o Mo5, o significado deste dado deve ser explorado futuramente. Nos casos Mo5D-7 e 9, o número de células retrógradas e duplas, nestes 
dois níveis, foi semelhante. Analisando estes dois casos, observamos semelhança entre as injeções. Já no caso Mo5D-10, tivemos um maior número de células retrogradamente marcadas, o que demonstra uma maior contaminação da região h pelo CTb. Porém, a porcentagem de células duplamente marcadas, neste caso, foi semelhante à porcentagem dos outros dois. Desta forma, sugerimos que as células que produzem ORX na LH se projetam de maneira proporcional para o Mo5 ou para a região h atuando de forma direta ou indireta sobre o Mo5.

Um outro núcleo no qual marcações em pequena quantidade foram obtidas em todos os casos, tanto de injeções boas como controles, sem grandes variações, foi o PVH. Não foram encontrados na literatura trabalhos que descrevessem conexões diretas ou indiretas do PVH com o Mo5. O PVH parece segundo Pyner e Coote (2000), ter conexões com núcleos autonômicos que regulam a função cardiovascular, além de conexões com neurônios prémotores da medula ventro-lateral rostral. Segundo Zheng et al. (1995), ele teria projeções diretas para o EW, núcleo parabraquial, NTS, núcleo dorsal motor do vago e para a medula espinal. O autor cita ainda uma conexão direta com o Sp5C. Hori et al. (2004) verificaram que após um estímulo estressante há um aumento do número de neurônios que expressam o CRF no PVH de ratos. Este número de neurônios diminui se durante o estímulo o rato puder morder um palito de madeira. Desta forma, segundo os autores, o ato de morder pode ter um efeito anti-estresse o que seria um caminho para explicar certas atividades mastigatória parafuncionais.

Observando nossas marcações acreditamos que existam essas conexões, principalmente de forma indireta do $\mathrm{PVH}$ com o Mo5 através da região h, e que provavelmente estas conexões estejam relacionadas com comportamentos emocionais nos quais seja alterado, por exemplo o rítmo cardíaco, diâmetro pupilar, freqüência respiratória, etc. Não observamos células imunorreativas ao CTb e CRF no PVH. Nos pareceu que as células retrogradamente marcadas se localizam mais cauldalmente em relação as células que expressam o CRF. Porém fibras CRF próximas à neurônios retrogradamente marcados foram verificados.

Uma outra marcação constante e uniforme tanto nos casos bons como nos controles, ocorreu no núcleo PSTh. Da mesma forma que no caso do PVH, não foram encontradas na literatura referências sobre conexões neuroanatômicas diretas ou indiretas do PSTh com o Mo5. Porém, Kawamura e Tsukamoto (1960a), realizaram estímulos elétricos na região medial do subtálamo de coelhos e obtiveram movimentos mastigatórios, muitas vezes 
associados a movimentos faciais. Estes movimentos foram principalmente de abaixamento mandibular semelhantemente aos obtidos com estímulo do córtex. Além disso, Parry et al. (1994), realizaram injeções de um agonista dopaminérgico no STh de ratos e notaram o surgimento dose-dependente de movimentos orofaciais anormais. Da mesma forma, Eberlewang et al. (1996), realizaram injeções no STh de ratos de um agonista da serotonina que age no receptor 5HT-2C. Estas injeções também levaram a movimentos orofaciais anormais. O PSTh está muito próximo ao STh, segundo Goto e Swanson, (2004), células mais rostrais do PSTh se confundem com as células do STh, desta forma, as injeções de agonistas dopaminérgicos e serotoninérgicos podem ter contaminado o PSTh e gerado os movimentos orofaciais. Ainda segundo os autores, o PSTh possui projeções moderadas para o Me5 influenciando de forma indireta o Mo5.

Assim, acreditamos que haja projeções neuroanatômicas diretas do PSTh para o Mo5, este núcleo provavelmente está relacionado à coordenação dos movimentos de abaixamento e elevação e também relacionado a respostas autonômicas, pois de acordo com nossas observações e conforme descrito por Goto e Swanson (2004) projeções maciças deste núcleo foram verificadas para o NTS.

Segundo Kawamura e Tsukamoto (1960b), estímulos do córtex cerebral motor levaram, principalmente, a movimentos de abaixamento da mandíbula, enquanto estímulos da amígdala levaram a movimentos de elevação. Além disso, os autores ainda afirmaram que estas duas regiões podem provocar movimentos mastigatórios de forma independente, pois provavelmente seguem caminhos diferentes até o Mo5. Segundo os autores, os neurônios corticais, assim como os localizados no subtálamo chegariam ao Mo5 através da formação reticular mesencefálica, onde poderia haver uma decussação de fibras, não passando pelo pedúnculo cerebral, pois movimentos foram obtidos mesmo com a destruição desta estrutura. Em relação aos neurônios da amígdala, os autores sugerem que o caminho não é o mesmo dos neurônios corticais ou subtalâmicos, porém as fibras também acabam chegando na formação reticular mesencefálica.

Nós acreditamos baseados na literatura e observando nossos casos que os axônios provenientes dos neurônios corticais e do PSTh (possivelmente também do STh), caminham pelo trato corticospinal, passando pela cápsula interna e deixando o trato antes do pedúnculo cerebral, atravessando a formação reticular mesencefálica e pontina até o Mo5.

Em relação ao BST, IPAC, CeA, LH e talvez o PVH, acreditamos que os axônios, de seus neurônios, chegam à formação reticular mesencefálica e pontina convergindo para o 
feixe prosencefálico medial localizado na LH, o que estaria de acordo com Saper et al. (1979), Nieuwenhuys et al. (1982) e Veening et al. (1982). 


\subsection{Considerações clínicas}

O nosso trabalho foi realizado em ratos, desta maneira, pretendemos neste capítulo apresentar apenas considerações e semear idéias comparando e discutindo dados clínicos com dados obtidos em estudos com animais.

Os motoneurônios do Mo5, atuam diretamente nos músculos da mastigação alterando seus tônus e provocando movimentos fisiológicos ou não. Desta forma, o Mo5 está relacionado às dores musculares decorrentes das dores intrarticulares da articulação temporomandibular (ATM), além das desordens motoras orofaciais, dentre elas, o bruxismo noturno, as discinesias e distonias orais.

A disfunção temporomandibular (DTM) é uma patologia multifatorial (Siqueira e Ching, 1999) que pode ter como origem fatores agudos ou crônicos. Como fatores agudos temos traumas diretos na ATM ou indiretos, por exemplo, no mento. Como fatores crônicos, temos, por exemplo, restaurações dentais que desrespeitam conceitos de forma e função ou o bruxismo noturno. Nos fatores agudos pode ocorrer um deslocamento do disco articular, normalmente para anterior e medial devido à ação do músculo pterigóideo lateral feixe superior, bem como a inflamação da cápsula articular. Se o deslocamento for grande o distúrbio poderá evoluir e o côndilo mandibular passará a pressionar a região retrodiscal bastante inervada e vascularizada (Dubrul, 1991) o que perpetuará a inflamação capsular e conseqüentemente a dor.

Em relação aos fatores crônicos, os primeiros componentes do sistema estomatognático a sofrerem serão os músculos mastigatórios e o primeiro sintoma será a dor muscular. No caso do bruxismo noturno, haverá um aumento do tônus muscular dos músculos de elevação da mandíbula, bem como do músculo ptergóideo lateral feixe superior que tem parte de sua inserção terminal no disco articular (Dubrul, 1991) e atua principalmente durante o apertamento dental tracionando o disco para anterior para que sua parte posterior, mais grossa, sirva como um calço, auxiliando o suporte das cargas mastigatórias e a estabilização da mandíbula (Okenson, 1998; Hiraba et al., 2000; Wang et al., 2001). Desta forma, com o tempo, poderá ocorrer um deslocamento do disco articular para anterior e o côndilo, assim como nos distúrbios com origem aguda, irá pressionar o tecido retrodiscal, o que levará a inflamação e dor.

Desta maneira, verificamos que nos dois casos a DTM poderá levar a dor intrarticular, o que provocará, segundo Sessle (1999), um reflexo muscular representado por um aumento da atividade tanto dos músculos de elevação quanto dos de abaixamento da mandibula na 
tentativa de funcionar como bloqueio, limitando a função. Esta teoria foi demonstrada em modelos animais nos quais constatou-se a ativação de neurônios no subnúcleo caudal espinal do trigêmeo (Sp5C) após injeção de irritante na ATM de ratos (Zhou et al., 1999), bem como um aumento da freqüência dos registros eletromiográficos em músculos de abaixamento e elevação mandibular (Tsai et al., 1999; Tambeli et al., 2001), freqüência esta que após diminuir, novamente aumenta com o uso de antagonistas do receptor $\mathrm{GABA}_{\mathrm{A}}$ (Seo et al., 2001) e diminuiu após lesão do Sp5C (Tsai et al., 1999).

Conforme LeResche et al. (1997), a procura por tratamento para DTMs aumenta em $77 \%$ para as mulheres que usam estrógeno suplementar após a menopausa e 19\% para as que utilizam contraceptivos orais. Em um estudo em animais, Tambeli et al. (2001) demostraram que os receptores opióides, principalmente o receptor $\mu$, modularia a ação do óleo de mostarda injetado na ATM, atuando no Sp5C. Flores et al. (2001) afirmaram que o estrógeno modularia o sistema opióide receptor no nível da medula espinal, porém o mecanismo de como o estrógeno regula este sistema opióide ainda não é conhecido.

Desta forma, verificamos que o Sp5C é um ponto chave para a transmissão de impulsos dolorosos no sistema nervoso central e para o aumento da atividade dos neurônios do Mo5, e além disso, o fato das mulheres serem o principal grupo a procurar tratamento para a DTM, pode estar relacionado a fatores hormonais como a ação do estrógeno, provavelmente atuando de forma antagônica aos receptores opióides no Sp5C.

Apesar do Sp5C parecer ter relação muito próxima ao Mo5, conexões diretas entre eles nunca foram descritas (Travers e Norgren, 1983; Grzanna et al., 1987; Fort et al., 1990; Turman et al., 1993; Li et al., 1995; Li et al., 1996; Yasui et al., 1997; Kolta et al., 2000; Luo et al., 2001; Yamamoto et al., 2007). Da mesma forma, nós não verificamos em nosso trabalho este tipo de conexão. Acreditamos, porém, que ela exista de forma indireta através de neurônios pré-motores localizados na PCRtA, no Su5 ou nos Sp5I, Sp5O, Pr5 ou ainda no núcleo parabraquial. Isto porque o Sp5C se projeta para a PCRtA (Zerari-Mailly et al., 2001), para o Su5 (Li et al., 1995), para os Sp5I, Sp5O e Pr5 (Nasution e Shigenaga, 1987) e para o núcleo parabraquial (Hiroshima et al., 2001), os quais emitem fibras para o Mo5 (Travers e Norgren, 1983; Grzanna et al., 1987; Fort et al., 1990; Turman et al., 1993; Li et al., 1995; Li et al., 1996; Yasui et al., 1997; Kolta et al., 2000; Luo et al., 2001; Yamamoto et al., 2007).

Segundo Clark (2006) as desordens motoras orofaciais, como o bruxismo noturno e as discinesia e distonias orais induzidas ou não por drogas, podem provocar dores de cabeça, destruição da ATM, além de criarem uma dificuldade no controle dos músculos mastigatórios 
podendo gerar perda de peso. As patofisiologias destas desordens motoras não são conhecidas.

O bruxismo noturno é uma desordem do sono, mediada pelo sistema nervoso central (Attanasio, 1991; Lobbezo e Naeije, 2001). Esta patologia parece estar ligada ao estresse ou ao uso de substâncias que afetam o metabolismo das catecolaminas, principalmente da dopamina (Winocur et al., 2003; Van der Zaag et al., 2007) além da serotonina (Winocur et al., 2003). Segundo Okenson et al. (1994), os batimentos cardíacos em humanos durante os episódios de bruxismo noturno aumentam em média 16,6\%. Lavigne et al. (2007), afirmam que a geração do bruxismo noturno esta relacionada a períodos do sono, denominados microdespertar, que ocorrem em todas as pessoas. Estes períodos ocorrem de 8 a 15 vezes por noite e duram 3 a 15 segundos. Nestes episódios, há uma mudança abrupta na atividade encefálica acompanhada de um aumento da taxa cardíaca e do tônus muscular. Os episódios de microdespertar ocorreriam para manter a homeostase e para uma certa vigilância, mesmo durante o sono. Assim, nos pacientes que apresentam bruxismo noturno há uma mudança da atividade cerebral registrada pelo eletroencefalograma seguida de um aumento dos batimentos cardíacos cerca de 1 segundo antes de se iniciar os movimentos mastigatórios. Portanto, nos parece que núcleos prosencefálicos que influenciem a taxa cardíaca e também se projetem para núcleos que controlam os movimentos mastigatórios devem participar da geração do bruxismo noturno. Após injeção de traçador retrógrado no Mo5 de ratos verificamos, no prosencéfalo, células retrogradamente marcadas, principalmente, no núcleo central da amígdala (CeA), na área hipotalâmica lateral (LH) e no núcleo parasubtalâmico (PSTh).

O CeA participa das respostas ao estresse (Valles et al., 2006), provocando alterações autonômicas, dentre elas as cardiovasculares (Heshmatian et al., 2007) devido às suas projeções para, por exemplo, o núcleo paraventricular do hipotálamo (PVH), para o núcleo do trato solitário (NTS) e para a medula ventrolateral. Além disso, o CeA atua diretamente no Mo5 ou indiretamente através da região h, possuindo também, grande eferência para o núcleo mesencefálico do trigêmeo (Me5), o qual controla indiretamente o Mo5. O CeA sofre influência da dopamina (Mascaro et al., 2005) e do fator liberador de corticotrofina (CRF) que tem sua expressão aumentada neste núcleo principalmente nas síndromes de abstinência a drogas como álcool, cocaína, opióides e canabinóides (Rodriguez de Fonseca et al., 1997).

A área hipotalâmica lateral (LH) é uma região relacionada a comportamentos de ataque e defesa (Weiner et al., 1993) que se projeta para núcleos pré-autonômicos (Ciriello et al., 2003; Larsen et al., 1994) também podendo influenciar no aumento do débito cardíaco observado nos períodos de micro-despertar logo antes do início dos episódios de bruxismo 
noturno. Segundo Larsen et al. (1994) a região perifornicial da LH se projetaria para áreas do PVH que possuem eferências descendentes atuando em núcleos pré-ganglionares do tronco encefálico e medula espinal. Porém, de acordo com o estudo eletrofisiológico de Smith et al. (1990), a região perifornicial da LH seria diretamente responsável pelo aumento do débito cardíaco em respostas emocionais e de defesa. Estímulos elétricos no PVH não geraram aumento do débito cardíaco, além disso, lesão no PVH não alterou o aumento do débito cardíaco provocado por estimulo elétrico da região perifornicial. Porém, lesão na LH restringiu bastante o aumento do débito. Neurônios da LH, são os únicos no sistema nervoso central a produzirem um neuromediador denominado hipocretina ou orexina (ORX) (de Lecea et al., 1998; Sakurai et al., 1998). A ORX inicialmente foi associada apenas a alterações do comportamento alimentar, posteriormente notou-se outros campos de atuação deste neuromediador e foi descrita a sua atuação decisiva na etiopatogenia da narcolepsia em ratos, cães e humanos, caracterizada por uma diminuição abrupta na quantidade dos neurônios produtores de ORX (Peyron et al., 2000; Thannickal et al., 2000; Siegel et al., 2001).Verificou-se também, a sua participação estimulando a medula rostral ventrolateral (Dun et al. 2000) o que gera um aumento do débito cardíaco, além de um efeito ansiogênico quando administrada intraventricularmente em ratos (Suzuki et al., 2005).

Em nosso trabalho, verificamos células retrogradamente, marcadas na LH, principalmente em sua porção perifornicial. Algumas destas células também são imunorreativas à (ORX). Portanto, a região perifornicial da LH poderia através dos neurônios orexinérgicos atuar na formação reticular do tronco encefálico iniciando a ativação do córtex nos episódios de microdespertar e simultaneamente atuar na medula rostral ventrolateral gerando um aumento do débito cardíaco. Além disso, neurônios orexinérgicos podem atuar no Mo5 diretamente (Fung et al., 2001) ou indiretamente através da região h ou do Me5 que recebe uma quantidade moderada de fibras imunorreativas à ORX, podendo participar da indução dos movimentos mastigatórios verificados no bruxismo noturno. Além disso, a região perifornicial da LH ainda possui eferências para o CeA (Touzani et al., 1996), e o CeA também se projeta para a LH (LeDoux et al., 1988) desta forma, estas duas áreas ainda podem atuar em conjunto.

Um outro núcleo interessante que pode participar das alterações dos movimentos mandibulares é o PSTh, descrito recentemente por Goto e Swanson (2004). O PSTh é um núcleo localizado entre a LH e o núcleo subtalâmico (STh). O STh é considerado como parte dos núcleos da base pois desempenha um papel muito importante no controle motor, estando diretamente relacionados a doenças como o mal de Parkinson. Lesões ou estímulos elétricos no STh auxiliam no controle dos tremores no Mal de Parkinson em macacos (Guridi et al., 
1996) e humanos (Kumar et al., 1998), e segundo Goto e Swanson, (2004), células mais rostrais do PSTh se confundem com as células do STh.

O PSTh, assim como o CeA e a LH, parece estar, segundo Goto e Swanson (2004) relacionado ao controle de núcleos autonômicos atuando no comando de glândulas como a lacrimal, as glândulas salivares, além de glândulas mucosas na cavidade nasal, palato, faringe, e laringe, atuando também no controle da musculatura lisa gastrointestinal e no músculo estriado cardíaco. Além disso, o PSTh participaria também do controle da motricidade orofacial atuando no campo retrorubral e no processamento de informações gustativas atuando no núcleo do trato solitário (NTS) e no núcleo parabraquial. Em nosso estudo, encontramos células retrogradamente marcadas no PSTh que se projetam, assim como o CeA e a LH, para o Mo5 de forma direta ou indireta pela região h ou pelo Me5. Verificamos projeções moderadas do PSTh para o Me5 o que concorda com Goto e Swanson (2004). Notamos ainda, que o PSTh sofre grande influência dopaminérgica (Mascaro et al., 2005).

O PSTh é um núcleo que não foi descrito em humanos, e devido as suas características hodológicas ele parece estar mais associado à LH que ao STh. Portanto, possivelmente, ele deve ter sido incorporado pela LH nos humanos. Acreditamos que o PSTh possa ter algum papel no bruxismo noturno, não como gerador desta patologia, mas atuando juntamente com a LH ou o CeA pois ele possui eferências para estes dois núcleos, sendo estas maciças para o último (Goto e Swanson, 2004; observação pessoal).

Portanto, em relação ao bruxismo noturno idiopático, ou seja, não relacionado ao uso de drogas lícitas ou ilícitas, acreditamos que ele possa ser inicialmente gerado na LH, com a participação da ORX, levando aos episódios de micro-despertar e ao aumento do débito cardíaco conforme descrito por Lavigne et al. (2007). O CeA pode ser ativado pela LH auxiliando na ativação de outros núcleos relacionados a respostas ao estresse como o PVH e atuando de forma conjunta com a LH no Mo5 e Me5. Um outra hipótese é que inicialmente o CeA seja ativado, com participação do CRF e que este núcleo ative a LH gerando os eventos já descritos. Acreditamos que o bruxismo possa ser também uma maneira que o organismo possui de alcançar a homeostase devido a alterações do nível de neurotransmissores relacionados ao estresse.

Em relação ao bruxismo provocado por drogas, podemos supor que qualquer substância que atue na LH, CeA ou PSTh, que talvez tenha sido incorporado pela LH em humanos, ou no Me5, na região h ou diretamente no Mo5 pode gerar movimentos mastigatórios. A dopamina, por exemplo, tem ação significativa em todos esse núcleos e diretamente no Mo5 (Mascaro et al. 2005) e gera um aumento do tônus do masseter (Sunden- 
Kuronen et al., 1983). A serotonina age na região perifornicial da LH (Kumar et al., 2007), além de atuar no Me5 (Copray et al., 1990) e diretamente no Mo5 (Nagase et al., 1997). Porém segundo Clark (2006), o bruxismo noturno induzido pelos antidepressivos inibidores da recaptação da serotonina seria bem mais discreto, gerando um aumento sustentado do tônus muscular dos músculos mastigatórios. Segundo Katakura e Chandler (1990), a serotonina agiria de forma modulatória nos motoneurônios trigeminais, principalmente facilitando a ação excitatória do glutamato.

Movimentos repetitivos e estereotipados é o que pode ocorrer com a mandíbula no caso das discinesias orais que podem ser idiopáticas, ocorrendo normalmente em pacientes idosos ou a chamada tardia, que ocorre meses depois do uso crônico de uma droga (Clark, 2006). Normalmente este tipo de patologia ocorre em pacientes que fazem uso de antagonistas dopaminérgicos, que são drogas antipsicóticas. Mais uma vez, observamos influência da alteração nos níveis de dopamina. A grande diferença entre as discinesias e o bruxismo noturno, além do padrão de movimento, é que nas discinesias o indivíduo está acordado. Assim, pode ocorrer agora a ação da dopamina nos núcleos da base e no córtex que poderá influenciar diretamente o Mo5.

Mais rara que as discinesias orais são as distonias que apresentam movimentos semelhantes às discinesias, porém, eles tendem a ser mais intermitentes, com contrações mais momentâneas e potentes, atuando principalmente nos músculos de abaixamento da mandíbula (Clark et al., 1993; Clark e Takeuchi, 1995; Clark, 2006). Normalmente não estão associadas ao uso de drogas, mas podem ocorrer após traumas encefálicos ou são genéticas (Clark, 2006).

Recentemente, Fride (2004a) detectou substâncias denominadas endocanabinóides no leite de ratas. Estas substâncias ativam receptores no sistema nervoso central que atuam de forma decisiva para o funcionamento da musculatura orofacial. Em humanos existe uma alteração em recém-nascidos denominada "nonorganic failure-to-thrive” (Fride, 2004b; Fride et al. 2005) que poderia ser traduzida como “falha não orgânica do desenvolvimento”, caracterizada por uma anormal perda de altura e peso. Acreditava-se que esta alteração estaria ligada a problemas psicosociais dos pais que negligenciariam a criança. Atualmente, há a hipótese desta alteração ocorrer devido a uma discreta disfunção encefálica que leva a um prejuízo da função oromotora impedindo a sucção ou a ingestão de leite pelo recém-nascido. Ainda segundo Fride et al. (2005), esta alteração está relacionada aos receptores para canabinóides do tipo 1 (CB1). Segundo Castañé et al. (2004), o bloqueio de receptores CB1 em ratos viciados em canabinóides na amígdala leva a movimentos mastigatórios. Desta 
forma, parece que os receptores CB1 devem atuar em neurônios pré-motores na amígdala e possivelmente em outros núcleos. Em nosso estudo não obtivemos boas marcações fluorescentes para os receptores CB1. Todavia, acreditamos que possam existir células no CeA que expressam o CB1 e projetam-se para Mo5. Esta hipótese, no entanto, deve ser melhor pesquisada utilizando outras metodologias de estudo. 


\section{CONCLUSÃO}

Cocluímos que:

- O núcleo motor do trigêmeo (Mo5) recebe aferências do tronco encefálico.

- Neurônios do núcleo central da amígdala (CeA), da área hipotalâmica lateral (LH) e do núcleo parasubtalâmico (PSTh) influenciam direta ou indiretamente o (Mo5) através dos pré-motoneurônios da região h e do núcleo mesencefálico do trigêmeo (Me5).

- Alguns neurônios do CeA que se projetam para o Mo5 recebem inervação de fibras imunorreativas ao fator liberador de corticotrofina (CRF) ou à tirosina hidroxilase.

- Alguns neurônios da LH que se projetam para o Mo5 são imunorreativos à orexina.

- Alguns neurônios do PSTh que se projetam para o Mo5 recebem inervação de fibras imunorreativas à tirosina hidroxilase.

- O Me5 recebe grande inervação do CeA e moderada da LH e do PSTh, possuindo, ainda, grande aferência de fibras imunorreativas ao CRF, à orexina e à tirosina hidroxilase.

- Os movimentos mandibulares podem ser modulados por projeções oriundas de núcleus prosencefálicos relacionados ao controle autonômico e de respostas ao estresse. 


\section{REFERÊNCIAS BIBLIOGRÁFICAS}

Agerberg G, Inkapool I. Craniomandibular disorders in an urban Swedish population. J Craniomandib Disord. 1990;4(3):154-64.

Attanasio R. Nocturnal bruxism and its clinical management. Dent Clin North Am. 1991;35(1):245-52.

Bassett A, Remick RA, Blasberg B. Tardive dyskinesia: an unrecognized cause of orofacial pain. Oral Surg Oral Med Oral Pathol. 1986;61(6):570-2.

Blanchet PJ, Rompre PH, Lavigne GJ, Lamarche C. Oral dyskinesia: a clinical overview. Int J Prosthodont. 2005;18(1):10-9.

Bobo EG, Bonvallet M. Amygdala and masseteric reflex. I. Facilitation, inhibition and diphasic modifications of the reflex, induced by localized amygdaloid stimulation. Electroencephalogr Clin Neurophysiol. 1975;39(4):329-39.

Breder CD, Smith WL, Raz A, Masferrer J, Seibert K, Needleman P, et al. Distribution and characterization of cyclooxygenase immunoreactivity in the ovine brain. J Comp Neurol. 1992;322(3):409-38.

Camparis CM, Siqueira JT. Sleep bruxism: clinical aspects and characteristics in patients with and without chronic orofacial pain. Oral Surg Oral Med Oral Pathol Oral Radiol Endod. 2006;101(2):188-93.

Card JP, Riley JN, Moore RY. The motor trigeminal nucleus of the rat: analysis of neuronal structure and the synaptic organization of noradrenergic afferents. J Comp Neurol. 1986;250(4):469-84.

Cassell MD, Gray TS, Kiss JZ. Neuronal architecture in the rat central nucleus of the amygdala: a cytological, hodological, and immunocytochemical study. J Comp Neurol. 1986;246(4):478-99.

Castane A, Maldonado R, Valverde O. Role of different brain structures in the behavioural expression of WIN 55,212-2 withdrawal in mice. Br J Pharmacol. 2004;142(8):1309-17.

Cavada C, Huisman AM, Kuypers HG. Retrograde double labeling of neurons: the combined use of horseradish peroxidase and diamidino yellow dihydrochloride (DY X 2HCl) compared 
with true blue and $\mathrm{DY} \mathrm{X} 2 \mathrm{HCl}$ in rat descending brainstem pathways. Brain Res. 1984;308(1):123-36.

Cavalcante JC, Canteras NS. Traçadores neuronais anterógrados. In Bittencourt JC, Elias CF. Métodos em neurociência. 1ed. São Paulo: Roca; 2007. p. 133-46.

Ciriello J, McMurray JC, Babic T, de Oliveira CV. Collateral axonal projections from hypothalamic hypocretin neurons to cardiovascular sites in nucleus ambiguus and nucleus tractus solitarius. Brain Res. 2003;991(1-2):133-41.

Clark GT. Medical management of oral motor disorders: dystonia, dyskinesia and druginduced dystonic extrapyramidal reactions. J Calif Dent Assoc. 2006;34(8):657-67.

Clark GT, Koyano K, Browne PA. Oral motor disorders in humans. J Calif Dent Assoc. 1993;21(1):19-30.

Clark GT, Takeuchi H. Temporomandibular dysfunction, chronic orofacial pain and oral motor disorders in the 21st century. J Calif Dent Assoc. 1995;23(4):41-2, 44-6, 48-50.

Copray JC, Ter Horst GJ, Liem RS, van Willigen JD. Neurotransmitters and neuropeptides within the mesencephalic trigeminal nucleus of the rat: an immunohistochemical analysis. Neuroscience. 1990;37(2):399-411.

Dawson TM, Bredt DS, Fotuhi M, Hwang PM, Snyder SH. Nitric oxide synthase and neuronal NADPH diaphorase are identical in brain and peripheral tissues. Proc Natl Acad Sci. U S A 1991;88(17):7797-801.

De Kanter RJ, Truin GJ, Burgersdijk RC, Van 't Hof MA, Battistuzzi PG, Kalsbeek H, et al. Prevalence in the Dutch adult population and a meta-analysis of signs and symptoms of temporomandibular disorder. J Dent Res. 1993;72(11):1509-18.

de Lacalle S, Hersh LB, Saper CB. Cholinergic innervation of the human cerebellum. J Comp Neurol. 1993;328(3):364-76.

de Lecea L, Kilduff TS, Peyron C, Gao X, Foye PE, Danielson PE, et al. The hypocretins: hypothalamus-specific peptides with neuroexcitatory activity. Proc Natl Acad Sci U S A. 1998;95(1):322-7.

Dubrul, EL. Anatomia oral de Sicher e Dubrul. 8.ed. São Paulo: Artes Médicas; 1991. p. 25575. 
Duckro PN, Tait RC, Margolis RB, Deshields TL. Prevalence of temporomandibular symptoms in a large United States metropolitan area. Cranio. 1990;8(2):131-8.

Dun NJ, Le Dun S, Chen CT, Hwang LL, Kwok EH, Chang JK. Orexins: a role in medullary sympathetic outflow. Regul Pept. 2000;96(1-2):65-70.

Eberle-Wang K, Lucki I, Chesselet MF. A role for the subthalamic nucleus in 5-HT2Cinduced oral dyskinesia. Neuroscience. 1996;72(1):117-28.

Eliava M, Yilmazer-Hanke D, Asan E. Interrelations between monoaminergic afferents and corticotropin-releasing factor-immunoreactive neurons in the rat central amygdaloid nucleus: ultrastructural evidence for dopaminergic control of amygdaloid stress systems. Histochem Cell Biol. 2003;120(3):183-97.

Ferreira, ABH. Aurélio século XXI-dicionário da língua portuguesa. 3.ed. Rio de Janeiro: Nova Fronteira; 1999.2128p.

Flores CA, Wang XM, Zhang KM, Mokha SS. Orphanin FQ produces gender-specific modulation of trigeminal nociception: behavioral and electrophysiological observations. Neuroscience. 2001;105(2):489-98.

Fort P, Luppi PH, Sakai K, Salvert D, Jouvet M. Nuclei of origin of monoaminergic, peptidergic, and cholinergic afferents to the cat trigeminal motor nucleus: a double-labeling study with cholera-toxin as a retrograde tracer. J Comp Neurol. 1990;301(2):262-75.

Fride E. The endocannabinoid-CB(1) receptor system in pre- and postnatal life. Eur J Pharmacol. 2004;500(1-3):289-97.

Fride E. The endocannabinoid-CB receptor system: Importance for development and in pediatric disease. Neuro Endocrinol Lett. 2004;25(1-2):24-30.

Fride E, Bregman T, Kirkham TC. Endocannabinoids and food intake: newborn suckling and appetite regulation in adulthood. Exp Biol Med (Maywood). 2005;230(4):225-34.

Fung SJ, Yamuy J, Sampogna S, Morales FR, Chase MH. Hypocretin (orexin) input to trigeminal and hypoglossal motoneurons in the cat: a double-labeling immunohistochemical study. Brain Res. 2001;903(1-2):257-62. 
Goto M, Swanson LW. Axonal projections from the parasubthalamic nucleus. J Comp Neurol. 2004;469(4):581-607.

Grzanna R, Chee WK, Akeyson EW. Noradrenergic projections to brainstem nuclei: evidence for differential projections from noradrenergic subgroups. J Comp Neurol. 1987;263(1):7691.

Guimaraes FS, Beijamini V, Moreira FA, Aguiar DC, de Lucca AC. Role of nitric oxide in brain regions related to defensive reactions. Neurosci Biobehav Rev. 2005;29(8):1313-22.

Guler N, Yatmaz PI, Ataoglu H, Emlik D, Uckan S. Temporomandibular internal derangement: correlation of MRI findings with clinical symptoms of pain and joint sounds in patients with bruxing behaviour. Dentomaxillofac Radiol. 2003;32(5):304-10.

Guridi J, Herrero MT, Luquin MR, Guillen J, Ruberg M, Laguna J, et al. Subthalamotomy in parkinsonian monkeys. Behavioural and biochemical analysis. Brain. 1996;119 ( Pt 5):171727.

Hasegawa Y, Ono T, Hori K, Nokubi T. Influence of human jaw movement on cerebral blood flow. J Dent Res. 2007;86(1):64-8.

Herkenham M, Lynn AB, Johnson MR, Melvin LS, de Costa BR, Rice KC. Characterization and localization of cannabinoid receptors in rat brain: a quantitative in vitro autoradiographic study. J Neurosci. 1991;11(2):563-83.

Heshmatian B, Parviz M, Karimian SM, Keshavarz M, Sohanaki H. Cardiovascular response to renin substrate microinjection into the central nucleus of the amygdala of rats. Neuroreport. 2007;18(7):675-8.

Hiraba K, Hibino K, Hiranuma K, Negoro T. EMG activities of two heads of the human lateral pterygoid muscle in relation to mandibular condyle movement and biting force. $\mathrm{J}$ Neurophysiol 2000;83(4):2120-37.

Hiroshima K, Maeda T, Hanada K, Wakisaka S. Temporal and spatial distribution of Fos protein in the parabrachial nucleus neurons during experimental tooth movement of the rat molar. Brain Res. 2001;908(2):161-73.

Holstege G. The Basic, somatic and emotional component of the motor system in mammals. In: Paxinos G. The rat nervous system. 2. ed. San Diego: Academic Press; 1995. p.137-154. 
Hope BT, Michael GJ, Knigge KM, Vincent SR. Neuronal NADPH diaphorase is a nitric oxide synthase. Proc Natl Acad Sci U S A. 1991;88(7):2811-4.

Hori N, Yuyama N, Tamura K. Biting suppresses stress-induced expression of corticotropinreleasing factor (CRF) in the rat hypothalamus. J Dent Res. 2004;83(2):124-8.

Katakura N, Chandler SH. An iontophoretic analysis of the pharmacologic mechanisms responsible for trigeminal motoneuronal discharge during masticatory-like activity in the guinea pig. J Neurophysiol. 1990;63(2):356-69.

Kawamura Y, Tsukamoto S. Analysis of jaw movements from the cortical jaw motor area and amygdala. Jpn J Physiol. 1960;10:471-88.

Kawamura Y, Tsukamoto S. Neural descending pathways from the cortical jaw motor area and amygdaloid nucleus to jaw muscles. Jpn J Physiol. 1960;10:489-98.

Knapska E, Nikolaev E, Boguszewski P, Walasek G, Blaszczyk J, Kaczmarek L, et al. Between-subject transfer of emotional information evokes specific pattern of amygdala activation. Proc Natl Acad Sci U S A. 2006;103(10):3858-62.

Koganemaru M, Takasaki M, Nishimori T. Simultaneous activation of N-methyl-D-aspartate and neurokinin-1 receptors modulates c-Fos and Zif/268 expression in the rat trigeminal nucleus caudalis. Neuroscience. 2000;98(2):317-23.

Kolta A. In vitro investigation of synaptic relations between interneurons surrounding the trigeminal motor nucleus and masseteric motoneurons. J Neurophysiol. 1997;78(3):1720-5.

Kolta A, Westberg KG, Lund JP. Identification of brainstem interneurons projecting to the trigeminal motor nucleus and adjacent structures in the rabbit. $\mathrm{J}$ Chem Neuroanat. 2000;19(3):175-95.

Kowada K, Kawarada K, Matsumoto N. Conditioning stimulation of the central amygdaloid nucleus inhibits the jaw-opening reflex in the cat. Jpn J Physiol. 1992;42(3):443-58.

Kruse MN, Erdman SL, Puri G, de Groat WC. Differences in Fluorogold and wheat germ agglutinin-horseradish peroxidase labelling of bladder afferent neurons. Brain Res. 1993;613(2):352-6. 
Kumar R, Lozano AM, Kim YJ, Hutchison WD, Sime E, Halket E, et al. Double-blind evaluation of subthalamic nucleus deep brain stimulation in advanced Parkinson's disease. Neurology. 1998;51(3):850-5.

Kumar S, Szymusiak R, Bashir T, Rai S, McGinty D, Alam MN. Effects of serotonin on perifornical-lateral hypothalamic area neurons in rat. Eur J Neurosci. 2007;25(1):201-12.

Landgren S, Olsson KA. The effect of electrical stimulation in the hypothalamus on the monosynaptic jaw closing and the disynaptic jaw opening reflexes in the cat. Exp Brain Res. 1980;39(4):389-400.

Larsen PJ, Hay-Schmidt A, Mikkelsen JD. Efferent connections from the lateral hypothalamic region and the lateral preoptic area to the hypothalamic paraventricular nucleus of the rat. $\mathrm{J}$ Comp Neurol. 1994;342(2):299-319.

Lavigne GJ, Huynh N, Kato T, Okura K, Adachi K, Yao D, et al. Genesis of sleep bruxism: motor and autonomic-cardiac interactions. Arch Oral Biol. 2007;52(4):381-4.

LeDoux JE, Iwata J, Cicchetti P, Reis DJ. Different projections of the central amygdaloid nucleus mediate autonomic and behavioral correlates of conditioned fear. J Neurosci. 1988;8(7):2517-29.

LeResche L, Saunders K, Von Korff MR, Barlow W, Dworkin SF. Use of exogenous hormones and risk of temporomandibular disorder pain. Pain. 1997;69(1-2):153-60.

Li YQ, Takada M, Kaneko T, Mizuno N. Premotor neurons for trigeminal motor nucleus neurons innervating the jaw-closing and jaw-opening muscles: differential distribution in the lower brainstem of the rat. J Comp Neurol. 1995;356(4):563-79.

Li YQ, Takada M, Kaneko T, Mizuno N. GABAergic and glycinergic neurons projecting to the trigeminal motor nucleus: a double labeling study in the rat. J Comp Neurol. 1996;373(4):498-510.

Lobbezoo F, Naeije M. Bruxism is mainly regulated centrally, not peripherally. J Oral Rehabil. 2001;28(12):1085-91.

Lund JP, Kolta A, Westberg KG, Scott G. Brainstem mechanisms underlying feeding behaviors. Curr Opin Neurobiol. 1998;8(6):718-24. 
Luo P, Moritani M, Dessem D. Jaw-muscle spindle afferent pathways to the trigeminal motor nucleus in the rat. J Comp Neurol. 2001;435(3):341-53.

Luppi PH, Fort P, Jouvet M. Iontophoretic application of unconjugated cholera toxin B subunit (CTb) combined with immunohistochemistry of neurochemical substances: a method for transmitter identification of retrogradely labeled neurons. Brain Res. 1990;534(1-2):20924.

Martin DS, Egland MC, Barnes LU, Vogel EM. Adrenergic nerves mediate the venoconstrictor response to PVN stimulation. Brain Res. 2006;1076(1):93-100.

Mascaro M. Estudo sistemático das aferências do núcleo motor do trigêmeo [Dissertação (Mestrado em Anatomia Humana)]. São Paulo: Instituto de Ciências Biomédicas da Universidade de São Paulo; 2002.

Mascaro MB, Bittencourt JC, Casatti CA, Elias CF. Alternative pathways for catecholamine action in oral motor control. Neurosci Lett. 2005;386(1):34-9.

McDonald AJ, Payne DR, Mascagni F. Identification of putative nitric oxide producing neurons in the rat amygdala using NADPH-diaphorase histochemistry. Neuroscience. 1993;52(1):97-106.

Mizuno N, Konishi A, Sato M. Localization of masticatory motoneurons in the cat and rat by means of retrograde axonal transport of horseradish peroxidase. J Comp Neurol. 1975;164(1):105-15.

Mizuno N, Matsuda K, Iwahori N, Uemura-Sumi M, Kume M, Matsushima R. Representation of the masticatory muscles in the motor trigeminal nucleus of the macaque monkey. Neurosci. Lett 1981;21(1):19-22.

Mogoseanu D, Smith AD, Bolam JP. Monosynaptic innervation of trigeminal motor neurones involved in mastication by neurones of the parvicellular reticular formation. J Comp Neurol. 1993;336(1):53-65.

Molina OF, dos Santos J, Nelson SJ, Nowlin T. A clinical study of specific signs and symptoms of CMD in bruxers classified by the degree of severity. Cranio. 1999;17(4):268-79.

Nagase Y, Moritani M, Nakagawa S, Yoshida A, Takemura M, Zhang LF, et al. Serotonergic axonal contacts on identified cat trigeminal motoneurons and their correlation with medullary raphe nucleus stimulation. J Comp Neurol. 1997;384(3):443-55. 
Nasution ID, Shigenaga Y. Ascending and descending internuclear projections within the trigeminal sensory nuclear complex. Brain Res. 1987;425(2):234-47.

Nieuwenhuys R, Geeraedts LM, Veening JG. The medial forebrain bundle of the rat. I. General introduction. J Comp Neurol. 1982;206(1):49-81.

Nitecka L, Ben-Ari Y. Distribution of GABA-like immunoreactivity in the rat amygdaloid complex. J Comp Neurol. 1987;266(1):45-55.

Novikov LN. Labeling of central projections of primary afferents in adult rats: a comparison between biotinylated dextran amine, neurobiotin and Phaseolus vulgaris-leucoagglutinin. J Neurosci Methods. 2001;112(2):145-54.

Novikova L, Novikov L, Kellerth JO. Persistent neuronal labeling by retrograde fluorescent tracers: a comparison between Fast Blue, Fluoro-Gold and various dextran conjugates. J Neurosci Methods. 1997;74(1):9-15.

Okenson JP. Orofacial Pain. Chicago: Quintessence Publishing Co; 1998. p. 1-14; 113-58.

Okeson JP, Phillips BA, Berry DT, Baldwin RM. Nocturnal bruxing events: a report of normative data and cardiovascular response. J Oral Rehabil. 1994;21(6):623-30.

Orlando S. O Bruxismo está à solta. RBO., 2000; 57:308-11.

Osborne TE, Grace EG, Schwartz MK. Severe degenerative changes of the temporomandibular joint secondary to the effects of tardive dyskinesia: a literature review and case report. Cranio. 1989;7(1):58-62.

Parry TJ, Eberle-Wang K, Lucki I, Chesselet MF. Dopaminergic stimulation of subthalamic nucleus elicits oral dyskinesia in rats. Exp Neurol. 1994;128(2):181-90.

Paxinos G. The rat nervous system. 2.ed. San Diego: Academic Press; 1995.

Paxinos G, Watson C. The rat brain in stereotaxic coordinates. 40.ed. San Diego: Academic Press; 1998.

Peever JH, Lai YY, Siegel JM. Excitatory effects of hypocretin-1 (orexin-A) in the trigeminal motor nucleus are reversed by NMDA antagonism. J Neurophysiol. 2003;89(5):2591-600. 
Peyron C, Faraco J, Rogers W, Ripley B, Overeem S, Charnay Y, et al. A mutation in a case of early onset narcolepsy and a generalized absence of hypocretin peptides in human narcoleptic brains. Nat Med. 2000;6(9):991-7.

Pieribone VA, Aston-Jones G. The iontophoretic application of Fluoro-Gold for the study of afferents to deep brain nuclei. Brain Res. 1988;475(2):259-71.

Potter E, Sutton S, Donaldson C, Chen R, Perrin M, Lewis K, et al. Distribution of corticotropin-releasing factor receptor mRNA expression in the rat brain and pituitary. Proc Natl Acad Sci U S A. 1994;91(19):8777-81.

Prewitt CM, Herman JP. Anatomical interactions between the central amygdaloid nucleus and the hypothalamic paraventricular nucleus of the rat: a dual tract-tracing analysis. J Chem Neuroanat. 1998;15(3):173-85.

Pyner S, Coote JH. Identification of branching paraventricular neurons of the hypothalamus that project to the rostroventrolateral medulla and spinal cord. Neuroscience. 2000;100(3):549-56.

Rauhala K, Oikarinen KS, Raustia AM. Role of temporomandibular disorders (TMD) in facial pain: occlusion, muscle and TMJ pain. Cranio. 1999;17(4):254-61.

Reiner A, Veenman CL, Medina L, Jiao Y, Del Mar N, Honig MG. Pathway tracing using biotinylated dextran amines. J Neurosci Methods. 2000;103(1):23-37.

Reyes BA, Valentino RJ, Xu G, Van Bockstaele EJ. Hypothalamic projections to locus coeruleus neurons in rat brain. Eur J Neurosci. 2005;22(1):93-106.

Ribeiro-do-Valle LE, Metzler CW, Jacobs BL. Facilitation of masseter EMG and masseteric (jaw-closure) reflex by serotonin in behaving cats. Brain Res. 1991;550(2):197-204.

Richmond FJ, Gladdy R, Creasy JL, Kitamura S, Smits E, Thomson DB. Efficacy of seven retrograde tracers, compared in multiple-labelling studies of feline motoneurones. J Neurosci Methods. 1994;53(1):35-46.

Rodriguez de Fonseca F, Carrera MR, Navarro M, Koob GF, Weiss F. Activation of corticotropin-releasing factor in the limbic system during cannabinoid withdrawal. Science. 1997;276(5321):2050-4. 
Ruangsri S, Whittle T, Wanigaratne K, Murray GM. Functional activity of superior head of human lateral pterygoid muscle during isometric force. J Dent Res. 2005;84(6):548-53.

Sakanaka M, Shibasaki T, Lederis K. Distribution and efferent projections of corticotropinreleasing factor-like immunoreactivity in the rat amygdaloid complex. Brain Res. 1986;382(2):213-38.

Sakurai T, Amemiya A, Ishii M, Matsuzaki I, Chemelli RM, Tanaka H, et al. Orexins and orexin receptors: a family of hypothalamic neuropeptides and $\mathrm{G}$ protein-coupled receptors that regulate feeding behavior. Cell. 1998;92(5):1 page following 696.

Saper CB, Swanson LW, Cowan WM. An autoradiographic study of the efferent connections of the lateral hypothalamic area in the rat. J Comp Neurol. 1979;183(4):689-706.

Sato T, Suzuki E, Yokoyama M, Watanabe S, Miyaoka H. Auditory fear conditioning and conditioned stress raise NO(3) level in the Amygdala. Neuropsychobiology. 2006;53(3):1427.

Schmued LC, Fallon JH. Fluoro-Gold: a new fluorescent retrograde axonal tracer with numerous unique properties. Brain Res. 1986;377(1):147-54.

Seo K, Hu JW, Cairns BE, Someya G. Involvement of GABA(A) receptor in modulation of jaw muscle activity evoked by mustard oil application to the rat temporomandibular joint. Brain Res. 2001;892(1):198-202.

Sessle BJ. The neural basis of temporomandibular joint and masticatory muscle pain. J Orofac Pain. 1999;13(4):238-45.

Shammah-Lagnado SJ, Alheid GF, Heimer L. Striatal and central extended amygdala parts of the interstitial nucleus of the posterior limb of the anterior commissure: evidence from tracttracing techniques in the rat. J Comp Neurol. 2001;439(1):104-26.

Shigenaga Y, Hirose Y, Yoshida A, Fukami H, Honma S, Bae YC. Quantitative ultrastructure of physiologically identified premotoneuron terminals in the trigeminal motor nucleus in the cat. J Comp Neurol. 2000;426(1):13-30.

Siegel JM, Moore R, Thannickal T, Nienhuis R. A brief history of hypocretin/orexin and narcolepsy. Neuropsychopharmacology. 2001;25(5 Suppl):S14-20. 
Siqueira JTTC, Ching LH. Dor orofacial/ATM: Bases para o diagnóstico clínico. Curitiba: Maio; 1999. 283 p.

Smith OA, DeVito JL, Astley CA. Neurons controlling cardiovascular responses to emotion are located in lateral hypothalamus-perifornical region. Am J Physiol. 1990;259(5 Pt 2):R94354.

Stoyanova, II, Lazarov NE. Localization of orexin-A-immunoreactive fibers in the mesencephalic trigeminal nucleus of the rat. Brain Res. 2005;1054(1):82-7.

Stoyanova, II, Lazarov NE. Localization of nitric oxide synthase in rat trigeminal primary afferent neurons using NADPH-diaphorase histochemistry. J Mol Histol. 2005;36(3):187-93.

Sunden-Kuronen B, Pohto P, Alanen E. Influence of central dopaminergic and oral sensory stimulation on the tone of the rat masseter muscle. Acta Odontol Scand. 1983;41(3):159-66.

Suzuki M, Beuckmann CT, Shikata K, Ogura H, Sawai T. Orexin-A (hypocretin-1) is possibly involved in generation of anxiety-like behavior. Brain Res. 2005;1044(1):116-21.

Szentpetery A, Huhn E, Fazekas A. Prevalence of mandibular dysfunction in an urban population in Hungary. Community Dent Oral Epidemiol. 1986;14(3):177-80.

Takemura M, Shimada T, Shigenaga Y. GABA B receptor-mediated effects on expression of c-Fos in rat trigeminal nucleus following high- and low-intensity afferent stimulation. Neuroscience. 2001;103(4):1051-8.

Takeuchi Y, Satoda T, Matsushima R. Amygdaloid projections to commissural interneurons for masticatory motoneurons. Brain Res Bull. 1988;21(1):123-7.

Tambeli CH, Seo K, Sessle BJ, Hu JW. Central mu opioid receptor mechanisms modulate mustard oil-evoked jaw muscle activity. Brain Res. 2001;913(1):90-4.

Thannickal TC, Moore RY, Nienhuis R, Ramanathan L, Gulyani S, Aldrich M, et al. Reduced number of hypocretin neurons in human narcolepsy. Neuron. 2000;27(3):469-74.

Touzani K, Taghzouti K, Velley L. Cellular organization of lateral hypothalamic efferents to the central amygdaloid nucleus of the rat. Neuroreport. 1996;7(2):517-20. 
Travers JB. Oromotor nuclei. In: Paxinos G. The rat nervous system. 2. ed. San Diego: Academic Press; 1995. p.239-42.

Travers JB, Norgren R. Afferent projections to the oral motor nuclei in the rat. J Comp Neurol. 1983;220(3):280-98.

Trojanowski JQ, Gonatas JO, Gonatas NK. Horseradish peroxidase (HRP) conjugates of cholera toxin and lectins are more sensitive retrogradely transported markers than free HRP. Brain Res. 1982;231(1):33-50.

Tsai C. The caudal subnucleus caudalis (medullary dorsal horn) acts as an interneuronal relay site in craniofacial nociceptive reflex activity. Brain Res. 1999;826(2):293-7.

Tsai CM, Chiang CY, Yu XM, Sessle BJ. Involvement of trigeminal subnucleus caudalis (medullary dorsal horn) in craniofacial nociceptive reflex activity. Pain. 1999;81(1-2):115-28.

Turman JE, Jr., Chandler SH. Immunohistochemical localization of glutamate and glutaminase in guinea pig trigeminal premotoneurons. Brain Res. 1994;634(1):49-61.

Uemura-Sumi M, Takahashi O, Matsushima R, Takata M, Yasui Y, Mizuno N. Localization of masticatory motoneurons in the trigeminal motor nucleus of the guinea pig. Neurosci Lett. 1982;29(3):219-24.

Usunoff KG, Itzev DE, Rolfs A, Schmitt O, Wree A. Nitric oxide synthase-containing neurons in the amygdaloid nuclear complex of the rat. Anat Embryol (Berl). 2006;211(6):72137.

Valles A, Marti O, Armario A. Long-term effects of a single exposure to immobilization stress on the hypothalamic-pituitary-adrenal axis: transcriptional evidence for a progressive desensitization process. Eur J Neurosci. 2003;18(6):1353-61.

Valles A, Marti O, Armario A. Long-term effects of a single exposure to immobilization: A C-fos mRNA study of the response to the homotypic stressor in the rat brain. J Neurobiol. 2006;66(6):591-602.

Van der Zaag J, Lobbezoo F, Van der Avoort PG, Wicks DJ, Hamburger HL, Naeije M. Effects of pergolide on severe sleep bruxism in a patient experiencing oral implant failure. $\mathrm{J}$ Oral Rehabil. 2007;34(5):317-22. 
Veening JG, Swanson LW, Cowan WM, Nieuwenhuys R, Geeraedts LM. The medial forebrain bundle of the rat. II. An autoradiographic study of the topography of the major descending and ascending components. J Comp Neurol. 1982;206(1):82-108.

Waite PME, Tracey DJ. Trigeminal sensory system. In: Paxinos, G. The rat nervous system. 2. ed. San Diego: Academic Press; 1995. p.705-24.

Wan XC, Trojanowski JQ, Gonatas JO. Cholera toxin and wheat germ agglutinin conjugates as neuroanatomical probes: their uptake and clearance, transganglionic and retrograde transport and sensitivity. Brain Res. 1982;243(2):215-24.

Wang MQ, Yan CY, Yuan YP. Is the superior belly of the lateral pterygoid primarily a stabilizer? An EMG study. J Oral Rehabil. 2001;28(6):507-10.

Weiner S, Shaikh MB, Siegel A. Electromyographic activity in the masseter muscle resulting from stimulation of hypothalamic behavioral sites in the cat. J Orofac Pain. 1993;7(4):370-7.

Winocur E, Gavish A, Voikovitch M, Emodi-Perlman A, Eli I. Drugs and bruxism: a critical review. J Orofac Pain. 2003;17(2):99-111.

Yamamoto M, Moritani M, Chang Z, Taki I, Tomita A, Ono T, et al. The somatotopic organization of trigeminal premotoneurons in the cat brainstem. Brain Res. 2007.

Yao ST, Antunes VR, Paton JF, Murphy D. Osmotic regulation of neuronal nitric oxide synthase expression in the rat amygdala: functional role for nitric oxide in adaptive responses? J Neurosci Res. 2007;85(2):410-22.

Yasui Y, Tsumori T, Ono K, Kishi T. Nigral axon terminals are in contact with parvicellular reticular neurons which project to the motor trigeminal nucleus in the rat. Brain Res 1997;775(1-2):219-24.

Zerari-Mailly F, Pinganaud G, Dauvergne C, Buisseret P, Buisseret-Delmas C. Trigeminoreticulo-facial and trigemino-reticulo-hypoglossal pathways in the rat. J Comp Neurol. 2001;429(1):80-93.

Zheng JQ, Seki M, Hayakawa T, Ito H, Zyo K. Descending projections from the paraventricular hypothalamic nucleus to the spinal cord: anterograde tracing study in the rat. Okajimas Folia Anat Jpn. 1995;72(2-3):119-35. 
Zhou Q, Imbe H, Dubner R, Ren K. Persistent Fos protein expression after orofacial deep or cutaneous tissue inflammation in rats: implications for persistent orofacial pain. J Comp Neurol. 1999;412(2):276-91. 


\begin{abstract}
ANEXO
Mascaro MB, Bittencourt JC, Casatti CA, Elias CF. Alternative pathways for catecholamine action in oral motor control. Neurosci Lett 2005;386(1):34-9.
\end{abstract}




\title{
Alternative pathways for catecholamine action in oral motor control
}

\author{
Marcelo Betti Mascaro ${ }^{\mathrm{a}, \mathrm{b}, *}$, Jackson Cioni Bittencourt ${ }^{\mathrm{a}, \mathrm{c}}$, \\ Cláudio Aparecido Casatti ${ }^{\mathrm{d}}$, Carol Fuzeti Elias ${ }^{\mathrm{a}, \mathrm{c}}$ \\ a Laboratory of Chemical Neuroanatomy, Department of Anatomy, Institute of Biomedical Sciences, \\ University of São Paulo - USP, Av. Prof. Lineu Prestes, 2415 Ed. B-III, 05508-900 São Paulo, SP, Brazil \\ ${ }^{\mathrm{b}}$ Nove de Julho University Center - UNINOVE, 01156-050 São Paulo, Brazil \\ ${ }^{\mathrm{c}}$ Center for Neuroscience and Behavior, Institute of Psychology, University of São Paulo - USP, 05508-900 São Paulo, Brazil \\ ${ }^{d}$ Department of Basic Sciences, Dentistry School of University of São Paulo State - UNESP 16015-050, Araçatuba, SP, Brazil
}

Received 24 March 2005; received in revised form 19 May 2005; accepted 19 May 2005

\begin{abstract}
Orofacial movement is a complex function performed by facial and jaw muscles. Jaw movement is enacted through the triggering of motoneurons located primarily in the trigeminal motor nucleus (Mo5). The Mo5 is located in the pontine reticular formation, which is encircled by premotor neurons. Previous studies using retrograde tracers have demonstrated that premotor neurons innervating the Mo5 are distributed in brainstem areas, and electrophysiological studies have suggested the existence of a subcortical relay in the corticofugal-Mo5 pathway. Various neurotransmitters have been implicated in oral movement. Dopamine is of special interest since its imbalance may produce changes in basal ganglia activity, which generates abnormal movements, including jaw motor dysfunction, as in oral dyskinesia and possibly in bruxism. However, the anatomical pathways connecting the dopaminergic systems with Mo5 motoneurons have not been studied systematically. After injecting retrograde tracer fluorogold into the Mo5, we observed retrograde-labeled neurons in brainstem areas and in a few forebrain nuclei, such as the central nucleus of the amygdala, and the parasubthalamic nucleus. By using dual-labeled immunohistochemistry, we found tyrosine hydroxylase (a catecholamine-processing enzyme) immunoreactive fibers in close apposition to retrograde-labeled neurons in brainstem nuclei, in the central nucleus of the amygdala and the parasubthalamic nucleus, suggesting the occurrence of synaptic contacts. Therefore, we suggested that catecholamines may regulate oralfacial movements through the premotor brainstem nuclei, which are related to masticatory control, and forebrain areas related to autonomic and stress responses.
\end{abstract}

(c) 2005 Elsevier Ireland Ltd. All rights reserved.

Keywords: Tyrosine hydroxylase; Dopamine; Mastication; Central nucleus of amygdala; Parasubthalamic nucleus; Oral dyskinesia

Orofacial movement is a complex function performed by facial and jaw muscles. Jaw movement is enacted through the triggering of motoneurons located primarily in the trigeminal motor nucleus (Mo5). The Mo5 is localized in the lateral pontine reticular formation surrounded by a ring of premotor neurons [20]. Employing injection of neuronal tracers, authors have described the distribution of premotor neurons innervating the Mo5 in a variety of brainstem nuclei $[20,32]$. In addition, studies have shown that electrical stimulation of the amygdala and the area close to the internal capsule induces jaw movement [19].

\footnotetext{
* Corresponding author. Tel.: +55 11 30917396x22; fax: $+551130917396 \times 24$.

E-mail address: mmcelo@usp.br (M.B. Mascaro).
}

Various neurotransmitters have been implicated in this function [23,33]. Among them, dopamine is of special interest since abnormal oral movements have been observed in complex disorders associated to dopamine imbalance [2]. Interestingly, oral movements seem to be influenced by dopamine receptors agonist or antagonist [2,24]. Oral dyskinesias [26,29], and possibly nocturnal bruxism, a motor dysfunction characterized by clenching or grinding of the dentition during sleep states [23], have been associated with dopaminergic dysfunction [24,34]. Moreover, the consumption of drugs that alter dopaminergic transmission such as cocaine and amphetamine can cause intense tooth grinding in humans [3]. Also, in rats, administration of dopamine receptors agonist and antagonist produce jaw movement [22]. Thus, it seems clear that variations in 
dopamine concentration could influence trigeminal motoneuron activity.

The major sources of dopamine in the central nervous system are the neurons located in the substantia nigra pars compacta, and in the ventral tegmental area [5], but the neural pathways connecting them to the Mo5 have not been observed [32]. Therefore, using tracing techniques and dual label immunohistochemistry we attempted to investigate the anatomical substrate underlying dopaminergic action in jaw motor control.

Adult male Wistar rats $(280-300 \mathrm{~g})$ were housed two per cage in a temperature- and light-controlled environment $\left(21-22^{\circ} \mathrm{C} ; 12 \mathrm{~h}\right.$ on $)$ and given free access to food and water. Experiments were carried out in accordance with the guidelines of the National Institute of Health Guide for the Care and Use of Laboratory Animals (1996) and of the Institutional Committee for Research and Animal Care of the Institute of Biomedical Sciences, University of São Paulo. We attempted to minimize the number of rats used, and every effort was made to ensure that no rat suffered unnecessarily.

Twelve male rats $(280-310 \mathrm{~g})$ were anesthetized with a cocktail $(0.2 \mathrm{ml} / 100 \mathrm{mg}$, s.c. $)$ containing ketamine $(1 \mathrm{mg})$, xylazine $(5 \mathrm{mg})$ and acepromazine $(0.2 \mathrm{mg})$. The retrograde fluorescent tracer fluorogold (FG, Fluorochrome, Englewood, USA) was iontophoretically injected into the Mo5 using a glass micropipette (internal diameter $=10-20 \mu \mathrm{m}$ ) by applying a $+5 \mu \mathrm{A}$ current pulsed interval over $15 \mathrm{~min}$. The stereotaxic coordinates were adjusted based on the Atlas of Stereotaxic Coordinates of the Rat Brain (Paxinos and Watson, 1998 [27]). After 20-24 days, the animals were thoroughly anesthetized with $35 \%$ chloral hydrate and perfused with $4 \%$ paraformaldehyde in $0.1 \mathrm{M}$ borax buffer ( $\mathrm{pH} 9.5$ ). The brains were removed, postfixed for $1 \mathrm{~h}$, and cryoprotected overnight in a solution of $10 \%$ sucrose in $0.02 \mathrm{M}$ potassium phosphate-buffered saline (KPBS) $\mathrm{pH}$ 7.4. Coronal sections $(30 \mu \mathrm{m})$ were cut in a freezing microtome.

Sections were processed using a standard immunoperoxidase method. In brief, the tissue was incubated overnight in primary antisera anti-FG raised in rabbit (Chemicon, 1:20,000; Temecula, USA). The tissue was then incubated in goat biotin-conjugated secondary antiserum (Vector, Burlingame, USA), followed by avidin-biotin complex (Vector, Burlingame, USA). Peroxidase reaction was performed using diaminobenzidine tetrahydrochloride (DAB, Sigma, St. Louis, USA) as chromogen, and hydrogen peroxide. An adjacent series was counterstained with thionin as reference.

In order to investigate the occurrence of close apposition between retrograde-labeled neurons and catecholaminergic fibers throughout the rat brain, we performed a dual label immunoperoxidase experiment. Initially, we proceeded with standard immunohistochemistry, for the detection of tyrosine hydroxilase ( $\mathrm{TH}$, a catecholamine-processing enzyme) immunoreactivity. Brain sections were incubated overnight in the primary antiserum anti-TH (Chemicon, 1:20,000; Temecula, USA) made in sheep. Sections were then incubated for $1 \mathrm{~h}$ in biotin-conjugated IgG donkey anti-rabbit $(1: 1,000$,
Jackson Laboratories) and for $1 \mathrm{~h}$ in avidin-biotin complex (1:500, Vector). This was followed by incubation in DAB with nickel sulfate as chromogen with $0.01 \%$ hydrogen peroxide yielding a black staining of the TH-immunoreactive fibers. Subsequently, we submitted the tissue to another immunoperoxidase procedure, with FG antisera as the second primary, using only DAB as chromogen, producing light brown cytoplamic staining.

Results were analyzed in a Leica DMR microscope. Subjective interpretation of the amount of retrograde-labeled neurons or TH-immunoreactive fibers was performed. Each area was classified according to this analysis: very dense $(++++)$, dense $(+++)$, moderate $(++)$, or low $(+)$. We considered a reading very dense when a substantial number of cell bodies or fibers were found, and low when only sparse cell bodies or fibers were present. Intermediate amounts were considered dense or moderate. Images were acquired through the Image ProPlus ${ }^{\circledR}$ software and a SPOT RT ${ }^{\circledR}$ digital camera adapted to the Leica DMR microscope, and a Dell computer. Photoshop 7.0 (Adobe) image-editing software was used to combine photomicrographs into plates. Only sharpness, contrast, and brightness were adjusted. Drawings were produced using a camera lucida adapted to the Leica microscope and Canvas 6.0 (Deneba) software was used to incorporate drawings into plates.

Four animals were considered prime for evaluation as their injections were successfully centered in the Mo5 (Fig. 1). We recognize though that the injections may have contaminated adjacent premotor areas, including the supratrigeminal, the intertrigeminal, and the juxtatrigeminal nuclei. Although we have used a relative small number of animals, in all cases, the pattern of retrograde-labeled neuron distribution was similar. In concordance with previous results [32], we observed retrograde-labeled neurons in a variety of brainstem areas such as the mesencephalic trigeminal nucleus (Me5), the principal trigeminal nucleus (Pr5), the spinal trigeminal oral and interpolar subnuclei ( $\mathrm{Sp5O}$ and $\mathrm{Sp5I}$ ), the supratrigeminal nucleus (Su5), the contralateral Mo5, the juxtatrigeminal and intertrigeminal nuclei, the nucleus reticular pontine caudal (nPC), the gigantocellular nucleus (GI) and GI pars $\alpha$ (GI $\alpha$ ), the parvicellular reticular formation pars $\alpha$ (PCRt $\alpha$ ), the raphe pallidus and obscurus nuclei (RPa and $\mathrm{ROb}$ ), and the nucleus of the solitary tract (NTS). In addition, we found moderate numbers of retrograde-labeled neurons in the central nucleus of the amygdala (CeA), and in the parasubthalamic nucleus (PSTh) (Table 1 and Fig. 2). We also observed sparse retrograde-labeled neurons in the lateral hyphotalamic area (LHA) located dorsal to the fornix at rostral tuberal levels.

We performed dual label immunoperoxidase to examine the relationship between tyrosine hydroxylase immunoreactive fibers (TH-ir) and the retrograde-labeled neurons. Most of the nuclei containing retrograde-labeled neurons present TH-ir fibers (Table 1). However, we observed TH-ir varicose fibers and terminal bulbs in close proximity to FG-ir cell bodies only in the Su5, the Me5, the PCRt $\alpha$, the CeA, and the 


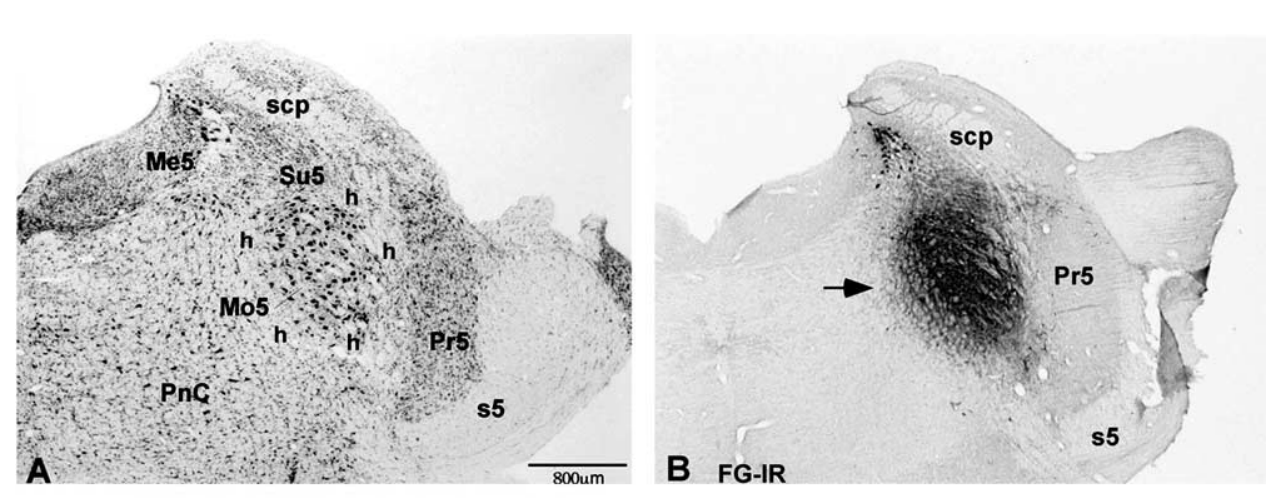

MV26
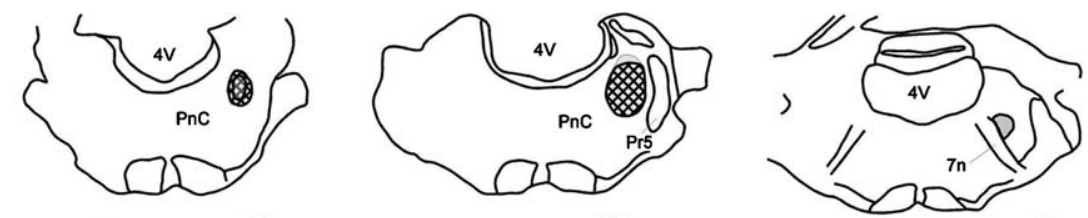

MV30
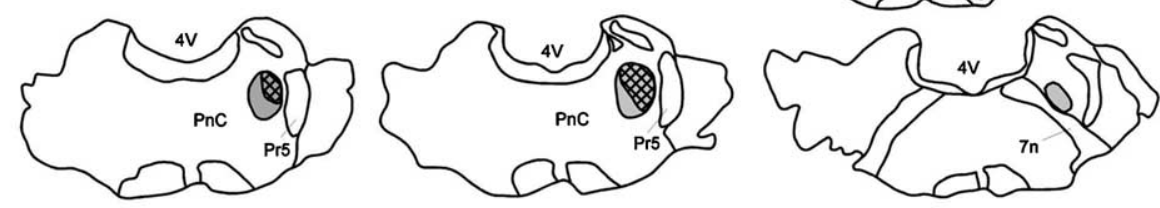

MV32
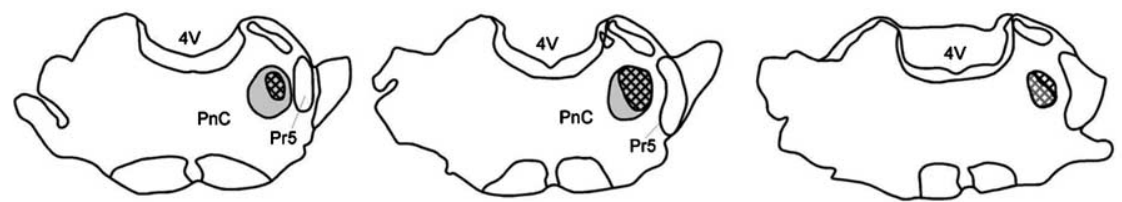

MV34
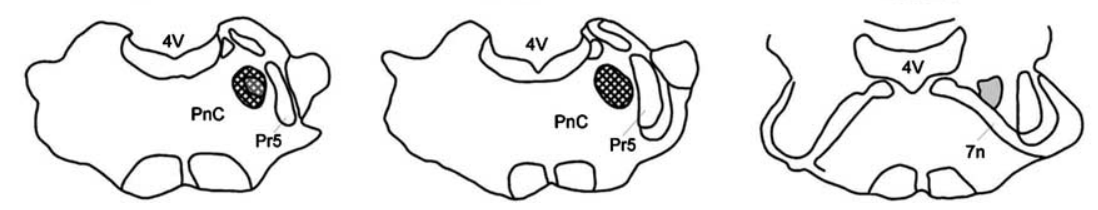

Fig. 1. Fluorogold injection site in the motor trigeminal nucleus (Mo5). (A) Brightfield photomicrograph of a reference section stained with thionin (Nissl method) showing the Mo5 and adjacent nuclei. (B) Brightfield photomicrograph showing an injection site of Fluorogold centered in the Mo5. (C) Representative drawings of three rostrocaudal levels of injection sites with FG (in gray) centered in the Mo5 (grid lines). Abbreviations: $4 \mathrm{~V}$, fouth ventricle; $7 \mathrm{n}$, facial nerve root; $\mathrm{h}$, regio h; Me5, mesencephalic trigeminal nucleus; PnC, pontine reticular nucleus caudal; Pr5, principal trigeminal nucleus; s5, sensory root of the trigeminal nerve; scp, superior cerebelar peduncle; Su5, supratrigeminal nucleus. (A and B) Scale bar $=800 \mu \mathrm{m}$.

PSTh (Fig. 3). This feature suggested to us the occurrence of apparent synaptic contact between TH-ir fibers and neurons projecting to the Mo5. In addition, we found TH-ir fibers surrounding the Mo5, particularly in its medial aspects. Very few TH terminals were observed inside the Mo5.

In the present study, we intended to identify $\mathrm{TH}$ innervation of brain nuclei projecting to the Mo5. Four cases with adequate FG injection sites were examined, all of which presented the same pattern of retrograde-labeled neuron distribution. After obtaining consistent results among cases, we then considered the number of animals satisfactory for evaluation. Only the injections of the retrograde tracer restricted to the limits of the Mo5 were considered adequate. However, we could not ensure that terminals from adjacent areas such as the Su5, the intertrigeminal and the juxtatrigeminal nuclei (considered a premotor station of the Mo5) had not absorbed some of the tracer. These areas encompass the Regio h, a ring of neurons that encircle the Mo5 and participate in the control of jaw movement [20]. These neurons project to the Mo5, as observed by others [20] and confirmed in the present study. Moreover, according to other studies [13,20,32], except in the caudal spinal trigeminal nucleus, retrograde-labeled neurons have been found throughout the trigeminal complex nuclei. The trigeminal sensory nuclei (Me5 and Pr5) may integrate sensory information used for maintenance of masticatory rhythm, which is generated in the reticular formation [25,33]. Concerning the $\mathrm{Me}$, we observed that the retrograde-labeled neurons receive a dense TH innervation that apparently originates in the locus coeruleus (personal observation). The locus coeruleus contains catecholaminergic neurons, expressing dopamine$\beta$-hydroxlase, a noradrenaline-converting enzyme, well recognized as the primary source of noradrenaline production [30]. Noradrenergic axons are found widespread in the brain, playing a fundamental role in arousal and alert waking states, providing for the maintenance of physiological 
Table 1

Brain areas that project to trigeminal motor nucleus (Mo5), and receive thyrosine hydroxilase immunoreactive (TH-ir) innervation

\begin{tabular}{|c|c|c|c|}
\hline Regions & Ipsilateral & Contralateral & TH-ir \\
\hline $\begin{array}{l}\text { Central nucleus of the amygdale } \\
\text { (CeA) }\end{array}$ & ++ & - & +++ \\
\hline Lateral hyphothalamic area (LH) & + & - & + \\
\hline Parasubthalamic nucleus (PSTh) & ++ & - & +++ \\
\hline $\begin{array}{l}\text { Mesencephalic trigeminal nucleus } \\
\text { (Me5) }\end{array}$ & ++++ & + & ++++ \\
\hline Motor trigeminal nucleus (Mo5) & - & ++ & + \\
\hline Principal trigeminal nucleus (Pr5) & +++ & ++ & - \\
\hline Supratrigeminal nucleus (Su5) & +++ & +++ & ++ \\
\hline Justatrigeminal regio & +++ & + & +++ \\
\hline Intertrigeminal nucleus & +++ & + & + \\
\hline Peritrigeminal regio & +++ & +++ & ++ \\
\hline $\begin{array}{l}\text { Reticular pontine nucleus caudal } \\
\quad(\mathrm{nPC})\end{array}$ & + & + & + \\
\hline $\begin{array}{l}\text { Parvicellular reticular nucleus pars } \alpha \\
\quad(\text { PCRt } \alpha)\end{array}$ & +++ & +++ & +++ \\
\hline Intermediate reticular nucleus (IRt) & +++ & +++ & +++ \\
\hline Gigantocellular nucleus (Gi) & ++ & ++ & ++ \\
\hline Gigantocellular nucleus pars $\alpha(\mathrm{Gi} \alpha)$ & ++ & - & ++ \\
\hline $\begin{array}{l}\text { Spinal trigeminal nucleus, oral part } \\
\quad(\mathrm{Sp} 5 \mathrm{O})\end{array}$ & +++ & ++ & - \\
\hline $\begin{array}{l}\text { Spinal trigeminal nucleus, interpolar } \\
\text { part (Sp5I) }\end{array}$ & ++ & + & - \\
\hline Nucleus of the solitary tract (NTS) & ++ & - & +++ \\
\hline
\end{tabular}

states necessary for the acquisition of sensory information, as reviewed by Berridge and Waterhouse [4]. The inputs that modulate locus coeruleus activity are not completely known, but axons containing corticotropin-releasing factor (CRF) and orexin/hypocretin have been observed along the nucleus $[7,15]$. Both neuropeptides participate in arousal and autonomic regulation, possibly through the activation of noradrenergic locus coeruleus neurons [8,15,21]. Studies have shown that noradrenaline may also indirectly influence oral movement $[6,13]$. This influence may be brought about through noradrenergic modulation of Me5 and/or reticular formation neurons projecting to the Mo5, as a consequence of arousal or autonomic stimulation.

In the reticular formation, retrograde-labeled neurons were observed primarily in the PCRt $\alpha$, in the GI and GI $\alpha$. These areas present moderate to dense TH innervation, but only a few TH immunoreactive varicosities or terminals are in close apposition to the retrograde-labeled neurons. Since it is known that brainstem nuclei participate in the generation and maintenance of the masticatory rhythm [25], our findings suggest that catecholamines might modulate these functions to some degree. Another possibility is that catecholamines in the reticular formation may play a role in motor activity and modulation of arousal states [28]. However, in order to test this hypothesis, studies investigating the origins of $\mathrm{TH}$ innervation of reticular formation neurons projecting to the Mo5 will be necessary.

In the present study, we observed that some forebrain nuclei also project to the Mo5 or to the last order interneurons in the regio $h$. Retrograde-labeled neurons were observed
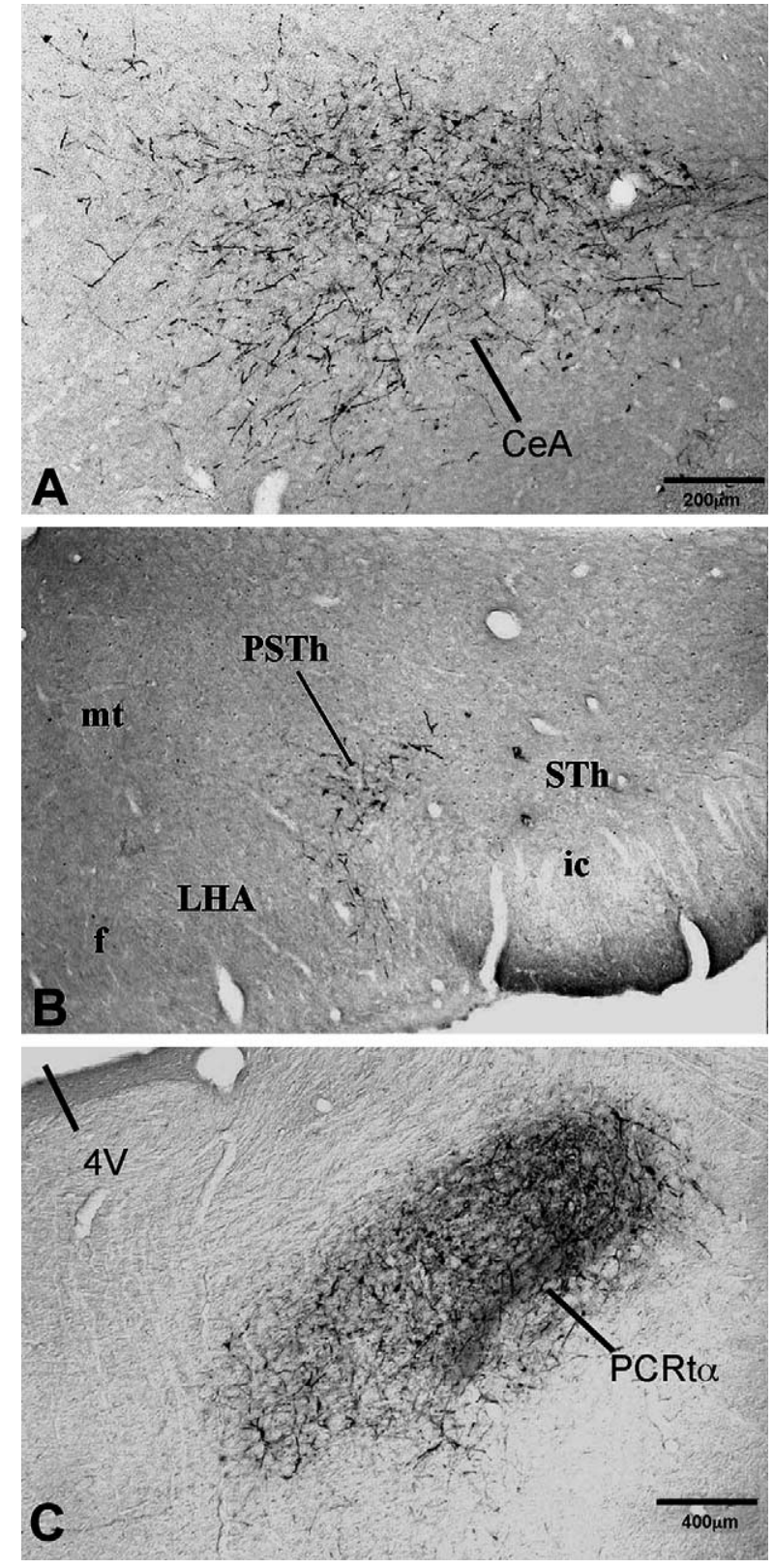

Fig. 2. Distribution of neurons projecting to the trigeminal motor nucleus (Mo5). (A-C) Brightfield photomicrographs showing retrograde-labeled neurons in (A) the central nucleus of the amygdala (CeA), (B) the parasubthalamic nucleus (PSTh), (C) and the pontine reticular formation, pars $\alpha$ (PCRt $\alpha$ ). Abbreviations: 4V, fourth ventricle; f, fornix; ic, internal capsule; LHA, lateral hypothalamic area; mt, mammillothalamic tract; STh, subthalamic nucleus. (A and B) Scale bar $=200 \mu \mathrm{m}$ and (C) scale bar $=400 \mu \mathrm{m}$.

in the LHA, the CeA, and the PSTh. There is a consensus that only primates possess forebrain premotor neurons that project directly to the Mo5 [32]. However, a recent study demonstrated that fibers and varicosities containing orexin/hypocretin, a neuropeptide expressed only in LHA neurons, might be found throughout the Mo5 [10]. Further studies will be necessary in order to investigate whether LHA retrograde-labeled neurons are the same as those that express orexin/hypocretin. 

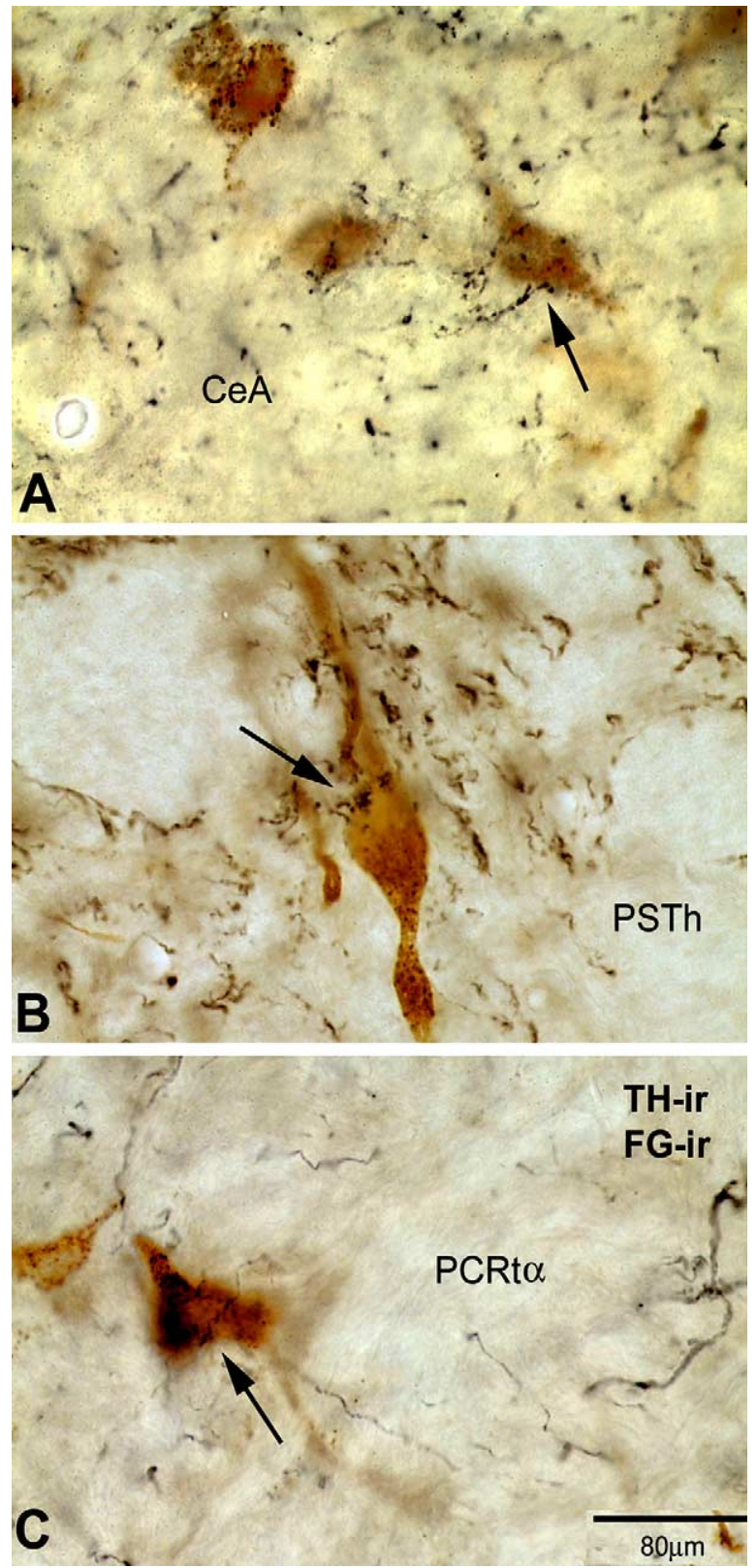

Fig. 3. Distribution of neurons projecting to the trigeminal motor nucleus (Mo5) that receive tyrosine hydroxilase (TH) innervation. (A-C) Brightfield photomicrographs showing fluorogold immunoreactive (FG-ir, cytoplasm brown) neurons with apparent $\mathrm{TH}$ immunoreactive (TH-ir) terminals (fibers in black, arrows) in (A) the central nucleus of the amygdala, (B) the parasubthalamic nucleus (PSTh), and (C) the pontine reticular formation, pars $\alpha$ (PCRt $\alpha)$. (A-C) scale bar $=80 \mu \mathrm{m}$.

We observed that CeA neurons projecting to the Mo5 and/or adjacent premotor areas receive catecholaminergic innervation. This innervation originates predominantly in dopaminergic neurons located in the ventral tegmental area and in the retrorubral field [14]. Studies using injection of anterograde tracer into the $\mathrm{CeA}$ have shown fibers around the Mo5, mainly in the Su5 [31], indicating that part of the retrograde-labeled neurons that we observed innervates the vicinity of the Mo5, targeting the last order interneurons in the Su5. Nevertheless, we have not disregarded the fact that Mo5 motoneurons dendrites extend beyond the limits of the nucleus [32], suggesting the likely occurrence of a direct CeA-motoneuron innervation. Experiments using electron microscopy will be necessary in order to test this hypothesis.

The physiological effects dopamine exerts in the CeA will depend on receptor subtypes, and the neurochemistry of neurons that project to the Mo5. The CeA contains the neuromodulator CRF, which is known to play a role in stress response [21]. Previous studies have shown that CRF neurons in the CeA are innervated by dopaminergic fibers [9]. Whether these are the same cells that project to the Mo5 is not known, but our results suggest that dopaminergic fibers may modulate $\mathrm{CeA}$ neurons innervating areas related to oral motor control. CeA stimulation induces autonomic responses such as an increase in blood pressure and cardiac rate [16,17]. In humans, during episodes of sleeping bruxism, electroencephalographic recordings and cardiac rate increases before the onset of rhythmic masticatory muscle activity. Thus, authors have suggested that brain nuclei activate autonomiccardiac acceleration that may anticipate muscle activation [18]. Our results indicate that, at least in rodents, the $\mathrm{CeA}$ is well located in order to participate in this activation.

Few retrograde-labeled neurons were also found in the PSTh, an area close to the internal capsule, medial to the subthalamic nucleus. It is possible that studies showing activation of jaw opening muscles after electrophysiological stimulation of areas close to the internal capsule [19] have targeted PSTh neurons. The PSTh presents a cytoarchitectonic characteristic intermediate between that of the well-defined subthalamic nucleus and the dispersed aspect of LHA neurons. Injections centered in the PSTh showed a significant projection to the substantia innominata, the retrorubral field, the parabrachial nucleus, and the nucleus of the solitary tract [12]. The organization of the PSTh projections suggested to the authors an involvement in autonomic control and in oral motor pattern generation. In agreement, we observed that neurons in the PSTh project to the Mo5 or adjacencies. These neurons are confined to an area traversed by the nigrostriatal bundle, a pathway that connects dopaminergic neurons of the substantia nigra to the striatum, well known for playing a fundamental role in motor control [1]. Striatal dopamine imbalance has been related to a variety of motor disorders [1]. Increase in dopaminergic transmission in the striatum was observed after stress induction in rats, and parafunctional masticatory activity seems to attenuate that exacerbation [11]. Moreover, studies have shown that reserpine, a drug that inactivates catecholaminergic vesicles, induces oral dyskinesias, an effect that is reversed by D2 dopamine receptor antagonist administration [26]. Interestingly, reserpine-induced oral diskynesias are not blocked by dopamine administration into the striatum, suggesting the existence of an alternative pathway for dopamine action in oral motor function [29].

According to the present results, we suggest that catecholamines may regulate oral movements alternatively through the innervation of premotor brainstem nuclei 
involved in masticatory control and forebrain areas related to autonomic and stress responses. Studies investigating the origin of this innervation and the chemical characteristics of this circuitry will be needed to corroborate and refine our findings.

\section{Acknowledgments}

We would like to thank Joelcimar Martins da Silva and Daniela Rodrigues Nogueira for technical assistance. We also thank Dr. Jarbas A. Bauer for valuable discussions, and Jim Hesson for revision of the manuscript. Financial support was provided in the form of grants from FAPESP (99/03490-0, 00/05530-8, 03/06022-4). J.C.B. and C.F.E. are CNPq investigators.

\section{References}

[1] R.L. Albin, A.B. Young, J.B. Penney, The functional anatomy of basal ganglia disorders, Trends Neurosci. 12 (1989) 366-375.

[2] I. Amir, H. Hermesh, A. Gavish, Bruxism secondary to antipsychotic drug exposure: a positive response to propranolol, Clin. Neuropharmacol. 20 (1997) 86-89.

[3] R.J. Baldessarini, Drugs and the treatment of psychiatric disorders, in: J.G. Hardman, L.E. Limbird (Eds.), Goodman \& Gilman's the Pharmacological Basis of Therapeutics, McGraw-Hill, New York, 1996, pp. 399-459.

[4] C.W. Berridgeand, B.D. Waterhouse, The locus coeruleusnoradrenergic system: modulation of behavioral state and statedependent cognitive processes, Brain Res. Rev. 42 (2003) 33-84.

[5] A. Bjorklund, T. Hokfelt (Eds.), Handbook of Chemical Neuroanatomy, Elsevier, New York, 1984.

[6] J.C.V.M. Copray, G.J. Ter Horsr, R.S.B. Liem, J.D. van Willigen, Neurotransmitters and neuropeptides within the mesencephalic trigeminal nucleus of the rat: an immunochemical analysis, Neuroscience 37 (1990) 399-411.

[7] S. Cummings, R. Elde, J. Ells, A. Lindall, Corticotropin-releasing factor immunoreactivity is widely distributed within the central nervous system of the rat: an immunohistochemical study, J. Neurosci. 3 (1983) 1355-1368.

[8] A.J. Dunn, C.W. Berridge, Physiological and behavioral responses to corticotrophin-releasing factor administration: is CRF a mediator of anxiety or stress reponses? Brain Res. Rev. 15 (1990) 71-100.

[9] M. Eliava, D. Yilmazer-Hanke, E. Asan, Interrelations between monoaminergic afferents and corticotropin-releasing factorimmunoreactive neurons in the rat central amygdaloid nucleus: ultrastructural evidence for dopaminergic control of amygdaloid stress systems, Histochem. Cell Biol. 120 (2003) 183-197.

[10] S.J. Fung, J. Yamuy, S. Sampogna, F.R. Morales, M.H. Chase, Hypocretin (orexin) input to trigeminal and hypoglossal motoneurons in the cat: a double-labeling immunohistochemical study, Brain Res. 903 (2001) 257-262.

[11] F.M. Gomez, M.T. Giralt, B. Sainz, A. Arrue, M. Prieto, P. GarciaVallejo, A possible attenuation of stress-induced increses in striatal dopamine metabolism by the expression of nom-functional masticatory activity in the rat, Eur. J. Oral Sci. 107 (1999) 461-467.

[12] M. Goto, L.W. Swanson, Axonal projections from the parasubthalamic nucleus, J. Comp. Neurol. 469 (2004) 581-607.

[13] R. Grzanna, W.K. Chee, E.W. Akeyson, Noradrenergic projections to brainstem nuclei: evidence for differential projections from noradrenergic subgroups, J. Comp. Neurol. 263 (1987) 76-91.

[14] R.H. Hasue, S.J. Shammah-Lagnado, Origin of the dopaminergic innervation of the central extended amygdala and accumbens shell: a combined retrograde tracing and immunohistochemical study in the rat, J. Comp. Neurol. 454 (2002) 15-33.

[15] T.L. Horwath, C. Peyron, S. Diano, A. Ivanov, G. Aston-Jones, T.S. Kilduff, A.N. van den Pol, Hypocretin (orexin) activation and synaptic innervation of the locus coeruleus noradrenergic system, J. Comp. Neurol. 415 (1999) 145-159.

[16] J. Iwata, K. Chida, J.E. LeDoux, Cardiovascular responses elicited by stimulation of neurons in the central amygdaloid nucleus in awake but not anesthetized rats conditioned emotional responses, Brain Res. 418 (1987) 183-188.

[17] C.B. Jin, R.W. Rockhold, Effects of paraventricular hypothalamic microinfusions of kainic acid on cardiovascular and renal excretory function in conscious rats, J. Pharmacol. Exp. Ther. 251 (1989) 969-975.

[18] T. Kato, P.H. Rompré, J.Y. Montplaisir, B.J. Sessle, G.J. Lavigne, Sleep bruxism: an oromotor activity secondary to microarousal, J. Dent. Res. 80 (2001) 1940-1944.

[19] Y. Kawamura, S. Tsukamoto, Analysis of jaw movements from the cortical jaw motor area and amygdaloid nucleus to jaw muscles, Jpn. J. Physiol. 10 (1960) 471-488.

[20] A. Kolta, K.G. Westberg, J.P. Lund, Identification of brainstem interneurons projecting to the trigeminal motor nucleus and adjacent structures in the rabbit, J. Chem. Neuroanat. 19 (2000) 175-195.

[21] G.F. Koob, Stress, corticotropin-realising factor and drug addiction, Ann. N. Y. Acad. Sci. 897 (1999) 27-45.

[22] N. Koshikawa, K. Kikuchi de Beltran, K. Tomiyama, M. Kobayashi, A.R. Cools, Functional interaction between dopamine D1 and D2 receptors in rat jaw movements, Eur. J. Pharmacol. 201 (1991) 47-51.

[23] G.J. Lavigne, T. Kato, A. Kolta, B.J. Sessle, Neurobiological mechanisms involved in sleep bruxism, Crit. Rev. Oral. Biol. Med. 14 (2003) 30-46.

[24] F. Lobbezoo, M. Naeije, Bruxism is mainly regulated centrally, not peripherally, J. Oral Rehabil. 28 (2001) 1085-1091.

[25] J.P. Lund, A. Kolta, K.G. Westberg, G. Scott, Brainstem mechanisms underlying feeding behaviors, Curr. Opin. Neurobiol. 8 (1998) 718-724.

[26] J.L. Neisewander, I. Lucki, P. McGonigle, Behavioral and neurochemical effects of chronic administration of reserpine and SKF38393 in rats, J. Pharmacol. Exp. Ther. 257 (1991) 850-860.

[27] G. Paxinos, C. Watson (Eds.), The Rat Brain in Stereotaxic Coordinates, Academic Press, Sydney, 1998.

[28] T.W. Robbins, S. Granon, J.L. Muir, F. Durantou, A. Harrison, B.J. Everitt, Neural systems underlying arousal and attention Implications for drug abuse, Ann. N. Y. Acad. Sci. 846 (1998) 222-237.

[29] A.N. Sussman, L.T. Tran-Nguyen, J.L. Neisewander, Acute reserpine administration elicits long-term spontaneous oral dyskinesia, Eur. J. Pharmacol. 337 (1997) 157-160.

[30] L.W. Swanson, B.K. Hartman, The central adrenergic system. An immunofluorescence study of the location of cell bodies and their efferent connections in the rat utilizing dopamine-beta-hydroxylase as a marker, J. Comp. Neurol. 163 (1975) 467-505.

[31] Y. Takeuchi, T. Satoda, R. Matsushima, Amygdaloid projections to commissural interneurons for masticatory motoneurons, Brain Res. Bull. 21 (1988) 123-127.

[32] J.B. Travers, R. Norgren, Afferent projections to the oral motor nuclei in the rat, J. Comp. Neurol. 220 (1983) 280-298.

[33] A. Tsuboi, A. Kolta, C.C. Chen, J.P. Lund, Neurons of the trigeminal main sensory nucleus participate in the generation of rhythmic motor patterns, Eur. J. Neurosci. 17 (2003) 229-238.

[34] E. Winocur, A. Gavish, A. Emodi-Perlman, I. Eli, Drugs and bruxism: a crirical review, J. Orofac. Pain 17 (2003) 99-111. 